\title{
برنامج إرشادي انتقائي تكاملي لخفض حدة الاليكسيثيميا وأثره في خفض الاضطرابات السيكوسوماتية لدى طالبات كلية التربية
}

\author{
إعداد \\ د.جيهان عثمان محمود \\ الأستاذ المساعد بقسم الصحة النفسية كلية التربية - جامعة الإسكندرية
}

DOI : $10.12816 / 0052303$

مجلة الدراسات التربوية والانسانية ـ كلية التربية ـ جامعة دمنهور

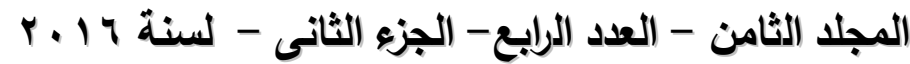


برنامج إرثادي انتقائي تكاملي لخفض حدة الاليكسيشيميا د.جيهان عثمان محمود 
برنامج إرشادي انتقائي تكاملي لخفض حدة الاليكسيشيميا وأثثره في خفض

الاضطرابات السيكوسوماتية لاى طالبات كلية التربية

\section{د.جيهان عثمان محمود}

DOI : 10.12816/0052303

مقدمة:

تعد القدرة على التعبير عن المشاعر والانفعالات أحد مؤشرات تمتع الفرد

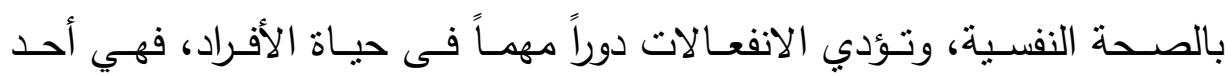

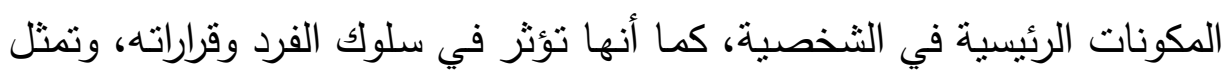

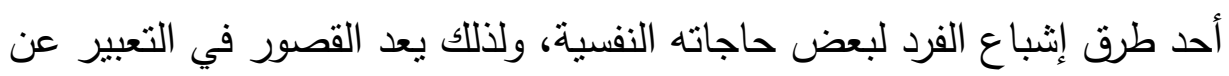

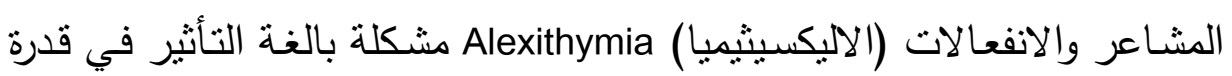

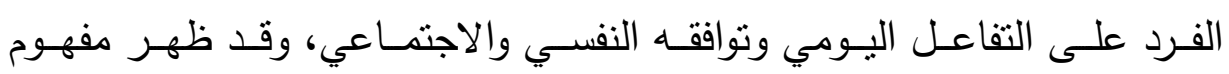

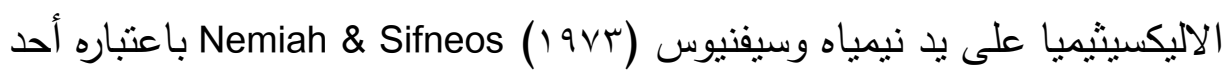

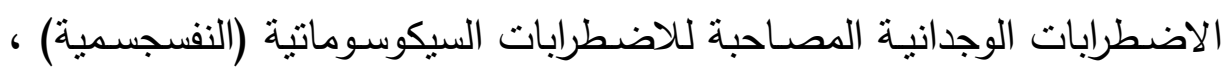
وتعد القدرة على التعرف ووصف الانفعالات والمشـاعر من الكفاءات الوجدانيـة

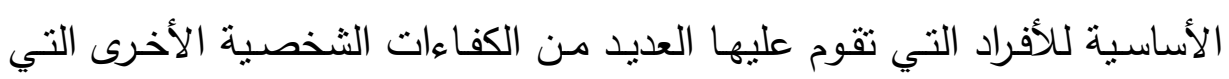

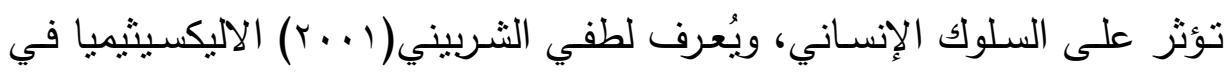

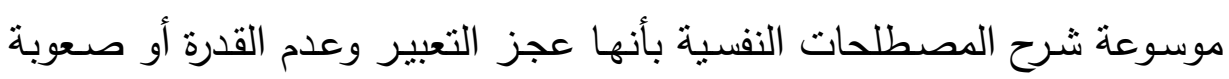

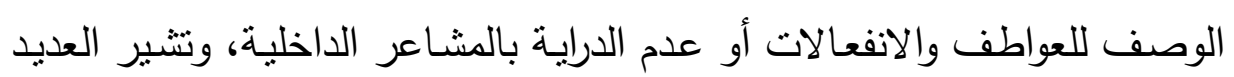

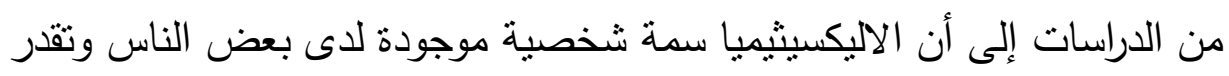

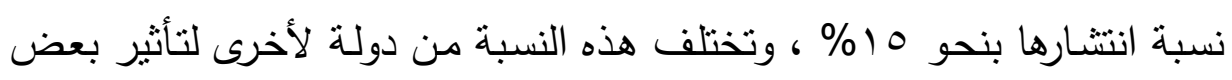

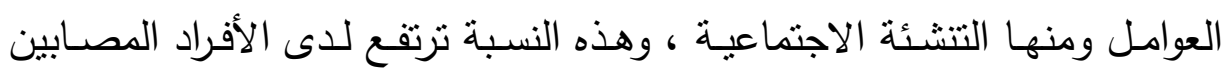

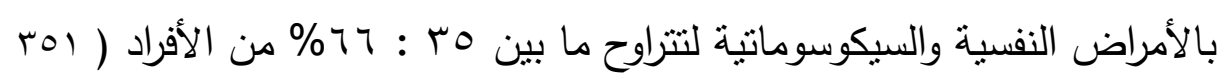
.(Taylor, 2000, 137), (Mc Millan, 2003, 
ويرجـع عدم الاهتمـام الكـافي بمشكلة الاليكسيثيميا إلى عدم الاهتمـام

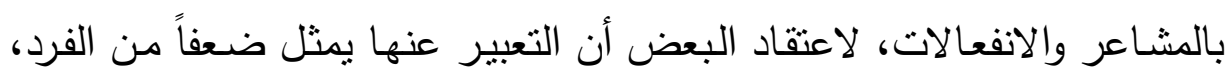

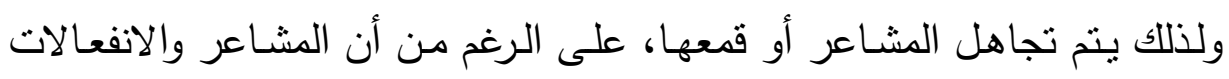

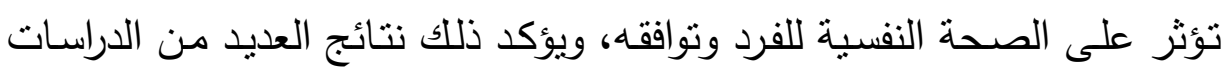
التي أثنارت إلى أن الأفراد الذين يعـانون مـن الاليكسيثيميا لديهم اضطرابات

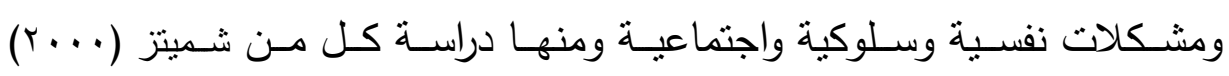
Aino, . ، Schmitz et.al

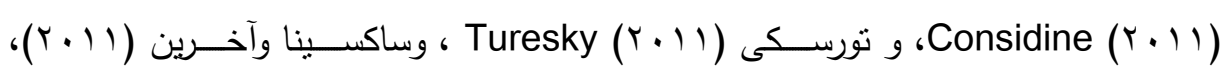

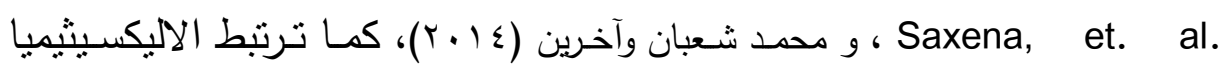

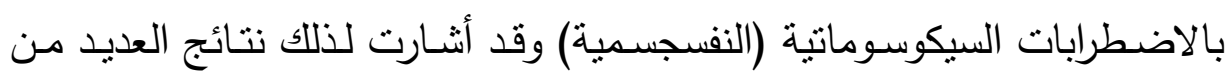

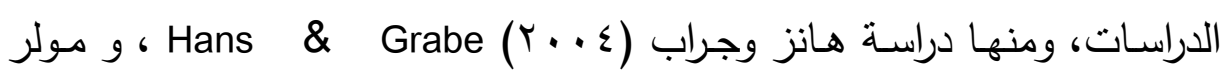

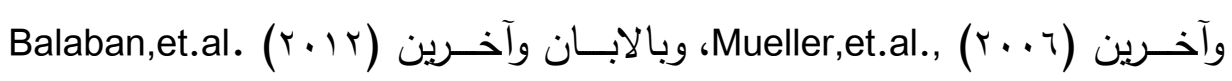

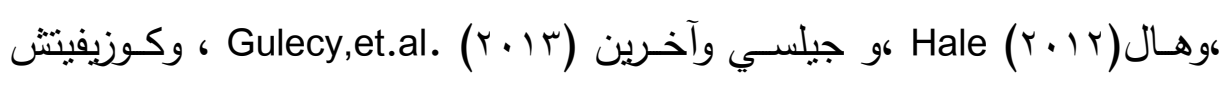

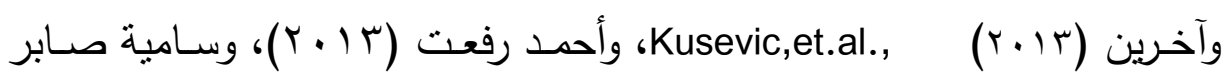

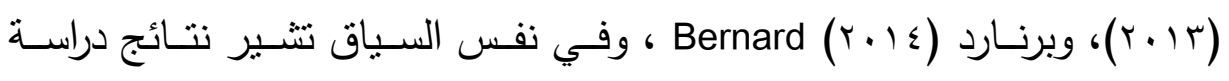

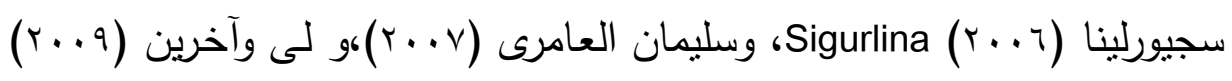

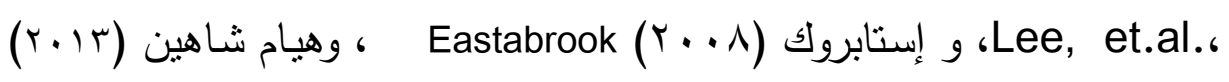

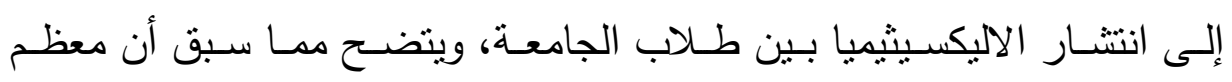
الدراسات اتجهت إلى دراسة علاقة الاليكسيثيميا بغيرها من المتغيرات والقليل منها

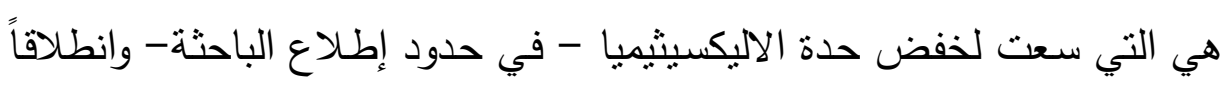

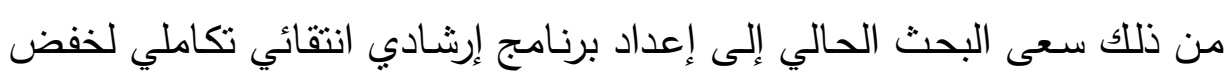

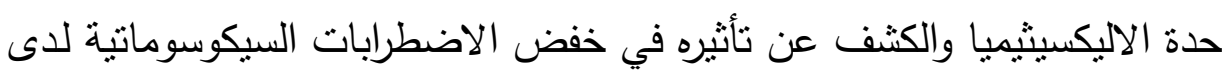
طالبات كلية التربية، وتمنل البرامج الإرشادية الانتقائية الاتجاه المتكامل والحديث الإنيث

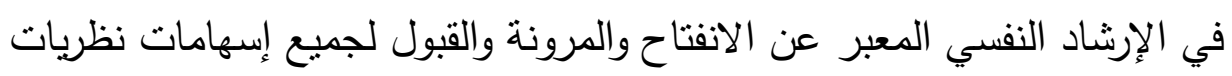
DOI : $10.12816 / 0052303$ 
الإرشاد النفسي لتحقيق أفضل النتائج للمسترشدين، وهي تقوم على انتقاء أفضل

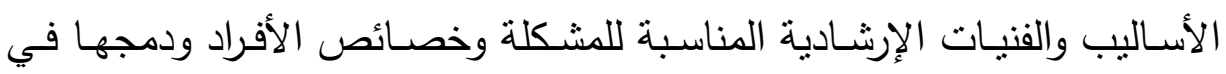

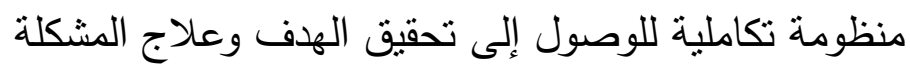

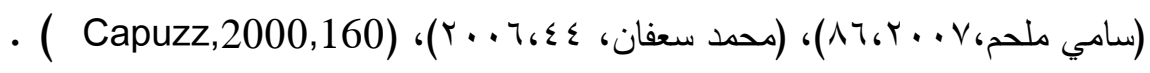

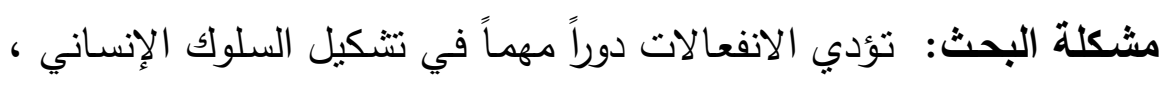

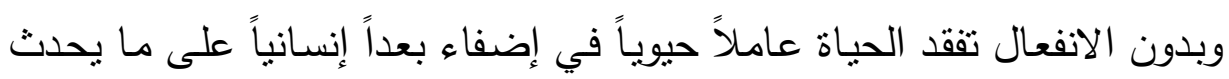

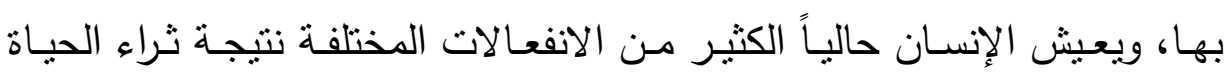

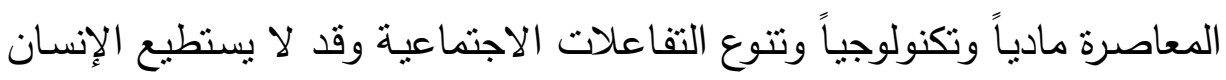

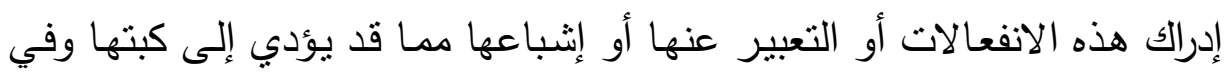

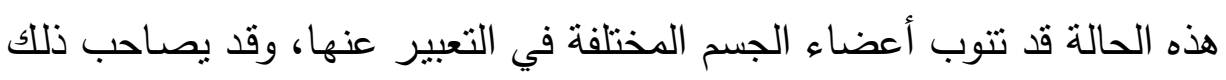
تغيرات فسيولوجية ينتج عنها الأضرار بالجسم ، وتكمن خطورة الاليكسيثميا في اعني

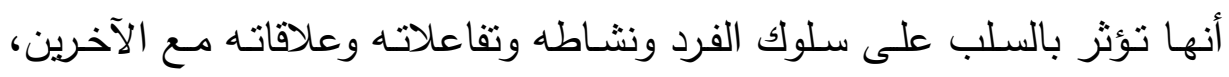

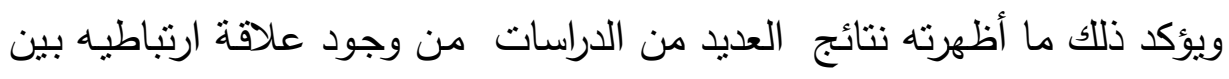

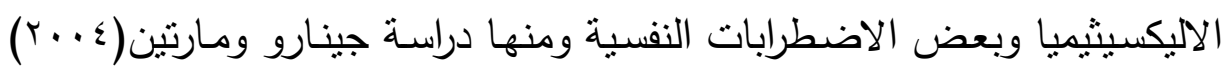
Gennaro\&Martin علاقة ارتباطيه بين الاليكسيثيميا والقلق والاكتئاب ، وتتشير دراسة كل من سارة ودينيس (Y. Sarah \& Dennis) إلى وجود علاقة ارتباطيه بين الاليكسيثيميا

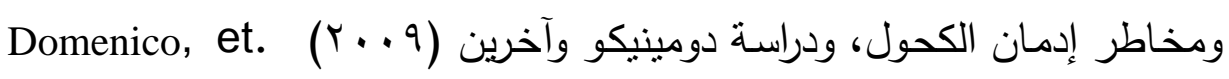

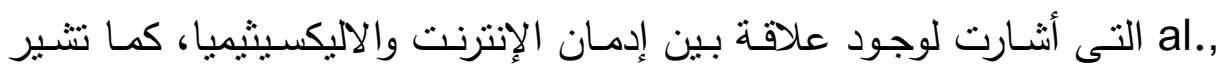

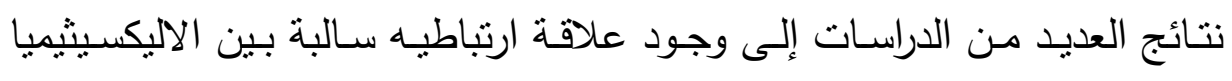

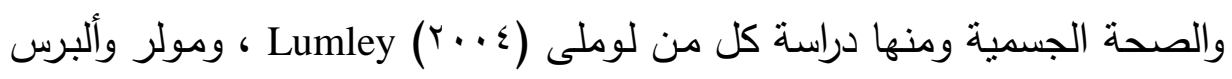

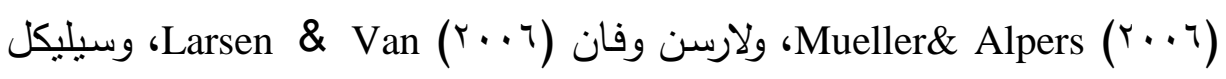

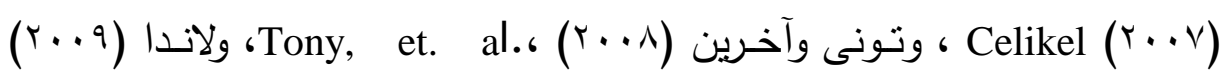

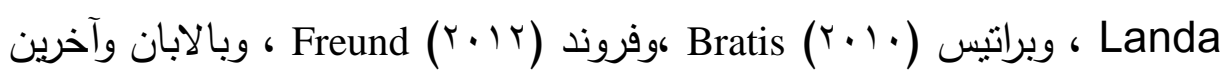




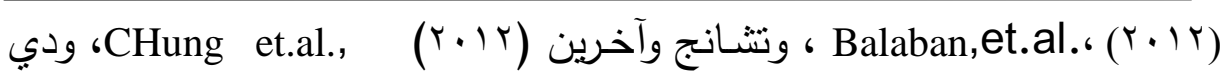

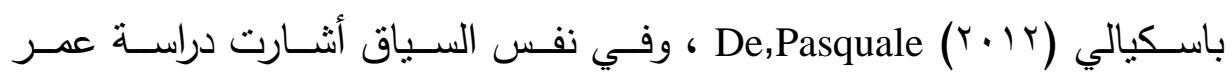

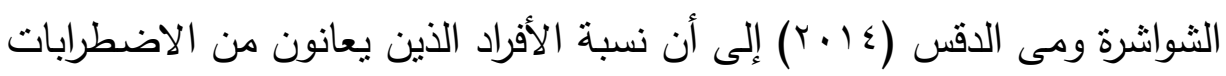

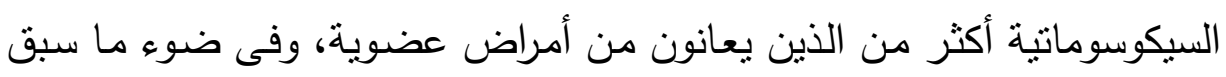

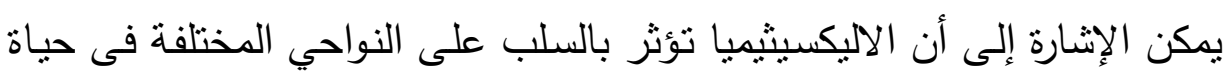

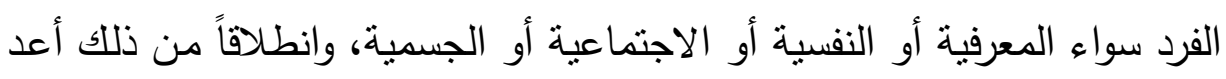

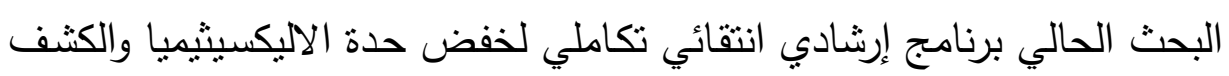
عن أثره في خفض الاضطرابات السيكوسوماتية لدى طالبات كلية التربية. ويمكن تحديد مشكلة البحث في الأسئلة التالية: ا. هل يوجد اختلاف بين الطالبات في المجموعة التجريبية في الاليكسيثيميا بعد تطبيق البرنامج الإششادي؟ r.هل يوجد اختلاف بين المجموعتين التجريبية والضـابطة في الاضطرابات الإئاتيات السيكوسوماتية بعد تطبيق البرنامج الإرشادي؟

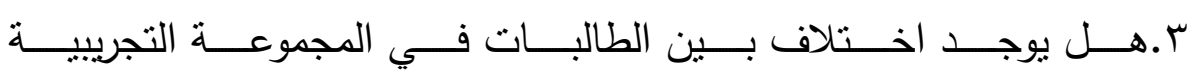
بالتخصصين(الأدبي/ العلمي) في الاليكسيثيميا بعد تطبيق البرنامج الإرشادي تعزى إلى التخصص الدراسي ؟ بالن

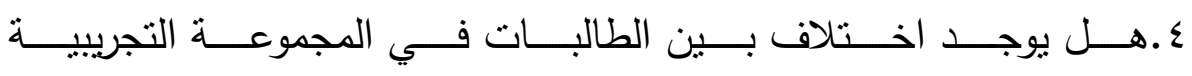
بالتخصصين(الأدبي/ العلمي) في الاضطرابات السيكوسوماتية بعد تطبيق

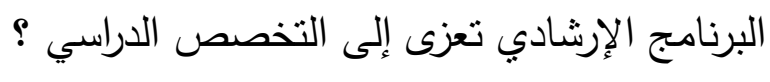

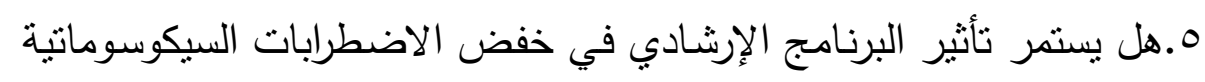

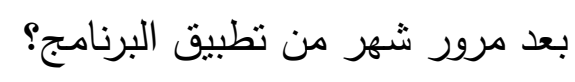

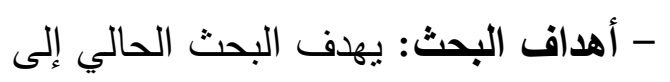
1. التعرف على تأثير البرنامج الإششادي في خفض حدة الاليكسيثميا. 
r.الكثف عن تأثثر البرنامج الإرشادي في خفض الاضطرابات السيكوسوماتية.

r.التعرف على الفروق في الاليكسيثيميا بين الطالبات تبعاً لمتغير التخصص الدراسي.

ع .التعرف على الفروق في الاضطرابات السيكوسوماتية بين الطالبات تبعاً لمتغير التخصص الدراسي. هـ الكثف عن استمرار أثز البرنامج الإرشادي بعد انتهاء التطبيق.

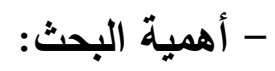

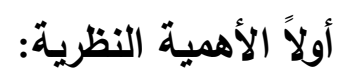

ا ـ إثراء المكتبـة النفسية بدراسـة عـن الاليكسيثيميا التي توئثر بالسـلب على التى

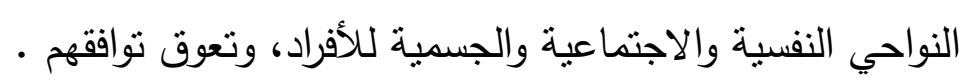

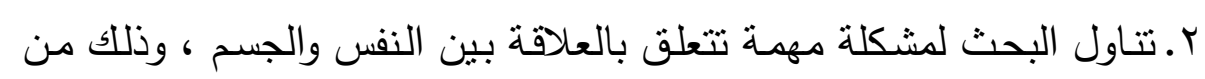

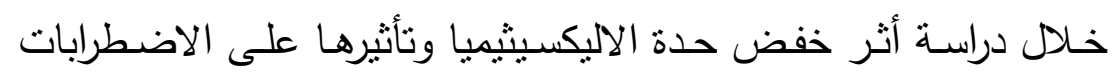

$$
\text { السيكوسوماتية. }
$$

r. يكتسب البحث أهميته من خصائص أفراد العينـة وهن طالبات كلية التربية

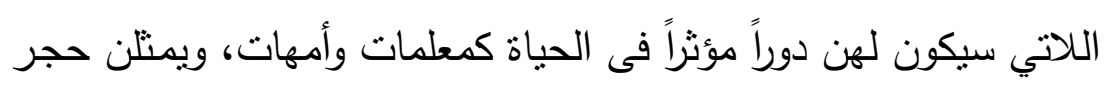

$$
\text { الزاوية في العملية التعليمية. }
$$

ع ـ مرحلة النمو لأفراد العينة هي نهاية مرحلة المراهقة، والتي تعد من المراحل

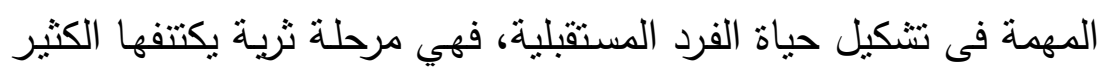

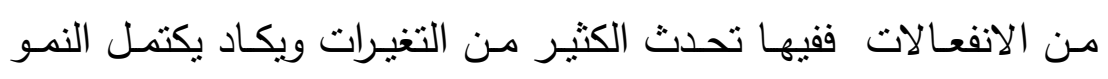
الجسمي والانفعالي والاجتماعي ،وتظهر بها بوادر بعض الاضطرابات.

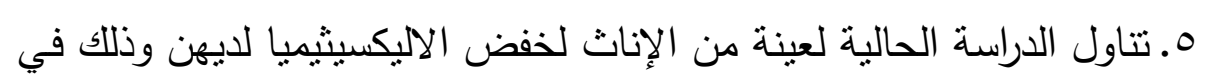

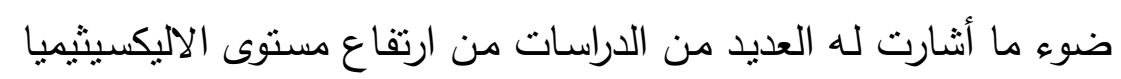

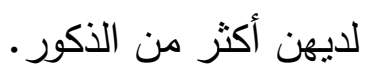


برنامج إرشادي انتقائي تكاملي لخفض حدة الاليكسيثيميا د.جيهان عثمان محمود

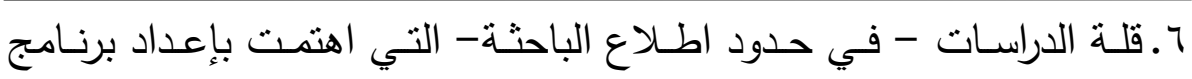
لخفض الاليكسيثيميا والكثف عن أثزه على الاضطرابات السيكوسوماتية.

ثانياً الأهمية التطبيقية:

1. إعداد برنامج إرشادي يخفض من حدة الاليكسيثيميا لدى طالبات الجامعة.

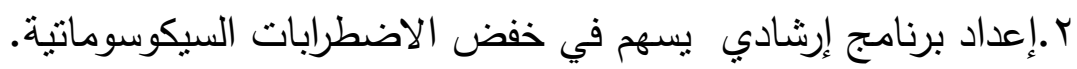
r.إعداد مقياس يقيس الاليكسيثيميا لدى طالبات الجامعة. ع.إعداد مقياس يقيس الاضطرابات السيكوسوماتية لدى طالبات الجامعة.

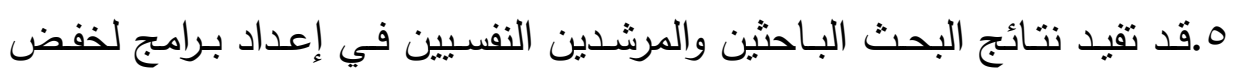
الاليكسيثيميا لفئات أخرى في المجتمع. - مصطلحات البحث: 1 - برنامج إرشادي انتقائي تكاملي :

\section{tegrative Selective indicative Counseling Program}

تعرفه الباحثة بأنه مخطط يتضمن سلسلة من الإجراءات المنظمة والمتكاملة

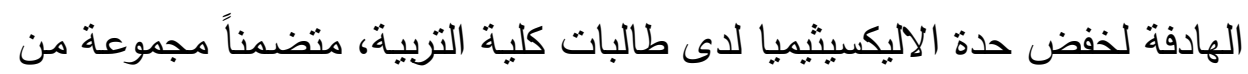

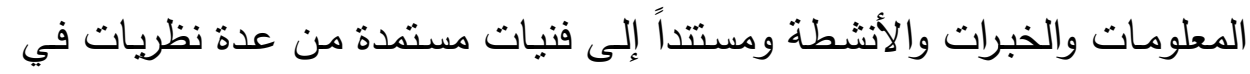

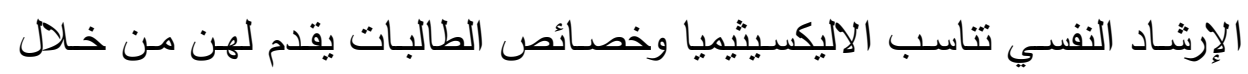
مجموعة من الجلسات المحددة زمنياً لخفض حدة الاليكسيثيميا.

\section{r الاليكسيثيميا: Alexithymia}

تعرفها الباحثة إجرائيـاً بأنها صسعوبة في التعرف والتعبير عن انفعالات

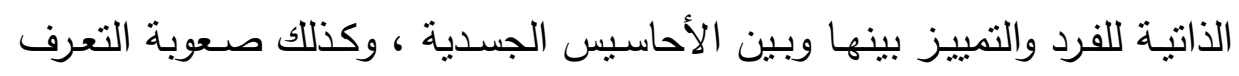
على مشاعر الآخرين والتعبير عن المشاعر نحوهم ، ويصاحب ذللك نمط تفكير

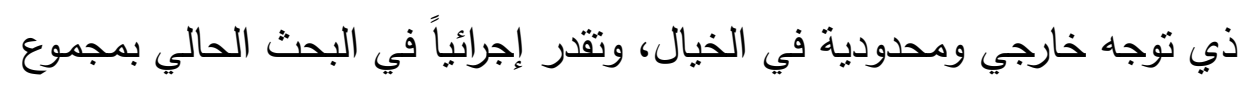

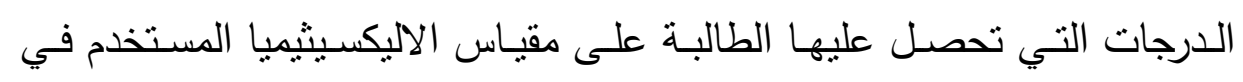
البحث الحالي، ويتضمن مفهوم الاليكسيثيميا الأبعاد التالية: 
أ . صعوبة التعرف والتعبير عن المشاعر والتمبيز بينها وبين الأحاسيس الجسدية: ويقصد بـه قصسور فى تحديد وتعرف الفرد على مشـاعره وانفعالاتهـ ووصفها لفظياً، وصعوبة التمييز بينها وبين الأحاسيس الجسدية.

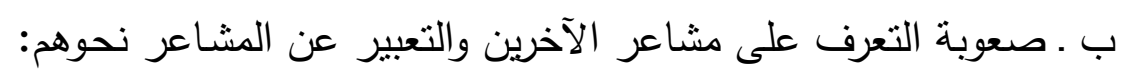

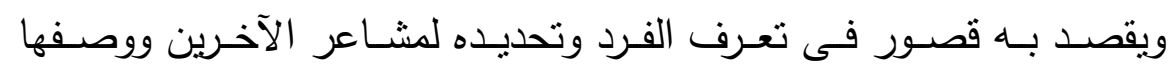
والتعامل معها، وصعوبة التعبير عن مشاعره نحوهم.

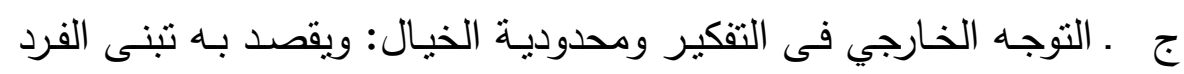
لأسلوب تقكير يهنم بالأحداث الخارجية والتفاصيل أكثر من مشاعر وخبرات الفرد

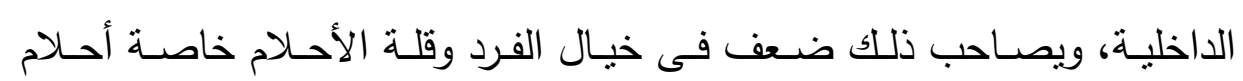
اليقظة.

\section{Psychosomatic} ب- الاضـــرابات السيكوســوماتية (النفسجسـمية)

Disorders

وتعرفها الباحثة إجرائياً بأنها أعراض أو شكاوى جسمية نفسية المنشأ تحدث

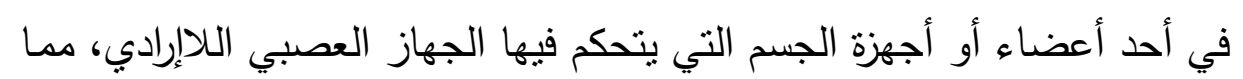
يؤدى إلى خلل وظيفي في هذا العضو ومع استمرار السبب النفسي يتحول هذا

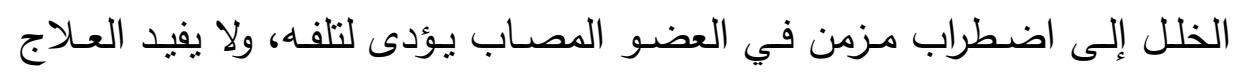

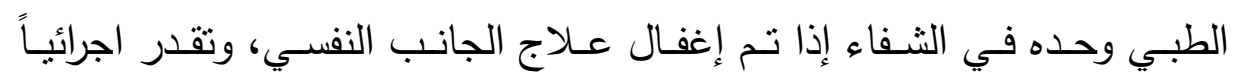

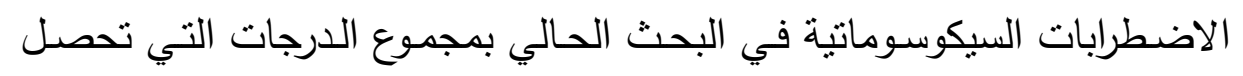

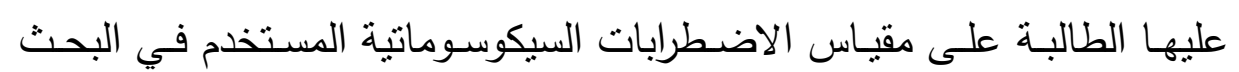
الحالي. - عينة البحث (المشاركون في البحث):

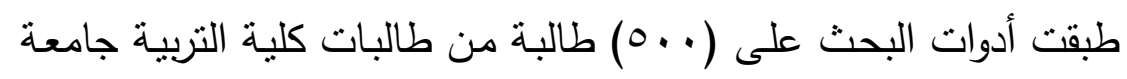

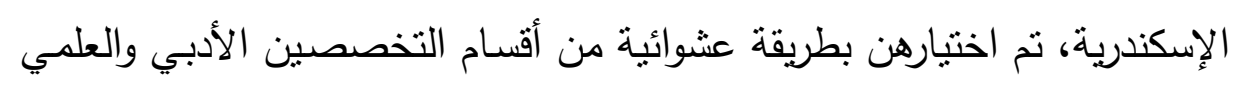

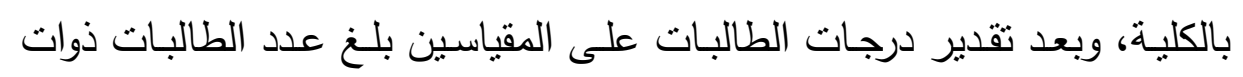
المستوى المرتفع في كل من الاليكسيثيميا والاضطرابات السيكوسوماتية(؟ ـ (1) 
برنامج إرشادي انتقائي تكاملي لخفض حدة الاليكسيثيميا د.جيهان عثمان محمود

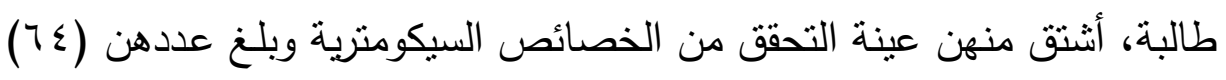

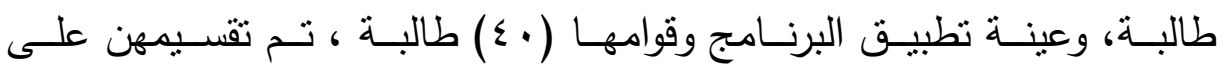

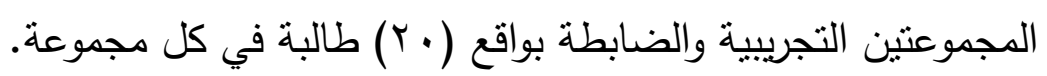
- منهج البحث:

اعتمـد البحث الحسالي على المنهج شـبه التجريبي،التصـميم ذو المجمـوعتين

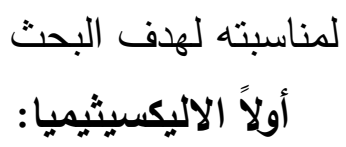

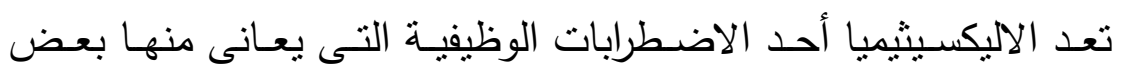
الأفراد، وتظهر في صـورة صـعوبة فى إدراك ومعالجـة المعلومـات الوجدانيـة

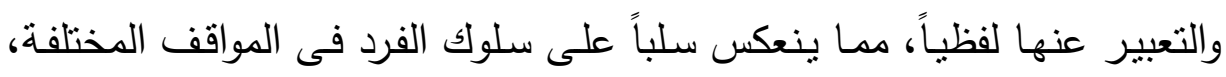

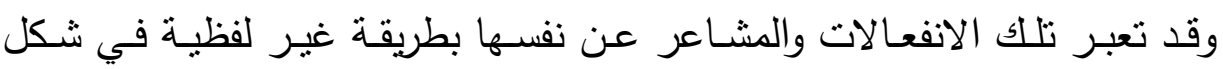
أعراض وشكاوى جسدية . وقد ظهر مصـطلح الأليكسـيثيميا Alexithymia في السـبعينيات على يـد

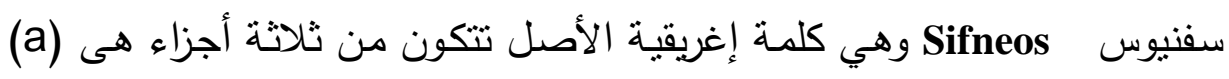
وتعنى بدون، (Lexi) تعنى كلمة، (Thymos) وتعنى انفعال أي أن المصطلح

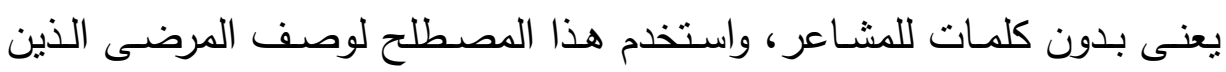

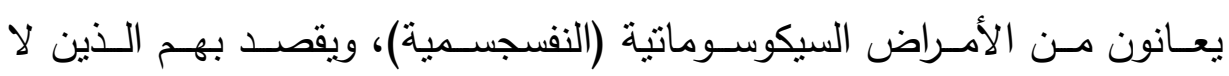
يستطيعون التعرف على مشـاعرهم والتعبير عنها، ويجدون صعوبة فى التمييز

$$
\text { بينها وبين الأحاسيس الجسمية }
$$

(Briody, 2005, 32 ),(Kagee \& Freeman, 2008, 7), ( Reddy, 2009, 1) , ( Hatin, 2011, 1) (Beshart \& Shahidi, 2011, 145),( Sutherland, 2011, 46),(Hale,2012, 55).

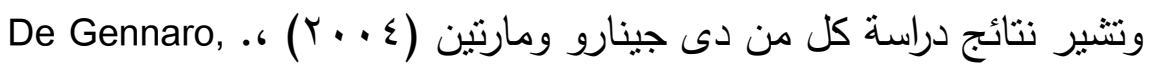
et. al

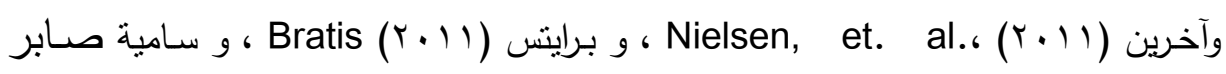

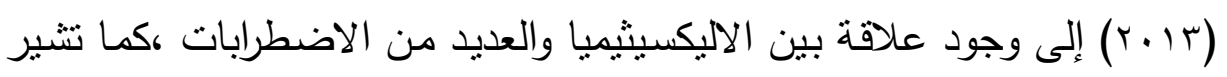




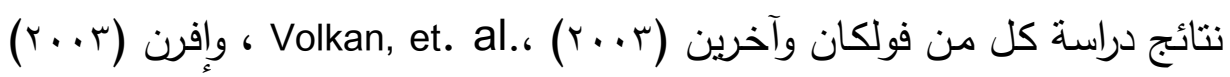
CEvern

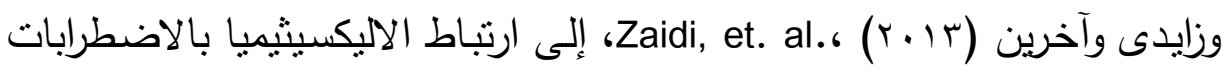

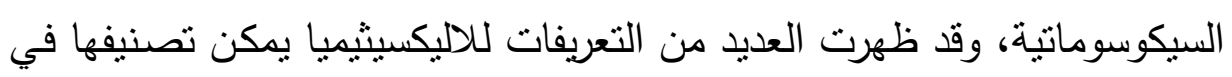

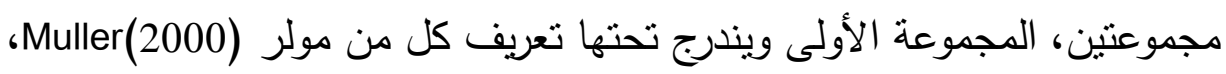

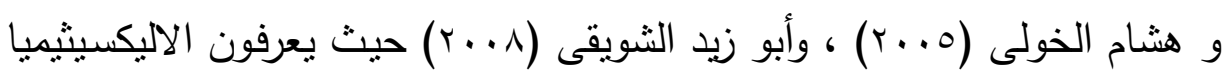

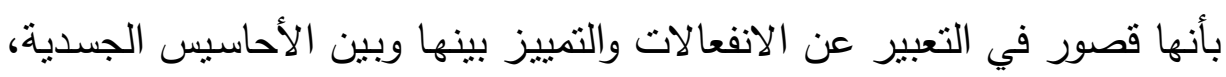
يصاحب ذللك أسلوب تفكير ذي نوجه خارجي وضعف في الخيال وهي ناتجة عن

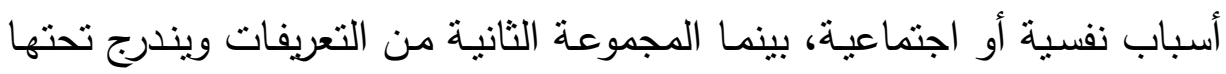

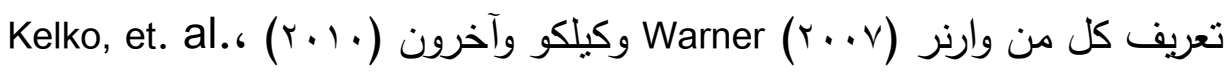

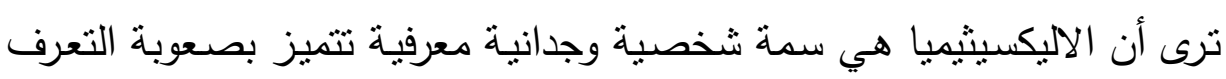

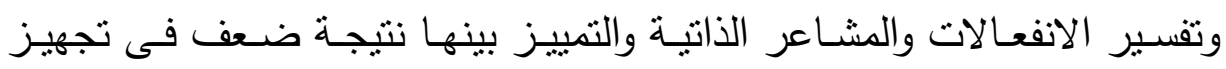

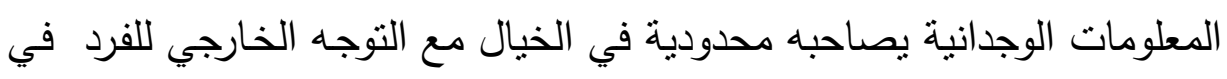

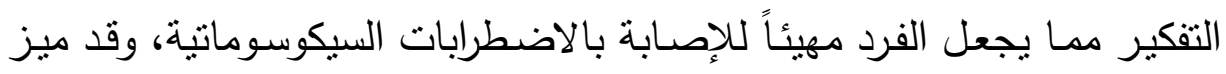
بعض الباحثين بين الاليكسيثيميا كسمة شخصية ويطلق عليها الاليكسيثيميا

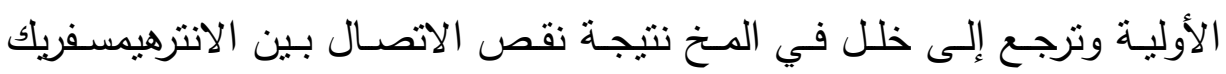

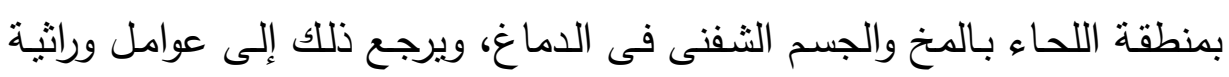

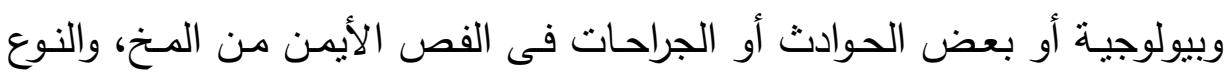

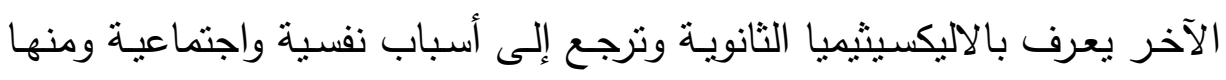

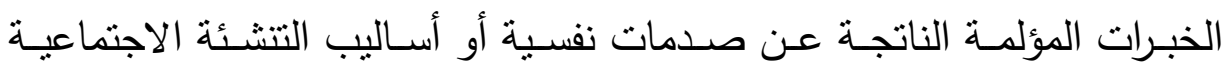
الخاطئة (Krystal, 1988 ,264), (Taylor \& Bagby, 2000, 59), (Rose, 2002, 8) ,(Pirlot \& Corces, 2012, 1410) • unilla,et.al.,2003,533-534), 
إن الاليكسيثيميا مفهوم سيكولوجي متعدد الأبعاد، يشمل عدة أبعاد هي الابيكي صعوبة التعرف على المشاعر الذاتية والتمييز بينها وبين الأحاسيس الجسدية، وضـف القدرة على التعبير عن المشـاعر في كلمات، وصعوبة وصف وفهم

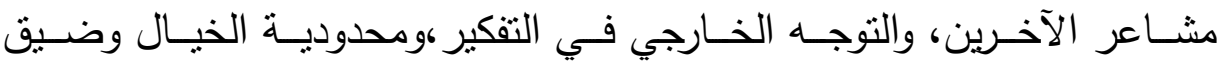

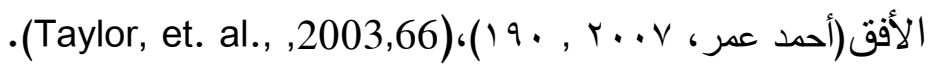

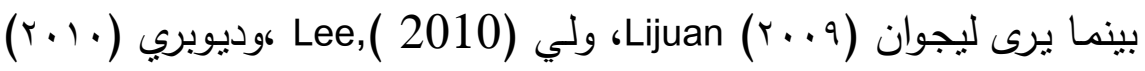
Duprey

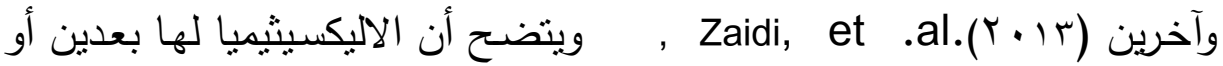
مكونين، وهما المكون الوجداني والمعرفي، فأما المكون الأول وهو الوجداني فهو قصور فى القدرة على التعبير عن الانفعالات وصعوبة تحديدها والتمييز بينها وبين الأحاسيس الجسدية المصاحبة لها، وصعوبة التعبير عن المشاعر أمام الآخرين ولهم مما يؤدى إلى صعوبات فى التواصل ، أمـا المكون التاني وهو

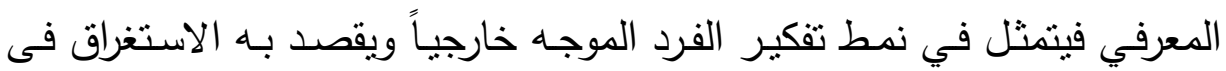

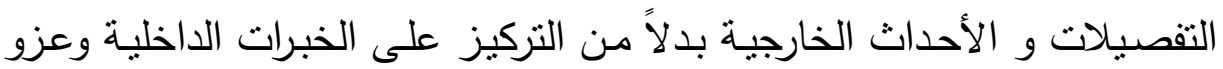
الأمور عموماً إلى عوامل خارجية بالإضافة إلى ضيق الأفق ومحدودية الخيال ويقصد به سطحية التفكير وقلة الأحلام والخيال. السمات المميزة للأفراد المصابين بالاليكسيثيميا:

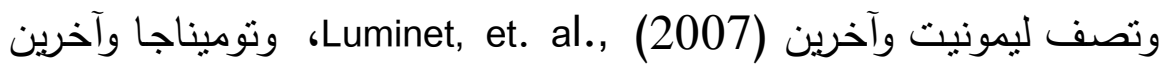
( Tominaga, et. al. السمات المميزة للأفراد المصابين بالاليكسيثيميا بأن لديهم صعوبة في تحديد المشاعر والتمييز بينها وبين الأحاسيس الجسدية و صعوبة في التعرف ووصف مشاعر الآخرين وندرة أحلام اليقظة ونقص الخيال

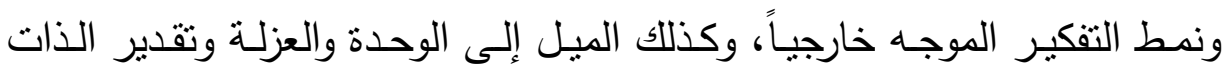
المنخفض وضعف القدرة على تكوين الصداقات وسرعة الغضب والميول العدوانية 
وأحياناً الانتحارية، والثعور بالارتباك كرد فعل على انفعالات الآخرين، ومعاناة

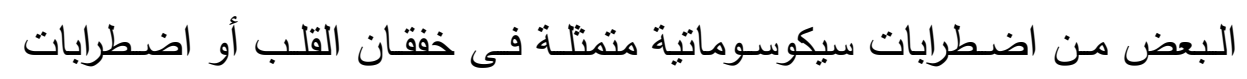

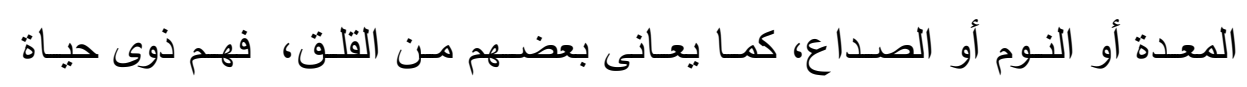
وجدانية فقيرة قليلى التعاطف مـع غيرهم وذوى علاقات سطحية وقليلي المبادأة

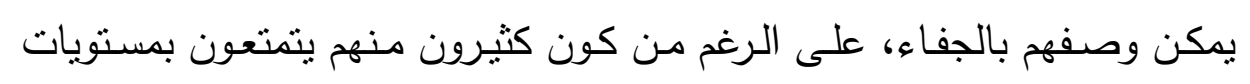

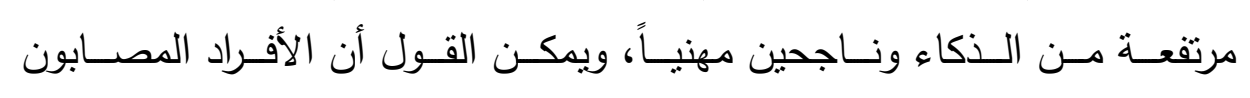

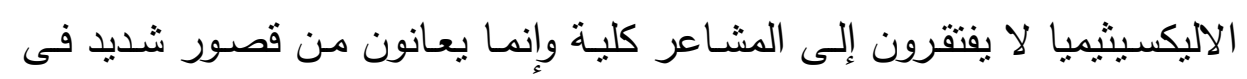

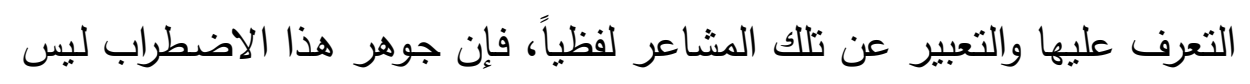
غياب المشاعر وإنما غياب المفردات الوجدانية. أسباب الاليكسيثيميا:

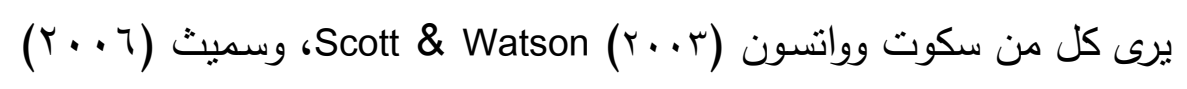

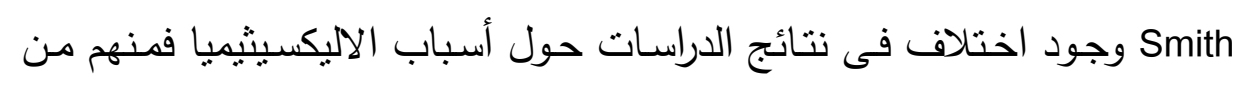

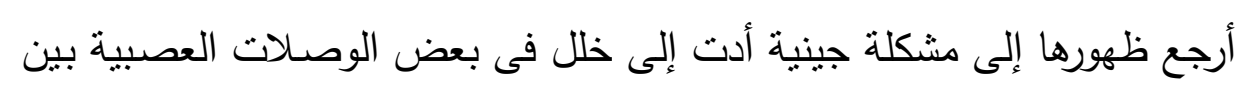

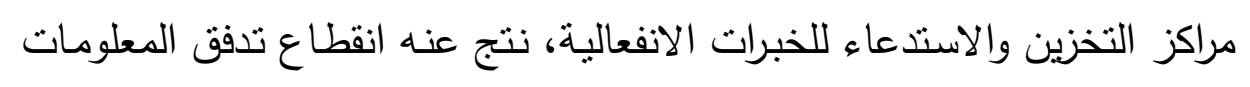

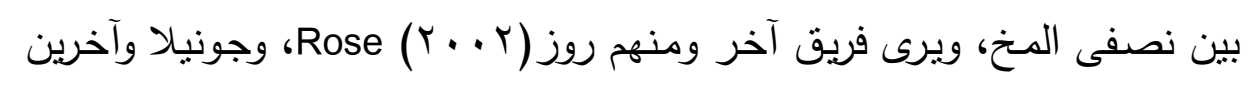

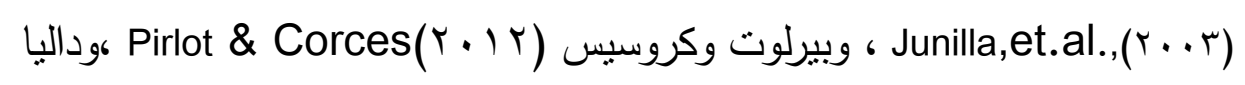

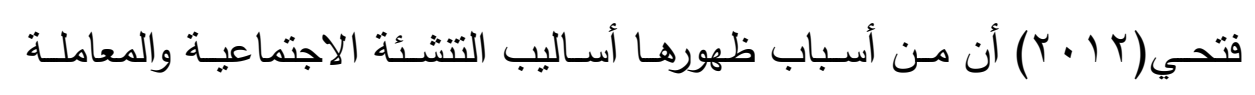

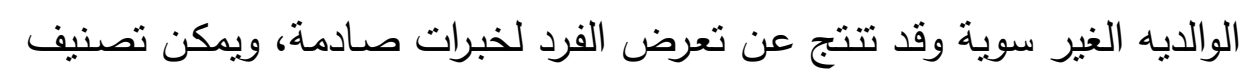

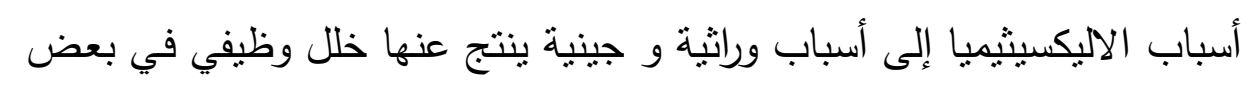
وظائف المخ المسئولة عن معالجة وإدراك المشاعر وقد ترجع إلى أسباب ثقافية

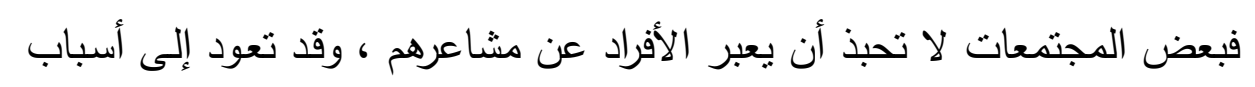

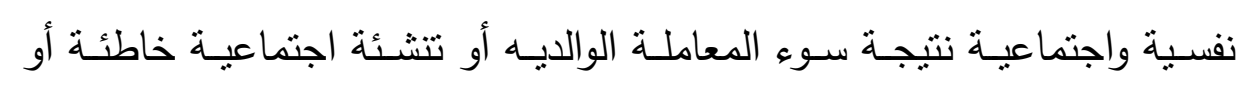

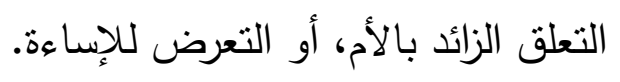




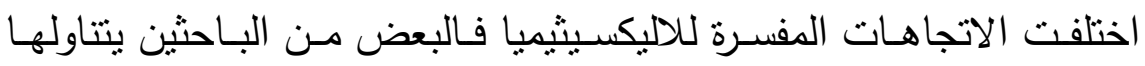
كسمة شخصية موجودة بدرجة ما لاى بعض الأفراد، وبعض الباحثين يرى أنها

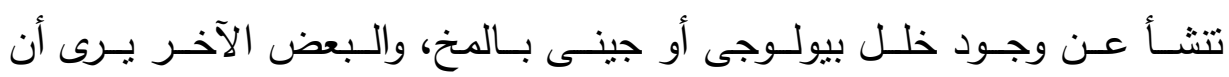

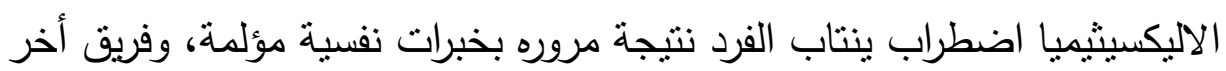

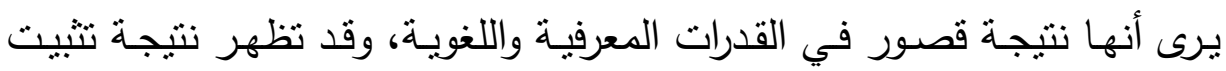
للنمو الانفعالي فى مرحلة مبكرة من النمو نتيجة أساليب تنشئة خاطئة (Luminet, et. al., 2001, 256), (Grabe, et. al., 2001, 264) (Smith, $2006,20)$ (besharat \&Shahid, 2011, 148),( Nicolo, et. al., 2011 , 1414.)، (Rudel, 2010 , 405) بينما تشير النظرية التكاملية ذات التأثير المنتظم إلى أن الفرد عندما يفقد

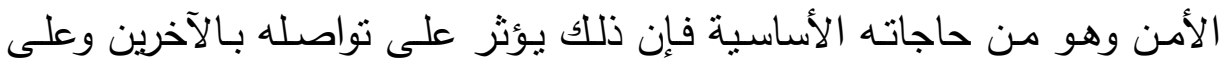

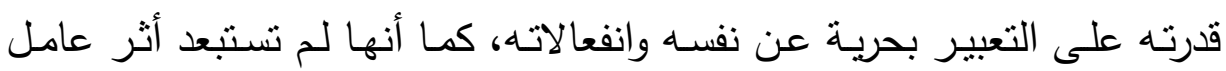
الوراثة فى كثير من الحالات التى تعانى من الاليكسيثيميا، فتشير إلى أنها قد

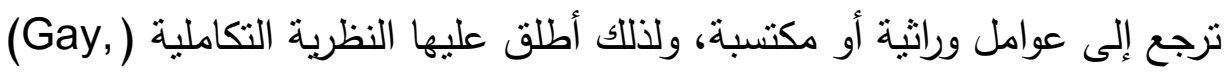
.et. al., 2008,7

وتبنت الباحثة وجهة نظر النظرية التكاميلية فى تفسير الاليكسيثيميا لأنها

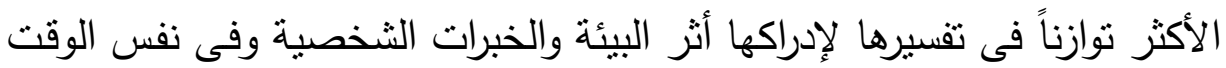
لم تهمل أثر عامل الوراثة فى ظهور الاليكسيثيميا، ، حيث من العسير الفصل لادريل في تأثثر الوراثة والبيئة فيما يتعلق بكثير من الأمور الإنسانية ، فالميل نحو تأثنير عامل دون باقي العوامل قد يشكل عائق ونقطة ضعف في فهم المشكلة والتعامل معها. 
- ثانياً الاضطرابات السيكوسوماتية (النفسجمية):

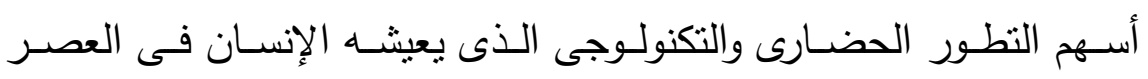

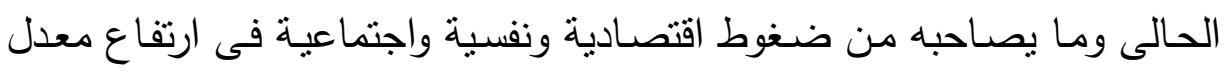
الانفعالات وتتوعها، و نتيجة لكبت الكثير من هذه الانفعالات وعدم القدرة على القى

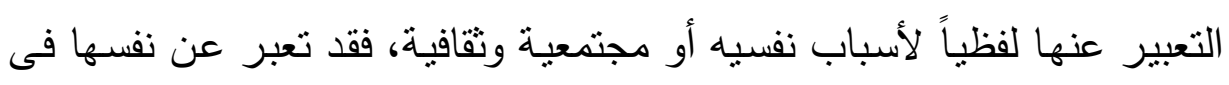
شكل اضطرابات عضوية تؤثر على الكفاءة الوظيفية لكثبر من أجهزة الجسم.

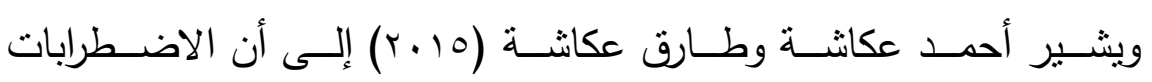

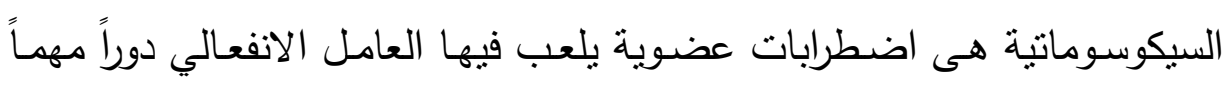

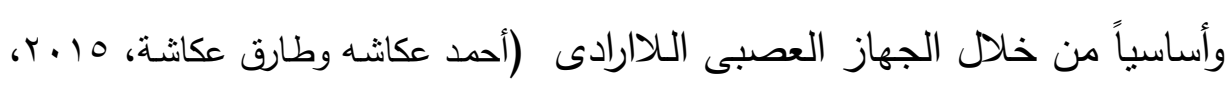
. $7 \leq r$

ويتفق العديد من الباحثين حول نعريف الاضطرابات السيكوسوماتية فيعرفها

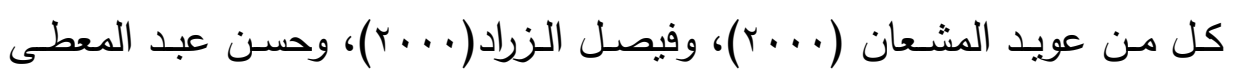

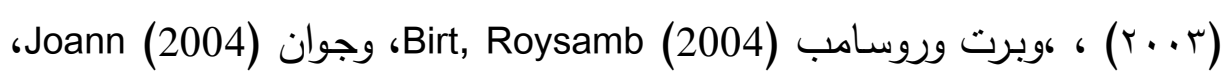

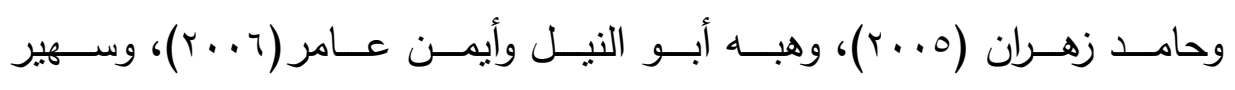

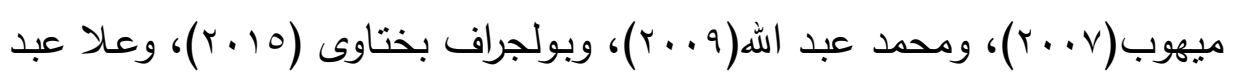

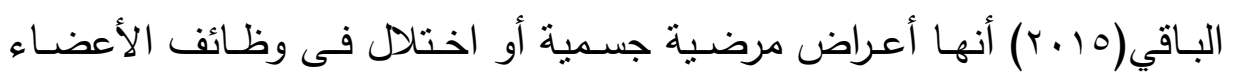

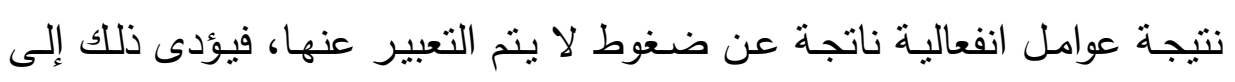

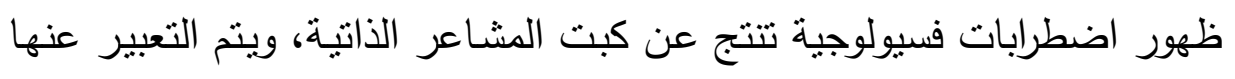

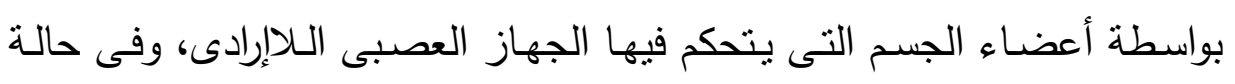

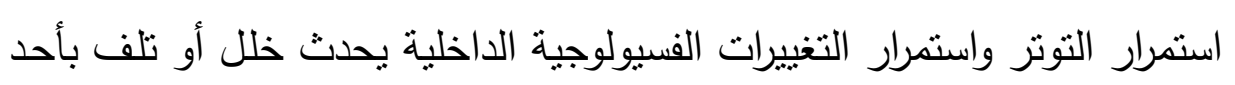

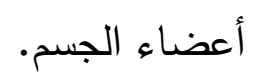

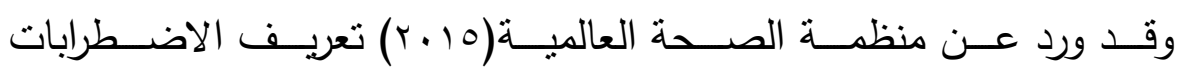

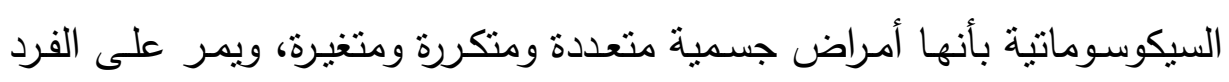

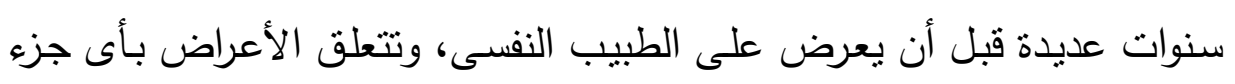

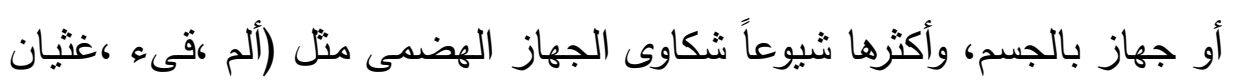
v) 


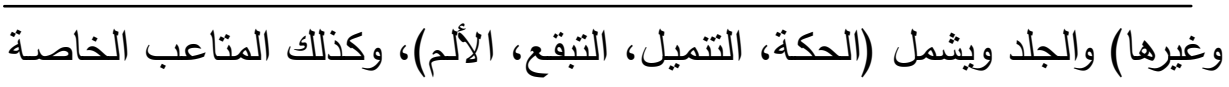

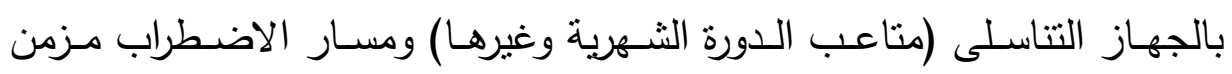
ومذبذب ويصاحبه اختلال فى السلوك الثخصى والاجنماعى على المدى الطويل

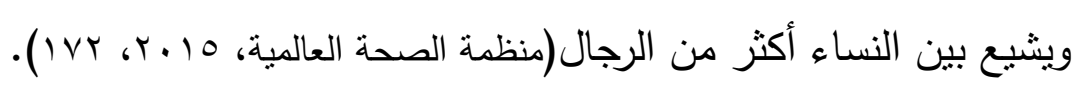

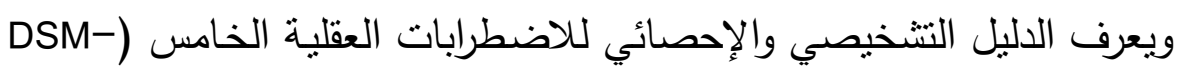

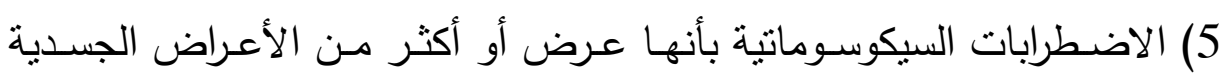

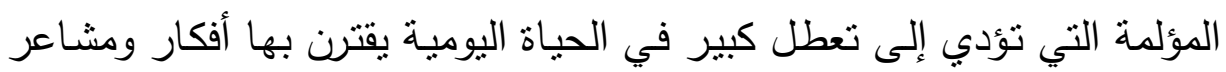

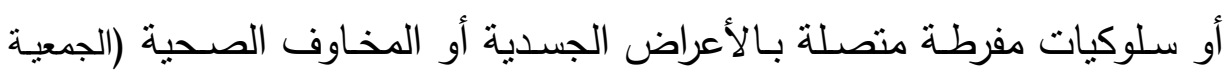

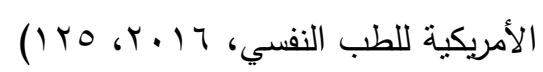

ويتضح من العرض السابق لتعريفات الاضطرابات السيكوسوماتية أنها

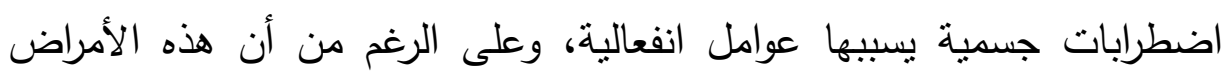

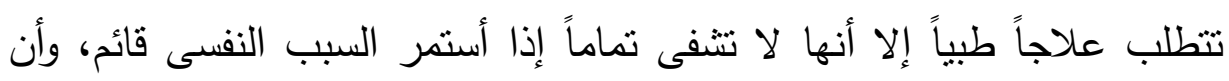

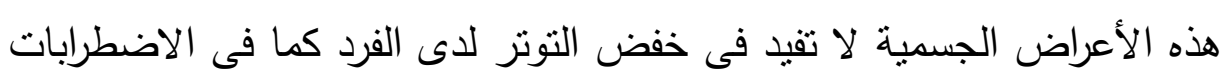

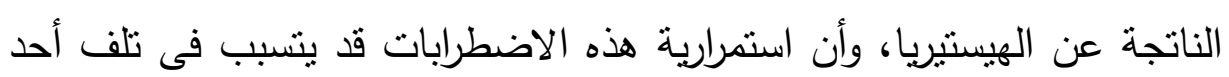

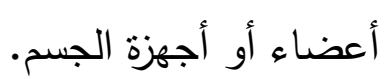

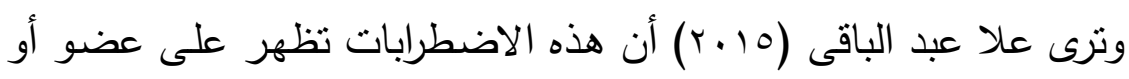

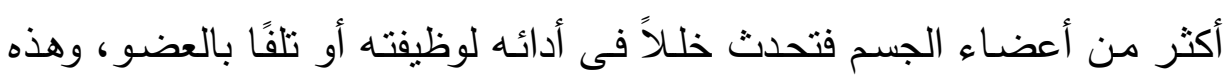
الأمراض لا يفلح معها العلاج الطبى وحده لأنها حدثت نتيجة اضطرابات انفعالية

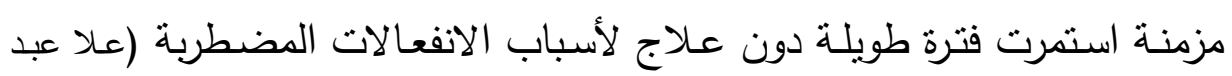

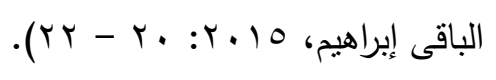
أسباب الاضطرابات السيكوسوماتية: تحدث تللك الاضطرابات نتيجة لتضافر العديد من العوامل البيولوجية والنفسية والاجتماعية، وهي 
1-عوامل نفسية: وتتمنل فى الضغوط النفسية والانفعالات التى تؤدى إلى

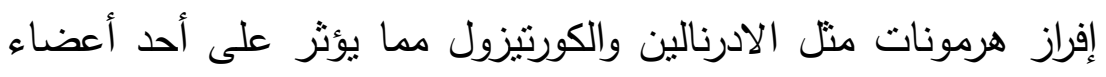

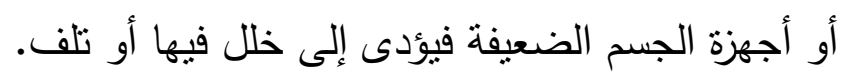

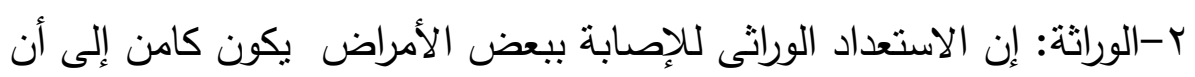
يتعرض الفرد لعوامل تساعد في ظهوره.

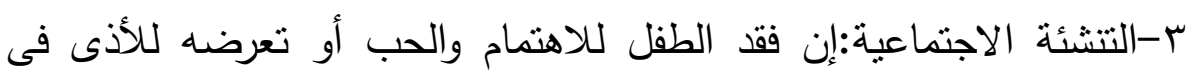

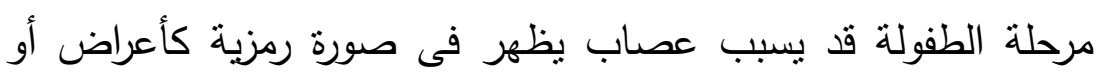

$$
\text { شكاوى فى أحد أعضاء الجسم. }
$$

ع-نمط الثخصية : الأفراد ذوى الطموح الزائد والمنافسين أكثر عرضه

للاصابه بالأمراض

ه- أسلوب حياة الفرد: إن الفرد الذى يعانى من اضطرابات انفعالية مستمرة،

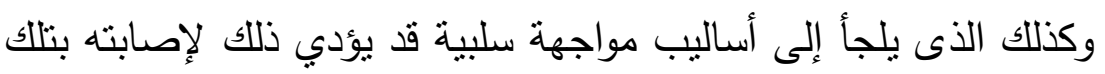
الاضطرابات

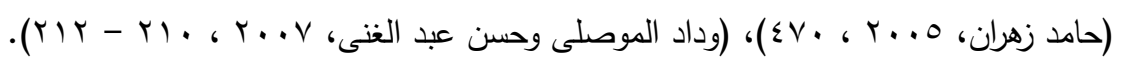

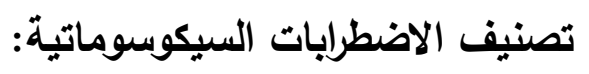

هى شكاوى أو أمراض تصيب عضو أو أكثر من الجسم، وتظهر في صورة

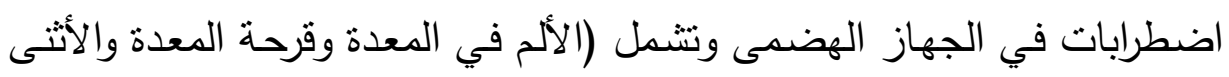

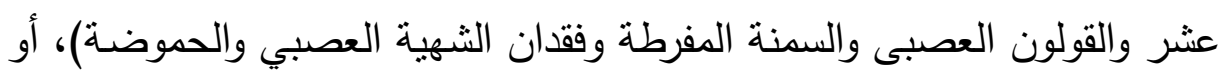

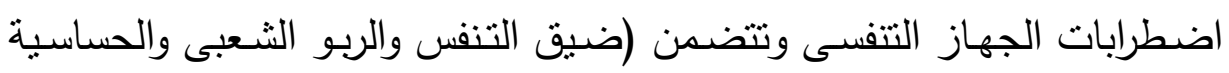

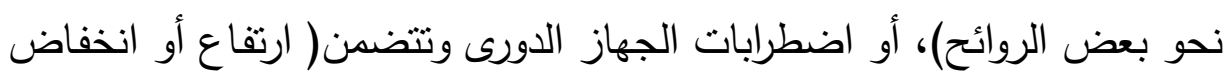

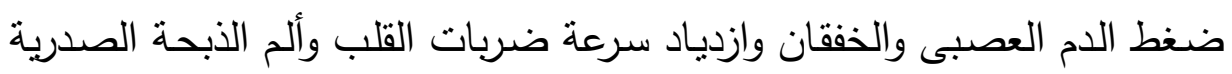

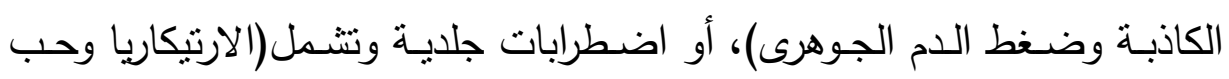
الثباب والحكة وتسـاقط الثـعر والأكزيما وفرط التعرق والصدفية)، واضطرابات التهات

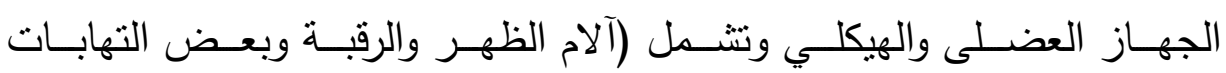
المفاصل)، أو اضطرابات الجهاز التتاسلي وتتمل (اضطرابات الحيض وألم ما والا VT 


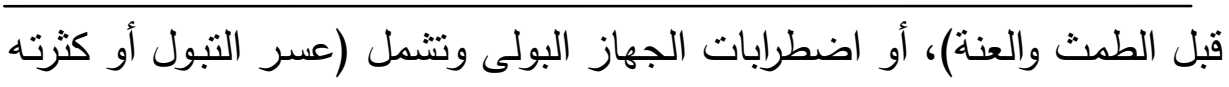

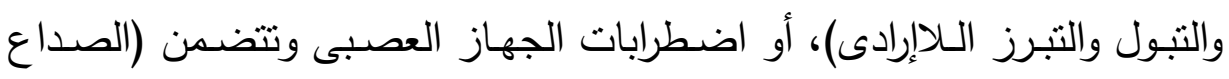

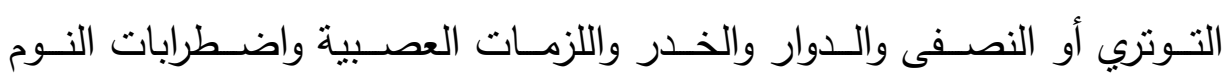
والرعشة)، أو اضطرابات الجهاز الغدى وتتضمن (الإصـابة بالسكر وزيادة إفراز

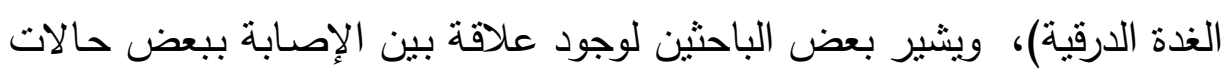

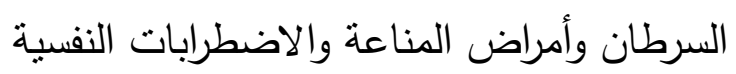

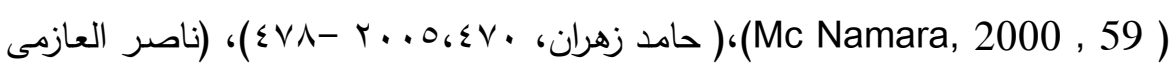

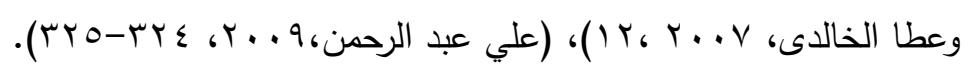

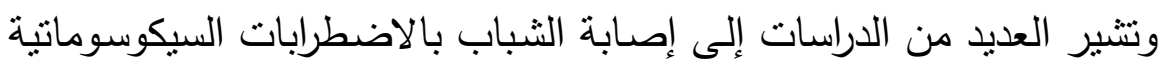

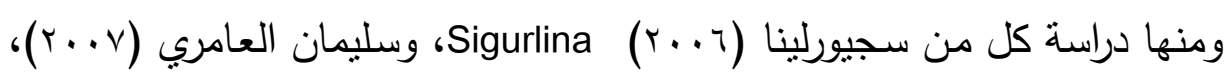

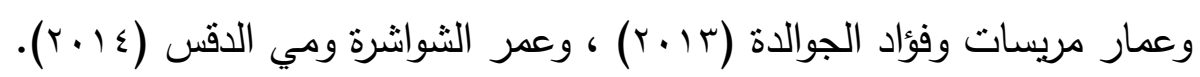

\section{الالائل التثخيصية للاضطرابات السيكوسوماتية:}

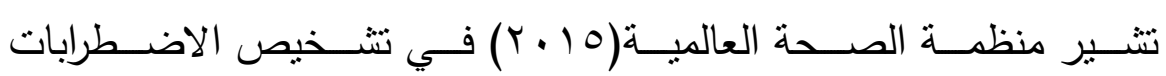
السيكوسوماتية إنه لابد من وجود ظواهر (أعراض) وهي أعراض جسمية متعددة

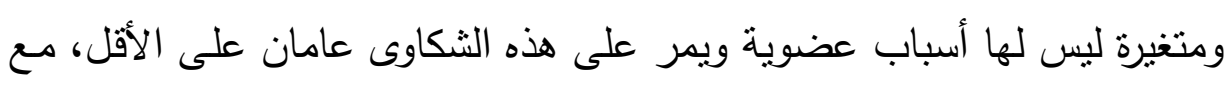
الرفض المستمر لنصح الأطباء بعدم وجود سبب عضوى أو جسمى، وتؤثر تلك عليه

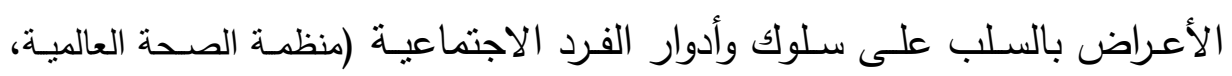

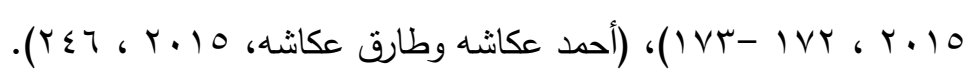

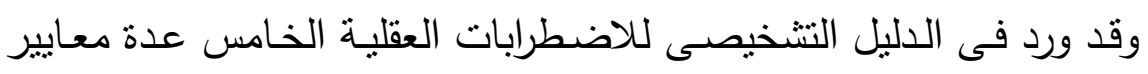

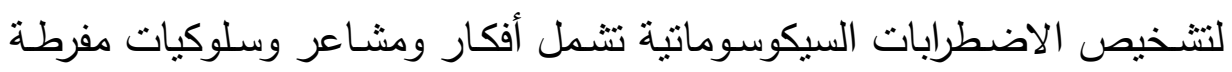

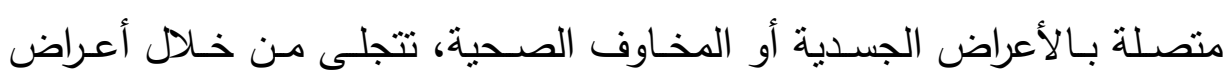
تتضمن أفكار غير متتاسبة ومستمرة حول خطورة الأعراض الجسمية،استغراق

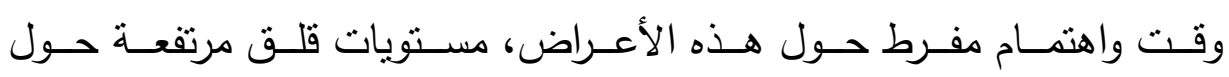

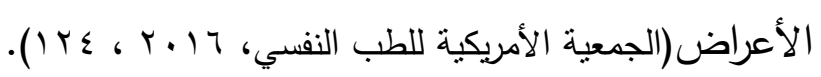


محكات تثخيص الاضطرابات الجسمية نفسية المنشأ:

ا ا.تبدأ الثكاوى الجسمية قبل سن الثناثثن.

$$
\text { r. ب.تستمر لسنوات عديدة. }
$$

r.يطلب الثخص العلاج ويتردد على الأطباء.

ع .يعانى الثخص من خلل فى الأداء الاجتماعى والمهنى.

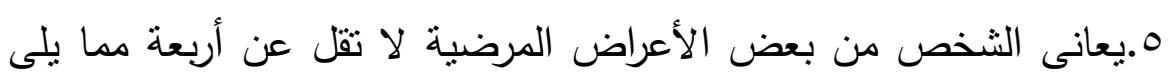

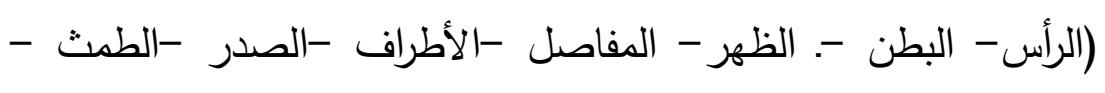

$$
\text { التبول - نواحى نفسية). }
$$

7.يعانى الفرد من الألم منت (الغثيان، القىء، الانتفاخ، الإسهال).

V.عرض جنسى واحد من التالى (عدم الاهتمام بالجنس، مشاكل بالطمث).

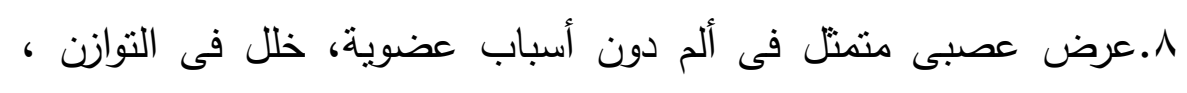

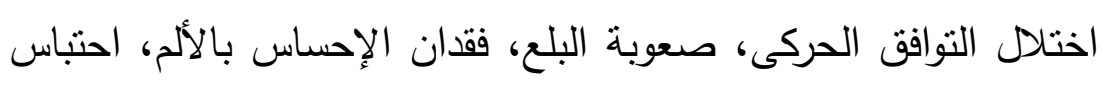

$$
\text { الصوت أو البول. }
$$

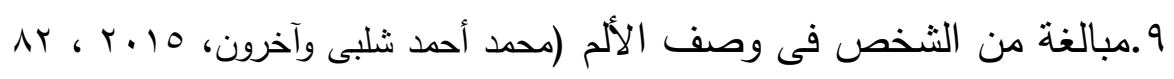

$$
\text { (^r- }
$$

\section{النماذج والنظريات المفسرة للاضطرابات السيكوسوماتية:}

تعددت النماذج والنظريات المفسرة لهذه الاضطرابات، فمنها النموذج الطبى

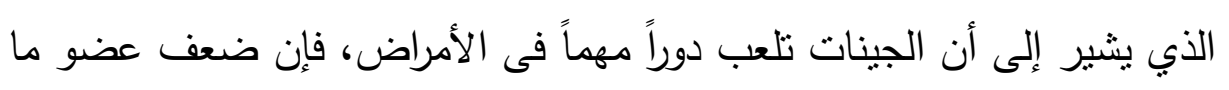

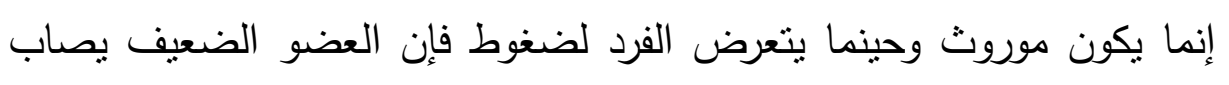

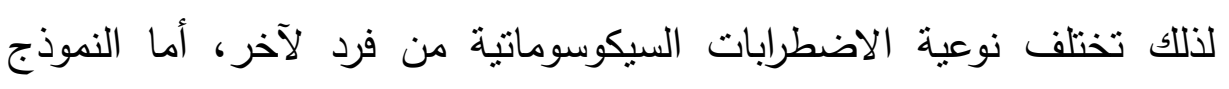

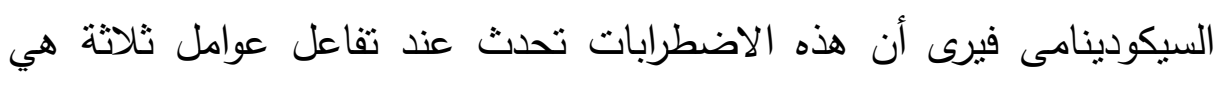

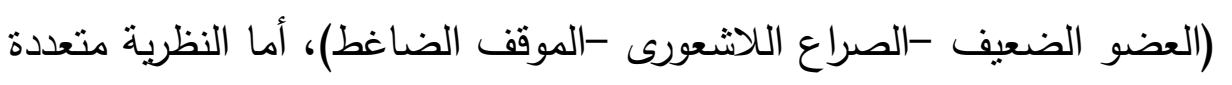

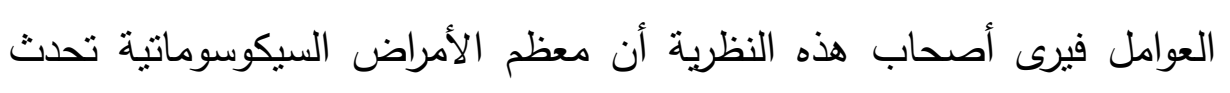

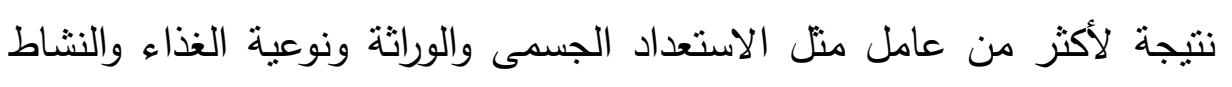

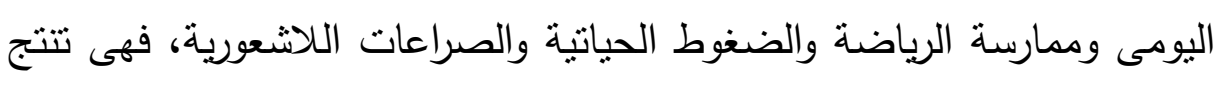
vo 
برنامج إرشادي انتقائي تكاملي لخفض حدة الاليكسيثيميا د.جيهان عثمان محمود

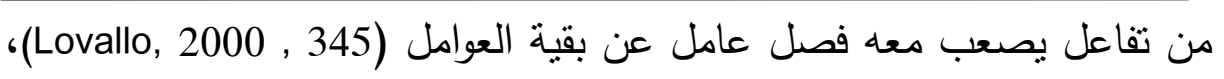

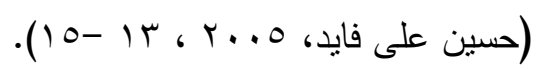

وقد تبنت الباحثة النظرية متعددة العوامل لأنها تفسر حدوث الاضطرابات السيكوسوماتية دون إغفال لأثر أي عامل من العوامل سواء البيئية أو الوراثية

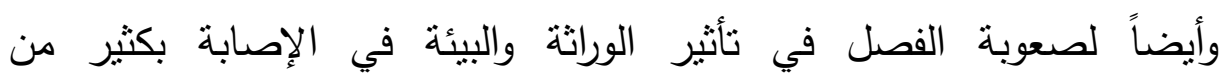
الاضطرابات، فالاتجاه التكاملي في تتاول الموضوعات يكون أفضل من الاتجاه

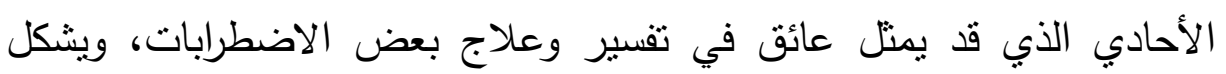
مصدر نقد ونقطة ضعف قد يحول دون نجاح أي تدخل علاجي أو إرشادي .

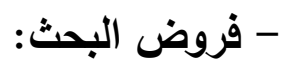

ا.توجد فروق دالـة إحصـائياً بـين منوسـي رتب درجـات طالبـات المجموعـة التجريبية في القياس القبلي والبعدي على مقياس الاليكسيثيميا في اتجاه القياس القبلي.

r.نوجد فروق دالة إحصائياً بين متوسطي رتب درجات المجموعتين التجريبية والضـابطة في القياس البعدي على مقياس الاضطرابات السيكوسوماتية في اتجاه طالبات المجموعة الضابطة .

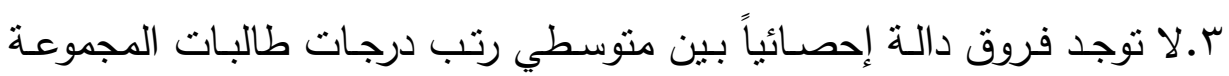

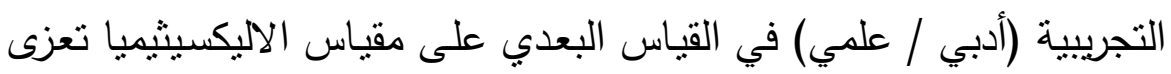
إلى التخصص الدراسي.

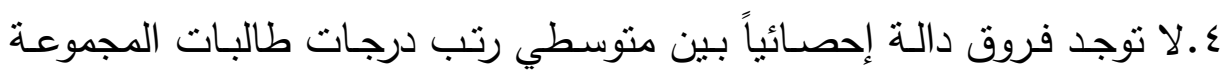

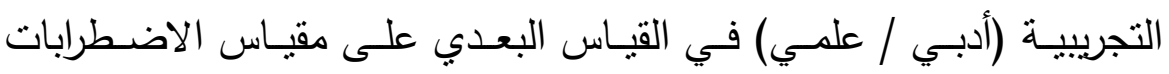
السيكوسوماتية تعزى إلى التخصص الدراسي.

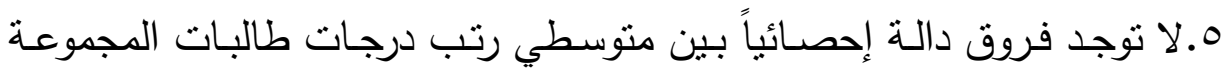

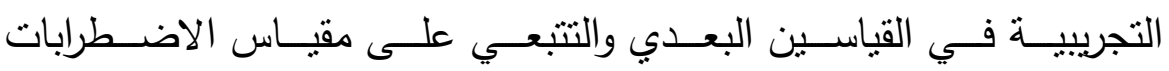
السيكوسوماتية. 
- إجراءات البحث:

أولاً مــنهج البحـث: اسـتخدمت الباحثـة المـنهج شـبه التجريبـى ،والتصـميم التجريبى ذى المجموعتين المكون من مجموعة ضابطة ومجموعة تجريبية للبحث

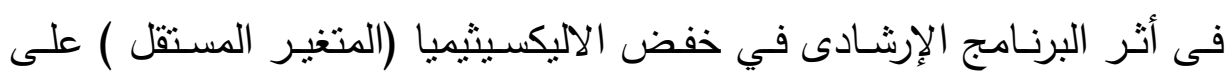

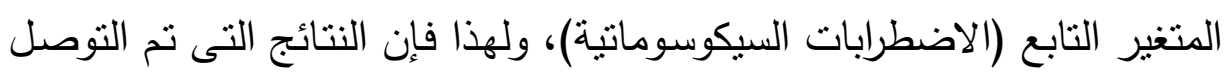
إليها تكون راجعة لتأثير المتغير المستقل.

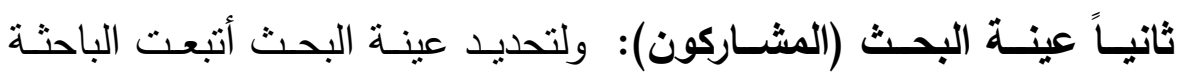

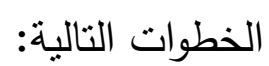
اشتقت عينة البحث الحالي من مجتمع الدراسة الأصلي وهو طلاب الأقسام

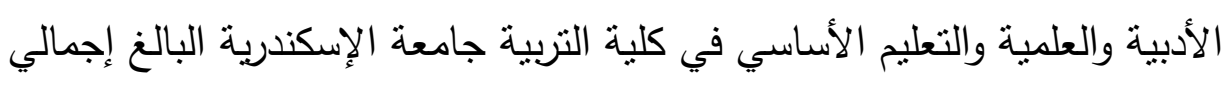

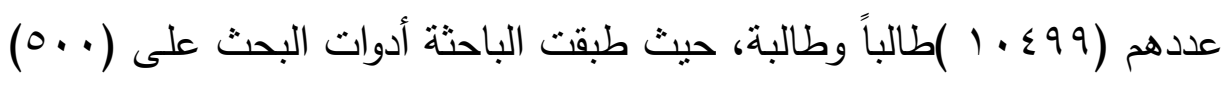
طالبة من طالبات الفرقة الأولى من أقسام الكلية من التخصصين الأدبي والعلمي

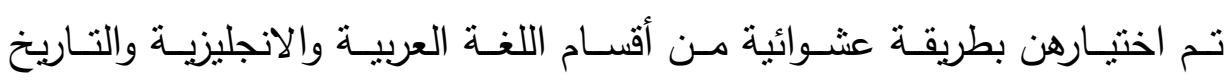
والجغرافيا وعلم النفس والرياضيات والكيمباء والأحياء، واستبعدت الباحثة منهن

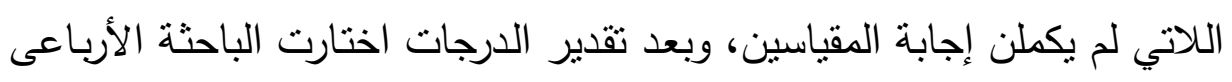

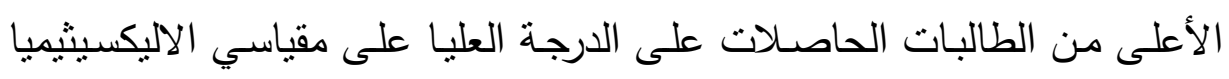

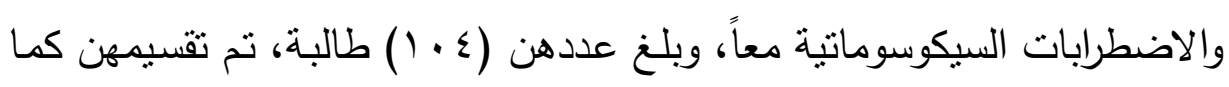
يلي:

\section{أ ـ عينة التحقق من الخصائص السيكومترية لأدوات البحث:}

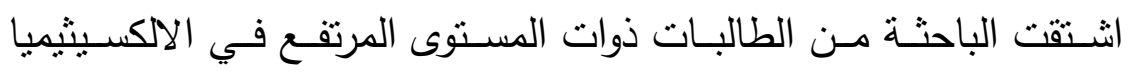

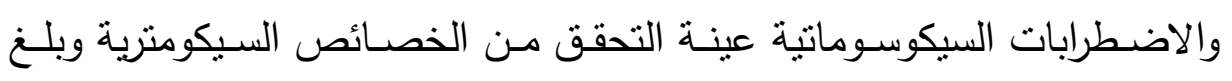

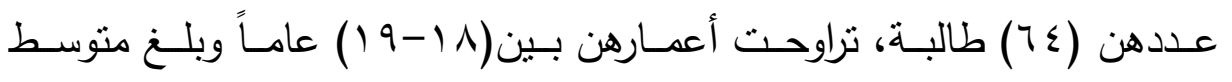

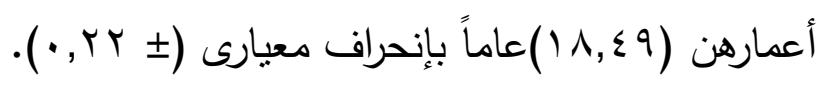


برنامج إرشادي انتقائي تكاملي لذفض حدة الاليكسيثيميا د.جيهان عثمان محمود

$$
\text { ب . عينة البحث (المشاركون في التطبيق): }
$$

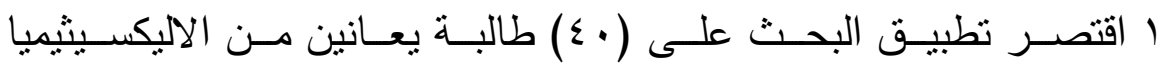

والاضطرابات السيكوسوماتية.

r. قسمت الباحثة الطالبات إلى مجموعتين، المجموعة الأولى تجريبية وعددهن

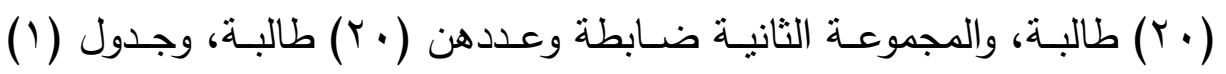
يوضح توزيع الطالبات.

جدول (1) توزيع أفراد عينة البحث

\begin{tabular}{|c|c|c|c|}
\hline المجموع & العدد & التخصص الدراسي & نوع المجموعة \\
\hline \multirow{2}{*}{$r}$. & 1. & أدبي & التجريبية \\
\hline & 1. & علمي & ( • ( ) طالبة \\
\hline \multirow{2}{*}{$r}$. & 1. & أدبي & الضابطة \\
\hline & 1. & علمي & (r) طالبة \\
\hline
\end{tabular}

r.ضبط المتغيرات الدخيلة: حاولت الباحثة ضبط بعض المتغيرات التى قد

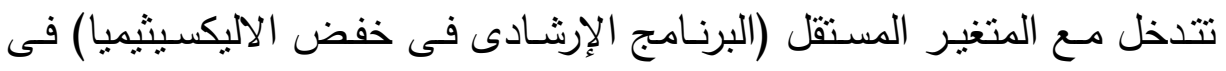

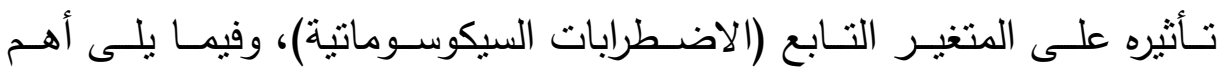

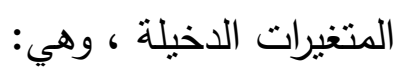

أ ـ النوع الاجتماعي: نظرًا لما نوصلت إليه بعض الدراسـات والبحوث السابقة

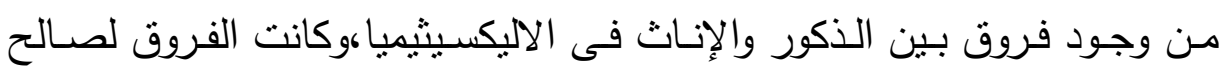

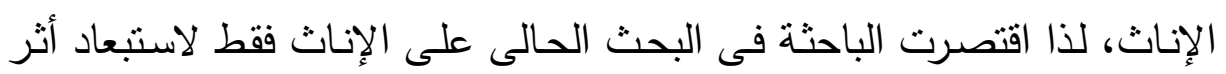

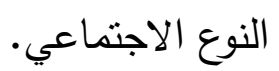

ب ـ العمر الزمنى: استبعدت الباحثة أثر متغير العمر الزمنى، حيث حسبت

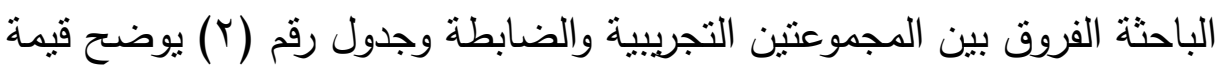
ود لالتهـا الإحصـائية للفروق فى متغيـرى العمـر الزمنسى بين المجمـوعتين باستخدام اختبار مان وينتى Man Wittny. 
جدول (r): نتائج اختبار مان وتينى للفروق بين متوسطى رتب درجات

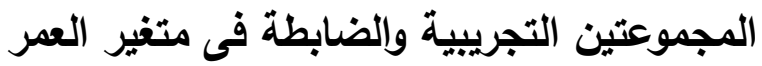

\begin{tabular}{|c|c|c|c|c|c|c|c|c|}
\hline الدلالة & القيمة & مجموع الرتب & متوسط & المعيارى & المتوسط & ن & المجموعة & المتغير \\
\hline \multirow{2}{*}{ غير دالة } & \multirow{2}{*}{104} & T4T & $1 \wedge, 1$. &.,$\Gamma$ & iv,rq & $r$. & الضابطة & العمر \\
\hline & & $\{0 \wedge$ & rr,q. & D r r & $\mid v, \S \wedge$ & $r$. & التجريبية & الزمنى \\
\hline
\end{tabular}

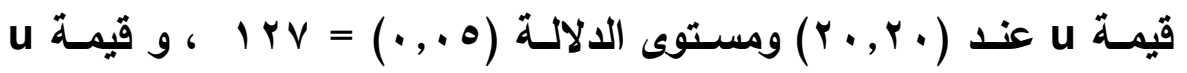

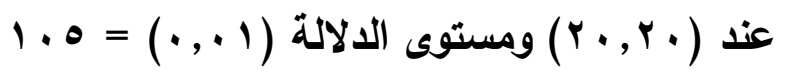

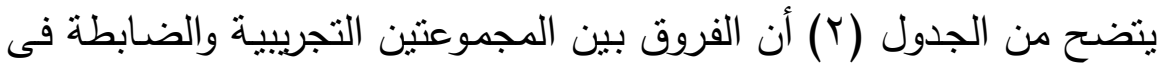

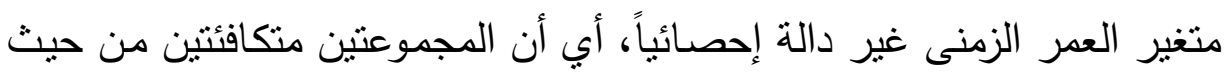

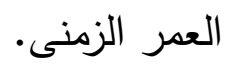

ج المستوى التعليمى: اختير أفراد العينة من طالبات الفرقة الأولى لتى

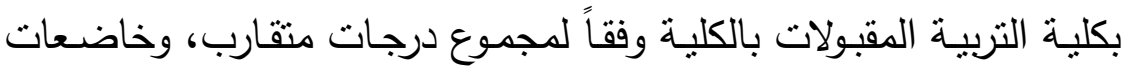
لنفس اللوائح المنظمـة للعملية التعليميـة فى الكليـة سواء مـن حيث عدد الساعات وطرق وأماكن التدريس وطرق التقويم • لتصني د. التكافوء بين المجموعتين (التجريبية والضـابطة) فى كل من الاليكسيثيميا والاضطرابات السيكوسوماتية: وللتحقق من التكافوء استخدمت الباحثة اختبار مان

$$
\text { ويتتى ، والجدولين (r)،(ع) يوضحان ذلك. }
$$

جدول(r) : نتائج اختبار مان ويتتى للفروق بين متوسطى رتب درجات

\begin{tabular}{|c|c|c|c|c|c|c|c|c|}
\hline الدلالة & قيمة & مجموع الرتب & متوسط الرتب & الانعراف & المستوسطى & ن & المجموعة & أبعاد الاليكسيثيميا \\
\hline \multirow[b]{2}{*}{ غير } & \multirow[b]{2}{*}{191} & $\varepsilon \cdot \Lambda$ & $r \cdot, \varepsilon$. & $\varepsilon, 10$ & $\vee \vee, \Lambda$. & $r \cdot$ & ضابطة & \multirow{2}{*}{ والتعبير عن المشاعر التعرف } \\
\hline & & \&ा & $r \cdot, r$. & \&,rV & $\vee \wedge, \bullet \bullet$ & r. & تجريبية & \\
\hline \multirow{2}{*}{ غير } & \multirow{2}{*}{ IVT } & $\varepsilon r \wedge$ & Y $1, q$. & $r, r q$ & $74, \Lambda$. & $r \cdot$ & ضابطة & صعوية التعرف على \\
\hline & & rAr & $19,1$. & $r, \wedge r$ & 74,1 . & $r \cdot$ & تجريبية & مشاعر الآخرين \\
\hline
\end{tabular}
المجموعتين التجريبية والضابطة فى الاليكسيثيميا

v9 
برنامج إرشادي انتقائي تكاملي لذفض حدة الاليكسيثيميا ـ.جيهان عثمان محمود

\begin{tabular}{|c|c|c|c|c|c|c|c|c|}
\hline & & & & & & & & والتعبير عن المشاعر \\
\hline \multirow{2}{*}{ غير } & \multirow[b]{2}{*}{$1 \wedge 1$} & $\leqslant V Y, T$ & $r r, Y A$ & $\varepsilon, \wedge$ & $v_{1}, \cdot 1$ & $r$. & ضابطة & \multirow{2}{*}{ التوجه الخارجى فى التفير ومحدودية } \\
\hline & & $0 . V$ & $r \Delta, r r$ & $r, O V$ & $\vee Y, q$. & $r$. & تجريبية & \\
\hline \multirow{2}{*}{ غير } & \multirow{2}{*}{$1 V \varepsilon$} & $r \wedge \varepsilon$ & $19, Y$. & $\vee, 77$ & Y 10,7 . & $r$. & ضابطة & \multirow{2}{*}{ المجموع الكلي } \\
\hline & & \& & $Y 1, \Lambda$. & $7,7 Y$ & riv,.0 & $r$. & تجريبية & \\
\hline
\end{tabular}

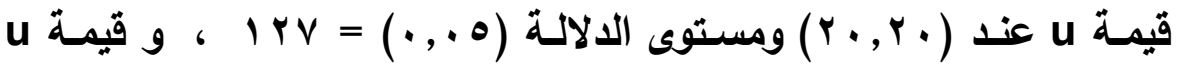

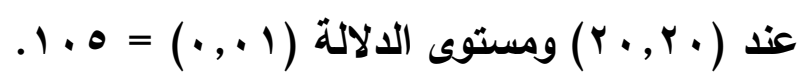

جدول( ) ): نتائج اختبار مان ويتنى بين متوسطى رتب درجات المجموعتين

التجريبية والضابطة في الاضطرابات السيكوسوماتية

\begin{tabular}{|c|c|c|c|c|c|c|c|c|}
\hline الدلالة & قيمة & مجموع الرتب & متوسط الرتب & الانحراف & الحسابى & العدد & المجموعة & المقياس \\
\hline غير & \multirow{2}{*}{171} & rVA & $1 \wedge, 9$. & $v, \cdot v$ & Y10,Yo & $r \cdot$ & ضابطة & الاضطرابات \\
\hline دالة & & $\leqslant \leqslant r$ & rr,l. & $V, r q$ & riv,. I & $r$. & تجريبية & السيكوسوماتية \\
\hline
\end{tabular}

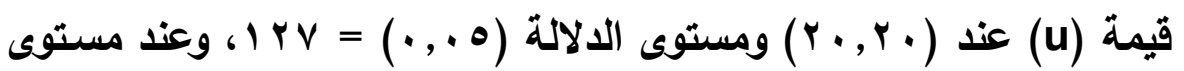

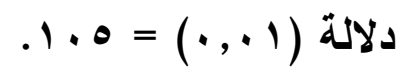

يتضح من جدول (r)، (ع) أن قيم (u) المحسوبة أكبر من قيم (u) الجدولية،

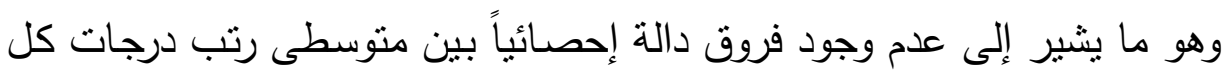

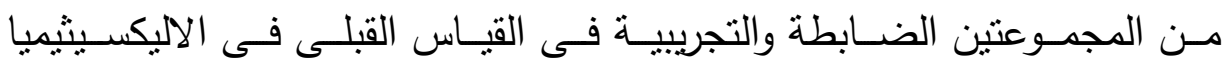

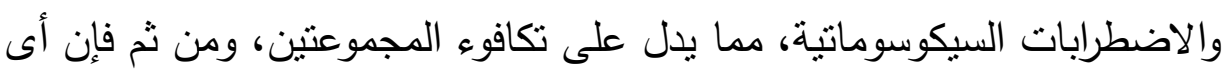
تأثثير يطرأ على الاضطرابات السيكوسوماتية (المتغير التابع ) يعزى إلى تأثنير البرنامج الارشادى لخفض الاليكسيثيميا (المتغير المستقل).

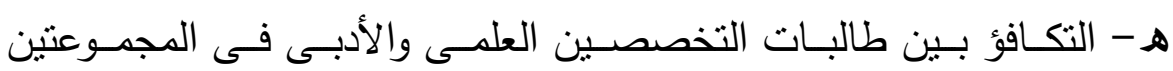
التجريبية والضـابطة: وتضم كل من المجموعتين التجريبية والضـابطة في كل

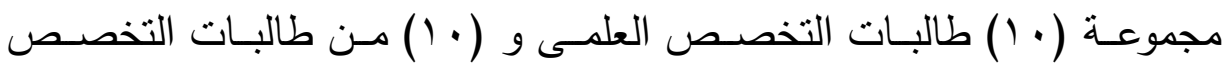

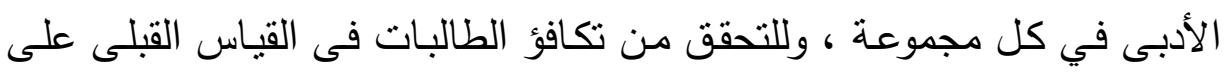


مقياس الاليكسيثيميا بأبعاده وفقاً لمتغير التخصص الدراسي (علمى/ أدبى) قامت

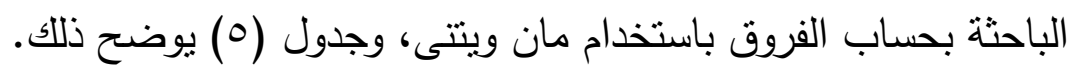

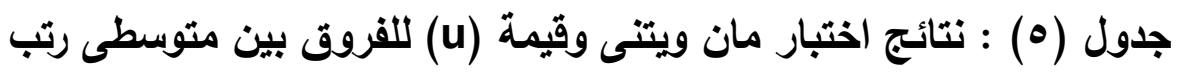
درجات طالبات كل من التخصصين العلمى والأدبى فى القياس القبلى ملى

\begin{tabular}{|c|c|c|c|c|c|c|c|c|c|}
\hline الدلالة & قيمة & مجموع الرتب & متوسط الرتب & الانحراف المعيارى & الحستوسطى & العدد & التخصص & المجموعة & المقياس \\
\hline \multirow{2}{*}{ غير } & \multirow{2}{*}{$\varepsilon V$} & $1 \cdot v, 0$. & $1 \cdot, \times 0$ & 7,70 & r.., 10 & 1. & أدبى & تجريبية & \multirow{4}{*}{ الاليكسيثيميا } \\
\hline & & $1 . r, 0$. & $1 \cdot, Y_{0}$ & $\wedge, \wedge \vee$ & rYY,r. & 1. & علمى & تجريبية & \\
\hline \multirow{2}{*}{ غير } & \multirow{2}{*}{$\varepsilon \wedge$} & $1 . r$ & .r., & $0,0 \leq$ & $r / Y, r r$ & 1. & أدبى & ضابطة & \\
\hline & & $1 \cdot v$ & $1 \cdot, v$. & $\wedge, \cdot 1$ & riv, V. & 1. & على & ضابطة & \\
\hline
\end{tabular}

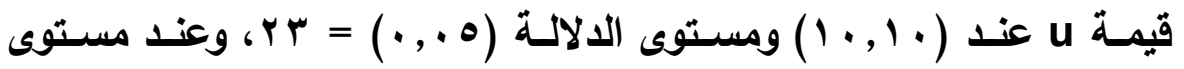

$$
\text { دلالة (1) } 19=
$$

يتضـح مـن جدول (0) أن قيم (u) المحسـوبة للفـروق بـين متوسطى رتب درجات طالبات التخصصين العلمي والأدبي بالمجموعة الضابطة والتجريبية أكبر

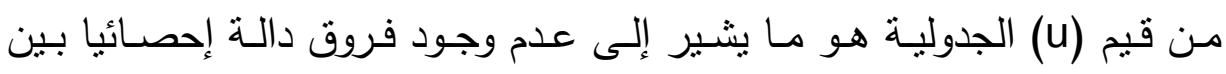
طالبات التخصصين العلمي والأدبي فى القياس القبلى على مقياس الاليكسيثيميا،

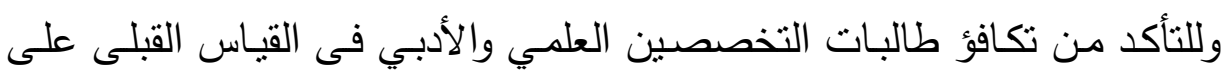

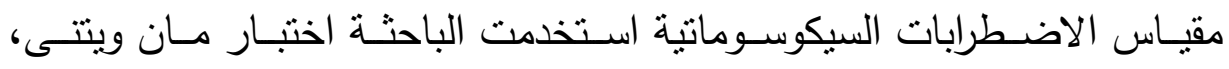

$$
\text { وجدول(T) يوضح النتائج. }
$$

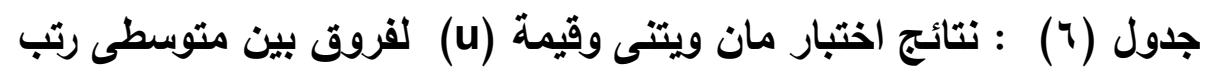

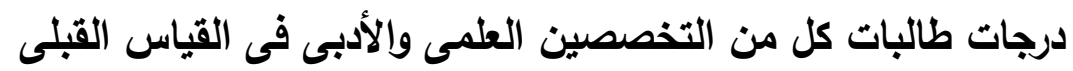

\begin{tabular}{|c|c|c|c|c|c|c|c|c|}
\hline الدلالة & قيمة & مجموع الرتب & متوسط الرتب & الانحراف & المسابى & العدد & التخصص & المقياس \\
\hline \multirow{2}{*}{ غير } & \multirow{2}{*}{$199,0}$. & $\{.9,0$. & $\uparrow \cdot, \leqslant \wedge$ & $\bullet, \wedge \wedge$ & $r \mid \theta, v$. & $r$. & أدبى & الاضطرابات \\
\hline & & $\leqslant 1,0$. & $r \cdot, O r$ & $\Lambda, Y^{\prime}$ & r 1 , 90 & $r$. & علمى & السيكوسوماتية \\
\hline
\end{tabular}
للاضطرابات السيكوسوماتية 
برنامج إرشادي انتقائي تكاملي لخفض حدة الاليكسيثيميا د.جيهان عثمان محمود

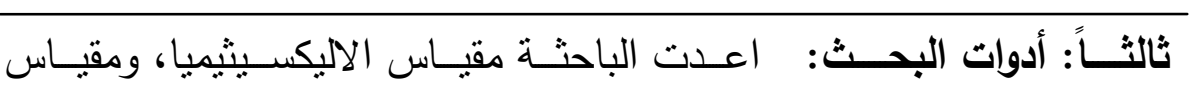

الاضطرابات السيكوسوماتية، والبرنامج الإرشادي لخفض الاليكسيثيميا، ، ويمكن

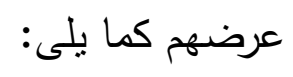

1- مقياس الاليكسيثيميا: إعداد الباحثة

- الهدف من المقياس: يهدف المقياس إلى قياس درجة الاليكسينيميا للى طالبات الجامعة.

( سبق تعريف الاليكسيثيميا وأبعادها سابقاً في مصطلحات البحث). - بنـاء المقيـاس: مر بناء المقياس بعدة خطوات حتى وصل إلى صسورته

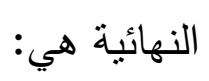

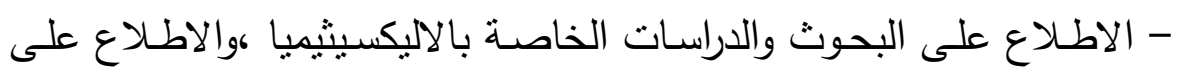

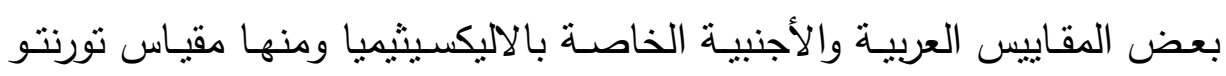

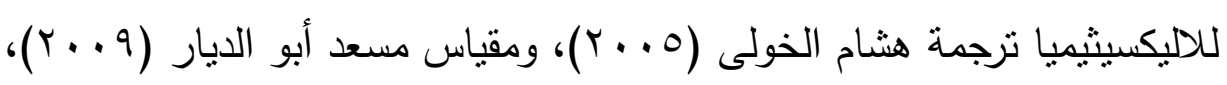

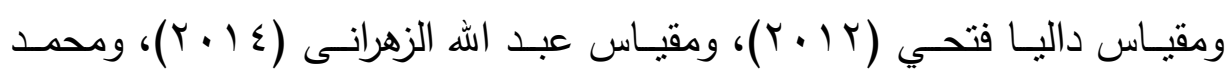

$$
\text { شعبان وآخرين (ع ا • ب). }
$$

- وصف المقياس: فى ضوء الاستفادة من الدراسات والبحوث السابقة والمقاييس

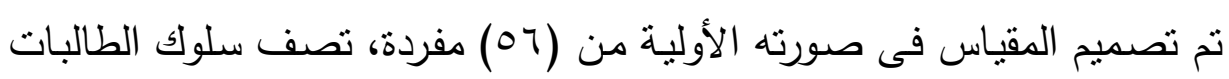
اللاتى يعانين من الاليكسيثيميا، موزعة على الأبعاد الثلاثة للاليكسيثيميا.

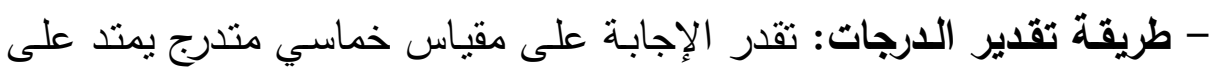

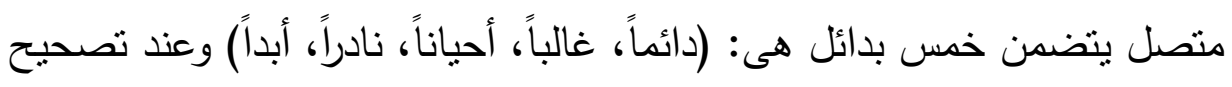

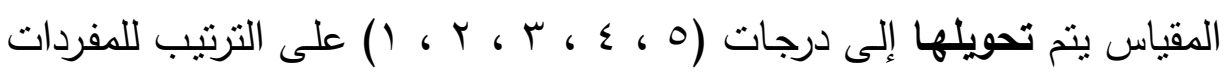

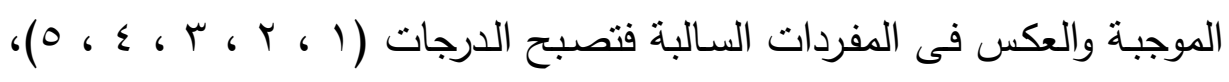

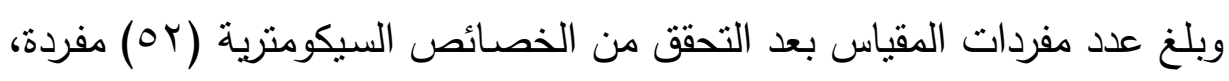

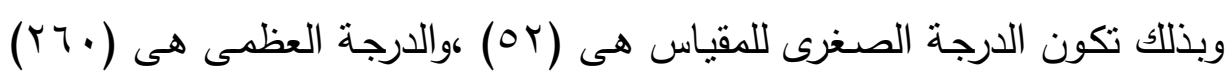
درجة. 
- التحقق من الخصائص السيكومترية لمقياس الاليكسيثيميا:

قامت الباحثة بحساب الصدق والثبات والاتساق الداخلى للمقياس كما يلي:

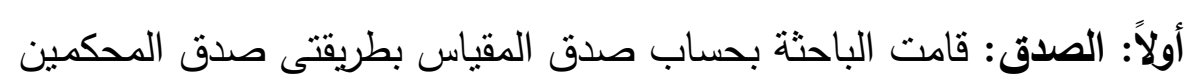
والصدق العاملى.

1- صساق المحكمين: تم عرض المقياس على ( • () محكمين من السـادة

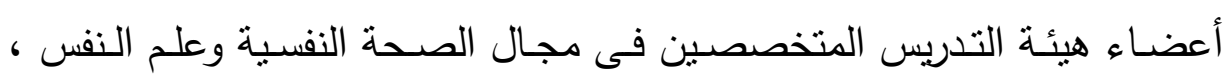
وقامت الباحثة بحساب نسب اتفاق السادة المحكمين على كل مفردة من مفردات المقياس،وتراوحت نسب اتفاق السـادة المحكمين على مفردات المقياس مـا ببن

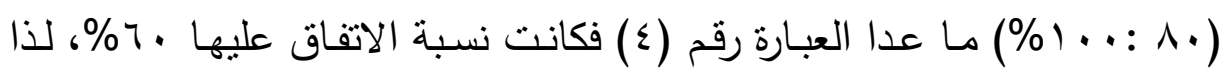
قامت الباحثة بحذفها، واستفادت الباحثة من نوجيهات سيادتهم فى تعديل صباغة بعض مفردات المقياس لتصبح أكثر دقة لغوياً، وتعديل صباغة بعض مفردات

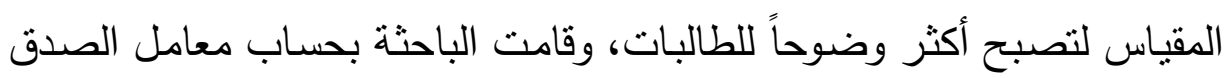

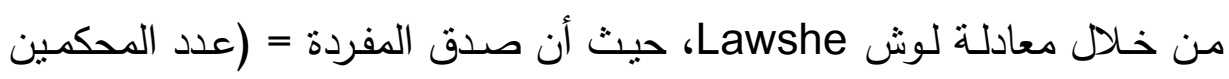

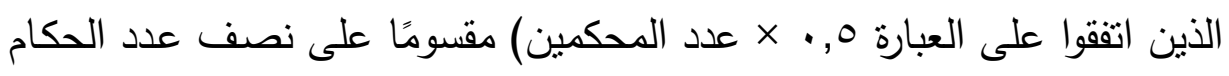

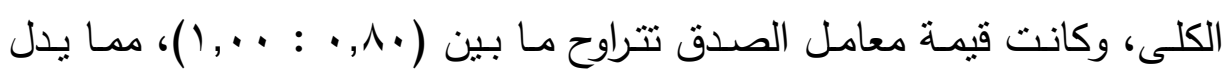
على صدق مفردات المقياس.

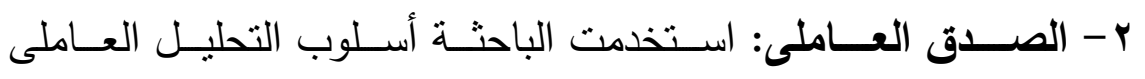

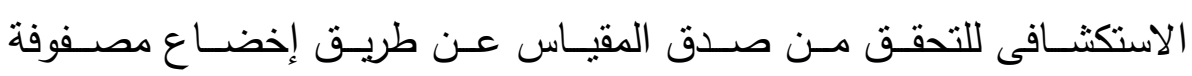

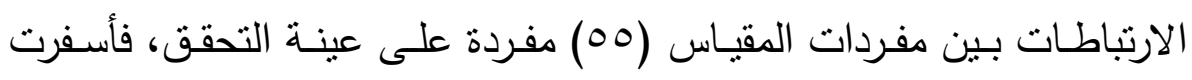

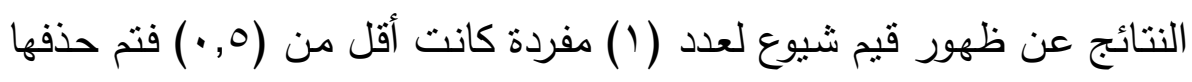
وأعيد إجراء التحليل العاملى على باقى المفردات وظهر أن معاملات التحقق

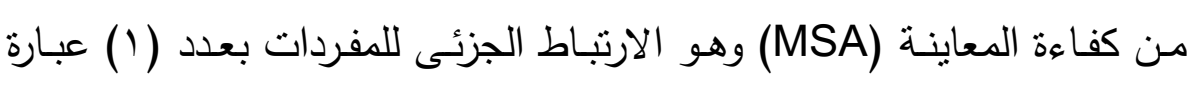

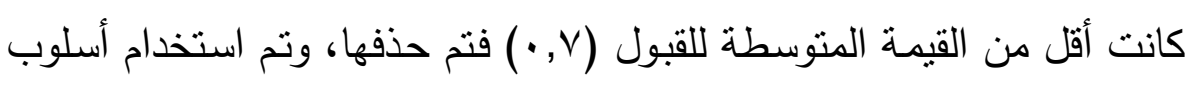
المكونات الأساسية فتم استخلاص (r) عوامل بعد تدوير الأبعاد تدوبراً متعامداً 


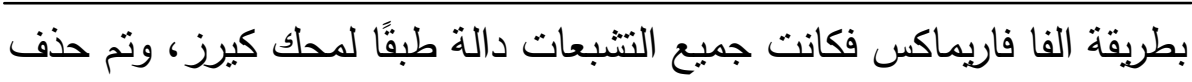

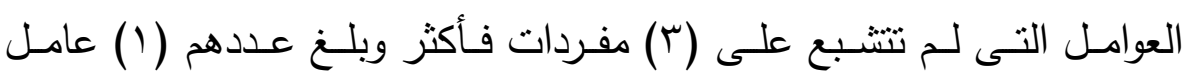

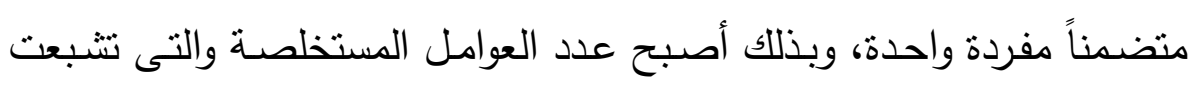

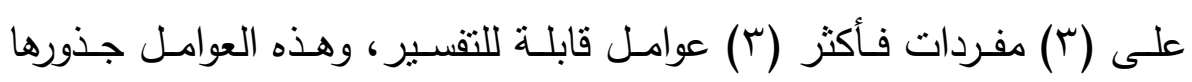

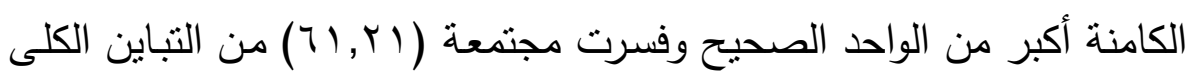
للمفردات، وأسفرت النتائج عن الآتى:

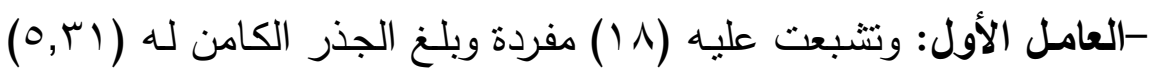

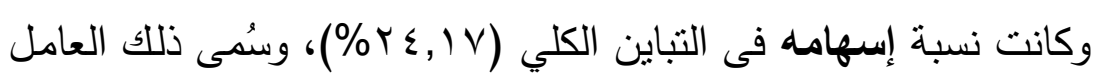

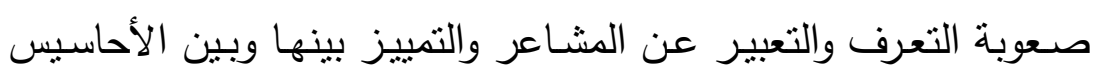
الجسدية.

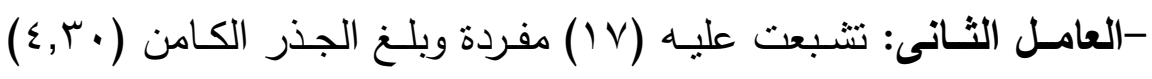

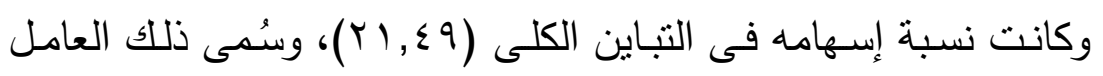
صعوبة التعرف على مشاعر الآخرين والتعبير عن المشاعر نحوهم

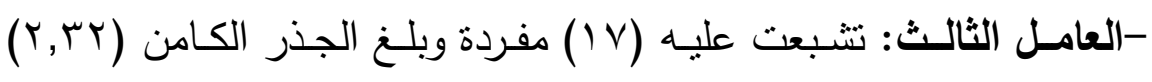

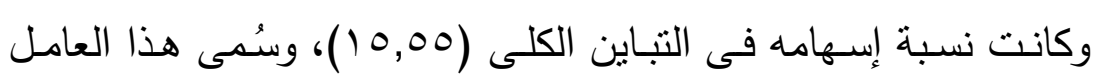
التوجه الخارجى فى التقكير ومحدودية الخيال.

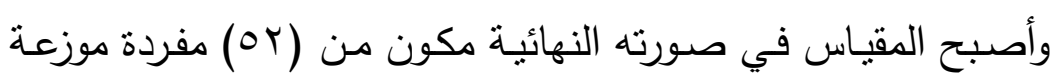
على أبعاد المقياس كما يلي:

1- صـعوبة التعـرف والتعبيـر عـن المشـاعر والتمييز بينهـا وبـين

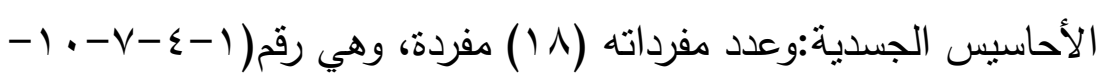

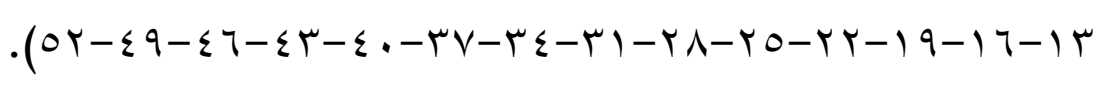
r-صعوبة التعرف على مشـاعر الآخرين والتعبير عن المشـاعر

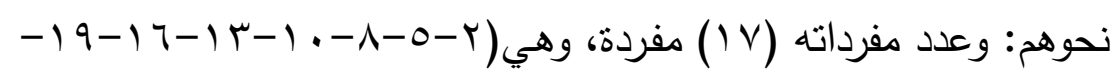
. ( $29-\varepsilon 7-\varepsilon r-\varepsilon \cdot-r V-r \varepsilon-r)-Y \Lambda-r 0-r r$ 
ب-التوجـه الخـارجى فـى التفكيـر ومحدوديـة الخيـال: وعـد مفرداتـهـ

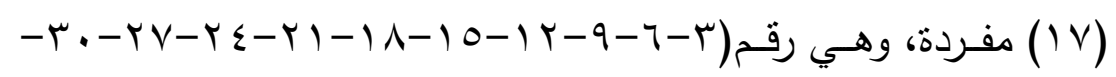

$$
.(0)-\varepsilon \Lambda-\varepsilon 0-\varepsilon r-r q-r q-r r
$$

ثانياً ثبات المقياس:

قامـت الباحثة بحسـاب ثبات المقيـاس الاليكسيثيميا بطريقتى ألفاكرونبـاخ

وإعادة التطبيق.

ا- طريقة ألفا كرونباخ Croonpach Apha method: قامت الباحثة

بحسـاب معامل ثبات المقياس فى حالة حذف المفردة، وبوضـح جدول (V) قيم

معاملات الثبات.

جدول (V) : قيم معاملات الثبات بطريقة ألفاكرونباخ ومعامل الثبات الكلى

لمقياس الاليكسيثيميا (ن = ع 7)

\begin{tabular}{|c|c|c|c|c|c|c|c|c|c|}
\hline الثبات فى معالة & المفردة & حالة حذف الثبات فلى المفردة & المفردة & 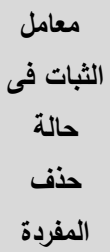 & المفردة رقم & حالة حلبات فى المف & المفردة & حالة حلبات فى المق & رالمفردة \\
\hline$\cdot, V Y r$ & $\leq 0$ & •, VMr & $r \varepsilon$ & •, VYr & rT & $\cdot, V \backslash V$ & Ir & $\cdot, \vee \backslash 0$ & 1 \\
\hline$\cdot, v \cdot \Delta$ & T & •, VYr & ro & $\cdot, \vee \backslash \wedge$ & $r \leq$ & •, VRr & ir & - VYr & $r$ \\
\hline$\cdot, V Y I$ & $\leq V$ & $\cdot, \vee \backslash \leqslant$ & r & $\cdot, \vee_{1}$. & ro & $\cdot, V \leq \varepsilon$ & $1 \leq$ & •, & $r$ \\
\hline$\cdot, v \cdot r$ & $\leq \Lambda$ & ${ }^{\prime, V Y}$ & $r v$ & $\cdot, V Y \leq \leq$ & YY & •, $\vee Y O$ & 10 & $\cdot, V \cdot r$ & $\varepsilon$ \\
\hline$\cdot, v \cdot l$ & $\leqslant 9$ & , , Vrr & $r \wedge$ & $\cdot, \vee \backslash \wedge$ & $r V$ & •, & 17 & $\cdot, V I r$ & 0 \\
\hline$\cdot, v \cdot l$ & o. & $\cdot, v \cdot \Lambda$ & $r q$ & $\cdot, v i r$ & $r \wedge$ & •, & iv & •, & 7 \\
\hline$\cdot, \mathrm{V} \cdot \varepsilon$ & 01 & $\cdot, v \cdot q$ & $\varepsilon$. & •, & rq & $\cdot, \vee \vee \leq$ & 11 & $\cdot, v \cdot r$ & $v$ \\
\hline \multirow[t]{4}{*}{$\cdot, \vee \wedge \wedge$} & or & $\cdot, V \backslash 1$ & $\leqslant 1$ & $\cdot, V Y I$ & $r$. & •, & 19 & $\cdot, v \leq 1$ & $\wedge$ \\
\hline & & •, $\vee Y Y$ & $\varepsilon r$ & $\cdot, v \cdot r$ & M & $\cdot, v \leq r$ & r. & $\cdot, v \cdot q$ & 9 \\
\hline & & $\cdot, V \backslash r$ & $\varepsilon r$ & $\cdot, V Y I$ & $r r$ & $\cdot, v \leq 0$ & YI & $\cdot, V \backslash r$ & 1. \\
\hline & & $\cdot, V \cdot \checkmark$ & \& & $\cdot, \nabla Y \Delta$ & r & $\cdot, v \cdot r$ & Yr & $\cdot, V \backslash r$ & 11 \\
\hline
\end{tabular}

يتضح من جدول (V) أن جميع مفردات المقياس يقل قيمة معامل ثباتها عن قيمة الثبات لمجموع مفردات المقياس ككل، وكانت قيمة معامل ثبات بطربقة ألفا 
برنامج إرشادي انتقائي تكاملي لخفض حدة الاليكسيثيميا د.جيهان عثمان محمود

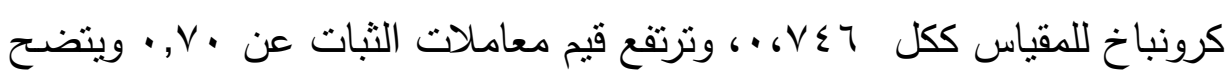

من ذلك تمتع المقياس بدرجة مقبولة من الثبات والتقة بالنتائج التى يسفر عنها.

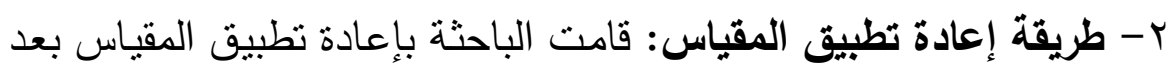

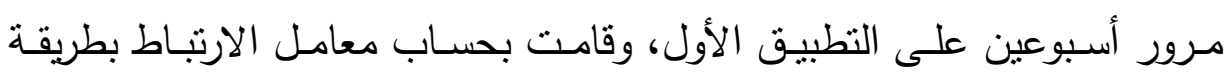
بيرسون Pearson بين درجات الطالبات فى التطبيقين ويوضح جدول (^) نتائج حساب معامل الارتباط للمقياس.

جدول (^) : قيم معاملات الثبات بطريقة إعادة التطبيق لمقياس

الاليكسيثيميا

\begin{tabular}{|c|c|}
\hline معاملات الثبات & أبعاد مقياس الاليكسيثيميا \\
\hline$\cdot, \mathrm{V} \bullet 0$ & الأحاسيس الجسدية - صسوية التعرف والتعبير عن المشــاعر والتمييز بينها ويسين \\
\hline$\cdot, \vee \wedge 1$ & نحوهم ب ب - صعوية التعرف على مشـاعر الآخرين والتعبير عن المشـاعر \\
\hline$\cdot, \mathrm{V} a \mathrm{r}$ & r- التوجه الخارجى فى التفكير ومحدودية الخيال \\
\hline$\cdot, \vee \vee १ ५$ & المجموع الكلى للمقياس \\
\hline
\end{tabular}

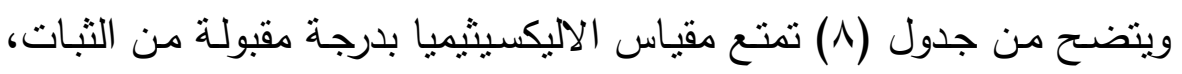

$$
\text { لذا يمكن الوثوق بنتائجه عند تطبيقه في البحث. }
$$

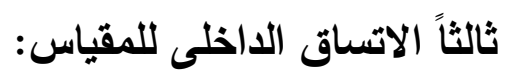

أ ـ الاتسـاق الداخلى لمفردات المقياس: تم حساب معاملات الارتباط بين درجة المفردة ودرجة كل بعد من أبعاد المقياس ويتضـح ذلك من خـلال جدول 
جدول (9) : قيم معاملات الارتباط بين درجة كل مفردة ودرجة كل بعد من أبعاد مقياس الاليكسيثيميا

\begin{tabular}{|c|c|c|c|c|c|}
\hline معامل الارتباط مع & المفردة & مع معامل الارتباط الثانى & المفردة & مع البعد الأول الارتباط & المفردة \\
\hline$\cdot, V Y$. & 1 & •, VTr & 1 & $\cdot, V Y I$ & 1 \\
\hline 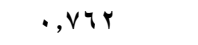 & $r$ & $\cdot, v \leq 1$ & $r$ & $\cdot, v \sim q$ & $r$ \\
\hline ,,$V Y r$ & $r$ &., 791 & $r$ & •, VRr & $r$ \\
\hline r, & $\varepsilon$ & •, VTr & $\varepsilon$ & $\cdot, r \cdot r$ & $\varepsilon$ \\
\hline$\cdot, v \leqslant 0$ & 0 & צ' & . & $\cdot, V Y I$ & 0 \\
\hline$\cdot, V \backslash r$ & 7 & •, VTr & 7 & $\cdot, V Y I$ & 7 \\
\hline - , VOr & $v$ & $\cdot, \vee Y q$ & $v$ & $\cdot, V M r$ & $v$ \\
\hline , , VOr & $\wedge$ & , VYO & $\wedge$ & •, VYr & $\wedge$ \\
\hline • VTr, & 9 & $\cdot, \uparrow \wedge \wedge$ & 9 & $\cdot, v \leqslant 0$ & 9 \\
\hline$\cdot, v \leqslant 0$ & 1. & אצד,. & 1. & $\cdot, V \leqslant r$ & 1. \\
\hline זיט, . & 11 & •, VYY & 11 & $\cdot, v \leqslant 1$ & 11 \\
\hline$\cdot, v \vee 1$ & ir & $\cdot, v \leq r$ & Ir & $\cdot, v \bullet \diamond$ & ir \\
\hline . & ir & $\cdot, v \leq r$ & $1 T$ & •, VYr & $1 r$ \\
\hline$\cdot, \times 10$ & $1 \varepsilon$ & $\cdot, v \backslash 1$ & $1 \varepsilon$ & $\cdot, v, 0$ & $1 \varepsilon$ \\
\hline$\cdot, V Y l$ & 10 & $\cdot, v \leq 1$ & 10 & $\cdot, \mathrm{Vrq}$ & 10 \\
\hline$\cdot, V \otimes r$ & 17 & $\cdot, V T V$ & 17 & $\cdot, v \leq r$ & 17 \\
\hline \multirow[t]{2}{*}{$\cdot, V Y \leq$} & iv & • & iv & - vor & iv \\
\hline & & & & 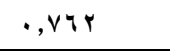 & 11 \\
\hline
\end{tabular}

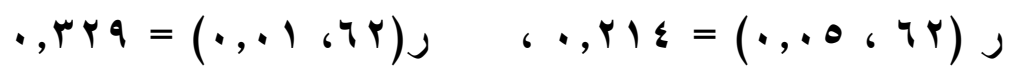

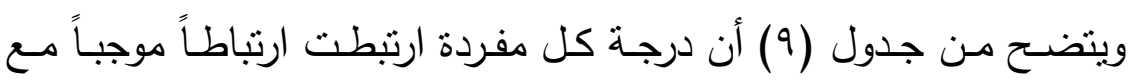

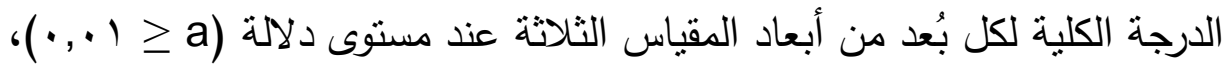

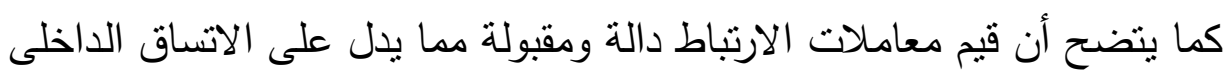
لمفردات المقياس.

ب ـ الاتسـاق الداخلى لأبعاد المقيـاس: للتحقق من اتساق المقياس ككل،

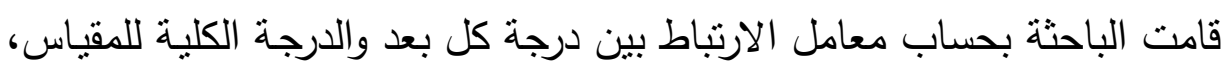
ويتضح ذلك فى جدول (· (1). 
برنامج إرشادي انتقائي تكاملي لخفض حدة الاليكسيثيميا د.جيهان عثمان محمود

جدول ( • 1) : قيم معاملات الارتباط بين درجة كل بعد والدرجة الكلية

لمقياس الاليكسيثيميا

\begin{tabular}{|c|c|}
\hline معاملات الارتباط مع الدرجة الكلية & أبعاد مقياس الاليكسيثيميا \\
\hline$\cdot, \mathrm{VYV}$ & الأحاسيس الجسدية - صـوية التعرف على المثــاعروالتمييز بينهـا ويسين \\
\hline$\cdot, V r \leq$ & ץ- صعوية التعرف والتعبير عن المشاعر للآخرين ونحوهم \\
\hline$\cdot, v \cdot q$ & r- التوجه الخارجى فى التفكير ومحدودية الخيال \\
\hline
\end{tabular}

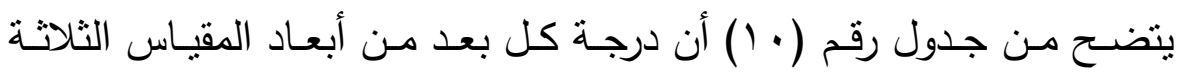

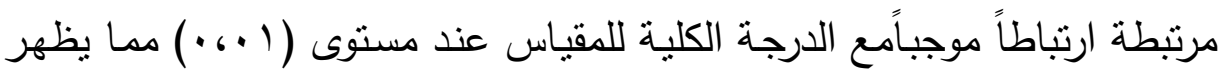
وجود انساقاً داخلياً للمقياس.

r - مقياس الاضطرابات السيكوسوماتية (النفسجمية): إعداد الباحثة - الهـدف مسن المقيـاس: يهدف هذا المقياس إلى قياس درجـة الاضطرابات

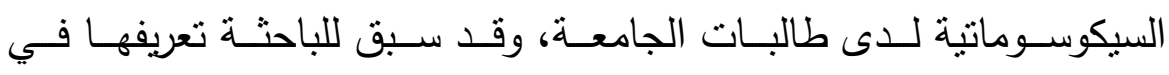
مصطلحات البحث.

- بنـاء المقيـاس: مـر بنـاء المقيـاس بعدة خطوات حتى وصـل إلى صـورته النهائية وهي:

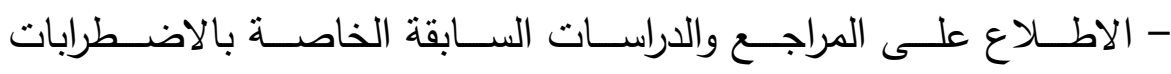

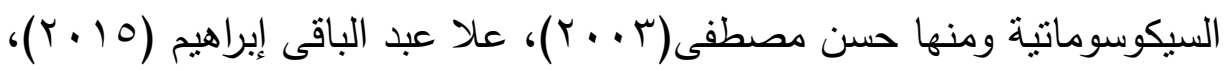

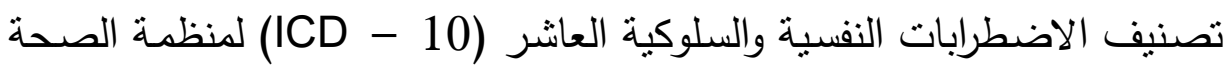

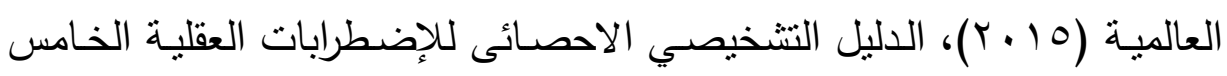

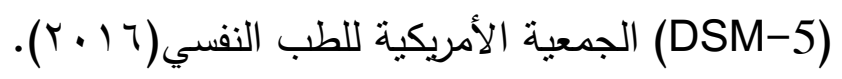

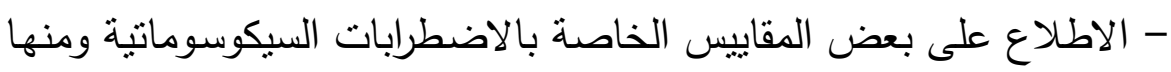

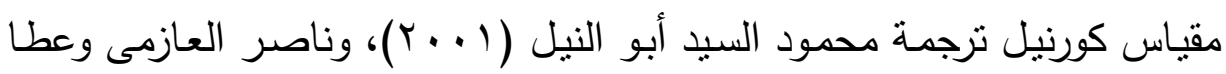

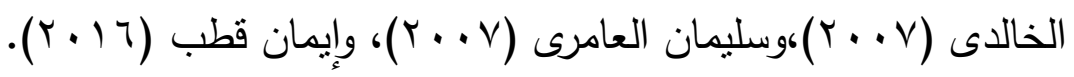


وصف المقياس: فى ضوء الاستفادة من الدراسات السابقة والمقاييس، تم تصميم

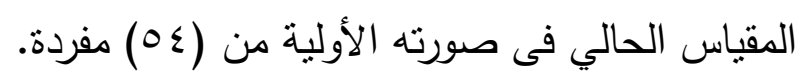

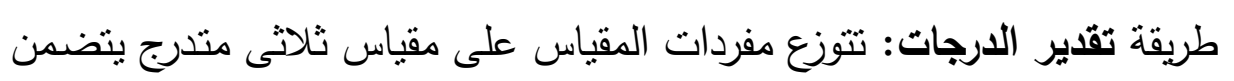

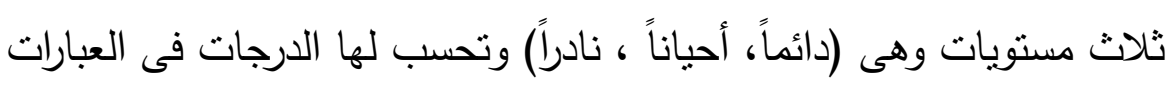

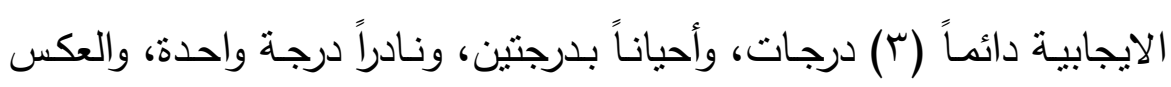

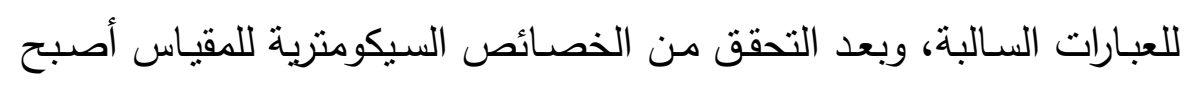
عدد المفردات (48) مفردة في صورته النهائية، وبذلك يكون الحد الأدنى

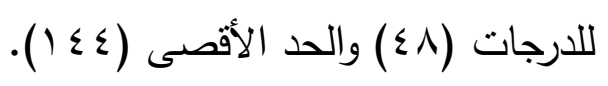

- التحقق من الخصائص السيكومترية لمقياس الاضطرابات السيكوسوماتية.

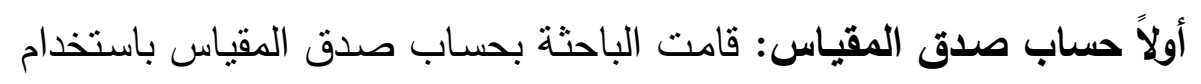
طريقتى صدق المحكمين والصدق العاملى.

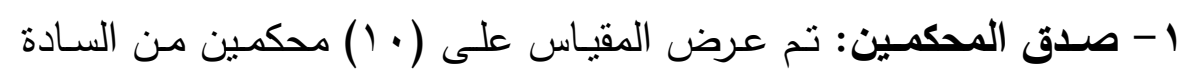
أعضاء هيئة التدريس المتخصصين فى مجال الصحة النفسية وعلم النفس بكليتى

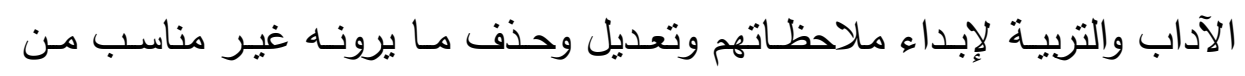

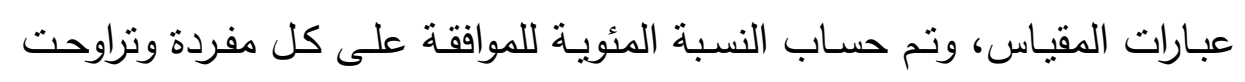

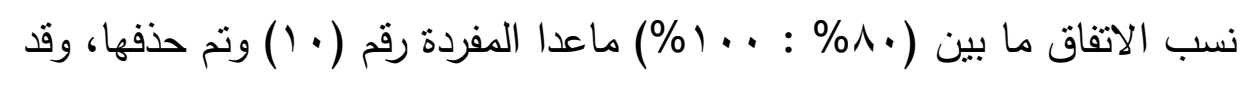

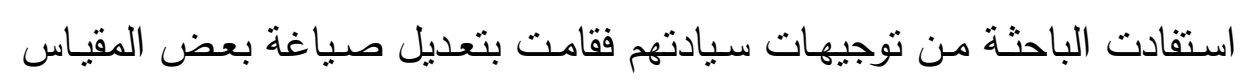

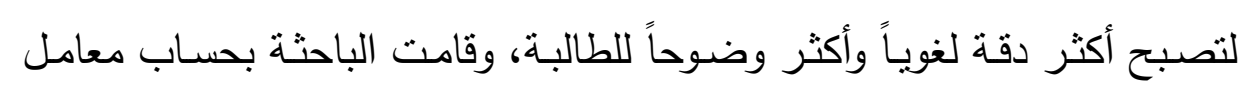

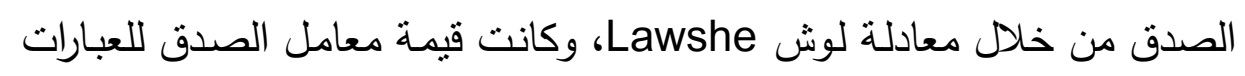

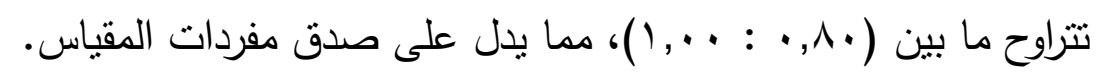

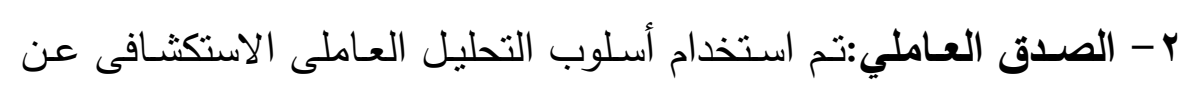

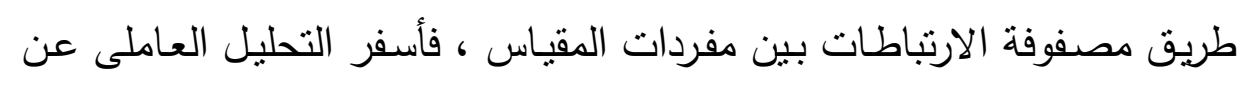

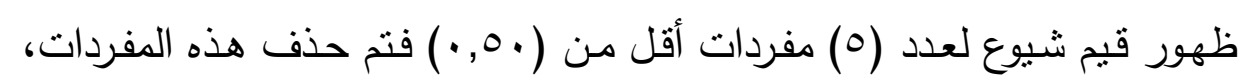

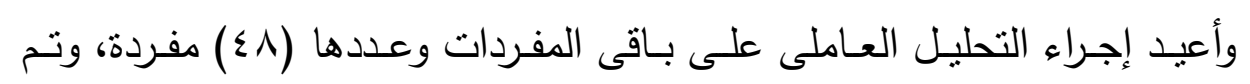




\section{برنامج إرشادي انتقائي تكاملي لخفض حدة الاليكسيثيميا د.جيهان عثمان محمود}

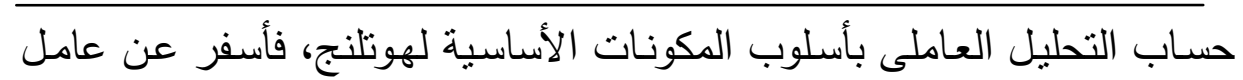

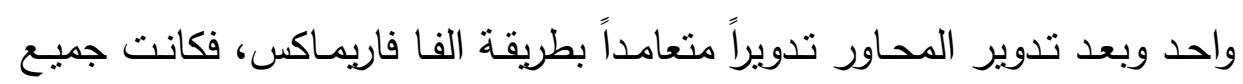

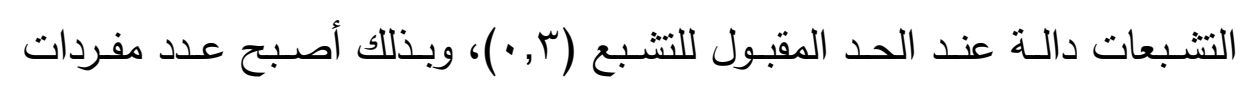
المقياس (^§) مفردة، وحيث أسفر الصدق العاملى عن التتبع على عامل عام

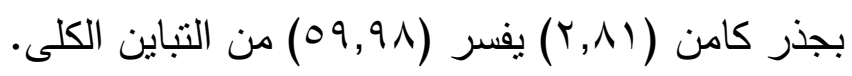

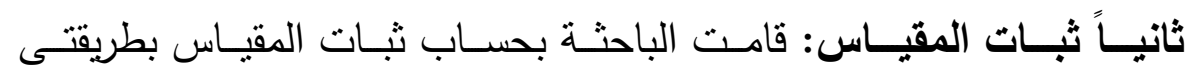
ألفاكرونباخ وإعادة التطبيق 1 ألفا كرونباخ: قامت الباحثة بحساب معامل ثبات المقياس فى حالة حذف المفردة ويوضح جدول (1) لقيم معاملات الثبات. جدول (11) : قيم معاملات الثبات بطريقة ألفاكرونباخ ومعامل الثبات الكلى لمقياس الاضطرابات السيكوسوماتية

\begin{tabular}{|c|c|c|c|c|c|c|c|c|c|}
\hline حعامل & العبارة & حالة الثبات فى حذف & المفردة & معامل الثبات فى حالة & المفردة & حالة الثبات فى حذف & المفردة & الثبات فحى المعل حذف & المفردة \\
\hline$\cdot, \vee \backslash \wedge$ & $\leqslant 1$ & -, $\vee Y \checkmark$ & $r$ & $\cdot, V Y I$ & ri & $\cdot, v \backslash V$ & 11 & $\cdot, v \cdot r$ & 1 \\
\hline$\cdot, V Y r$ & $\varepsilon r$ & $\cdot, V \backslash r$ & rr & •, & rr & •, • & Ir & $\cdot, \mathrm{V} \leq 0$ & r \\
\hline$\cdot, V \backslash r$ & $\varepsilon r$ & $\cdot, V \cdot \neg$ & r & $\cdot, V Y Y$ & rT & $\cdot, \vee \backslash \wedge$ & ir & $\cdot, v \leq r$ & $r$ \\
\hline$\cdot, v \cdot q$ & $\leqslant \varepsilon$ & $\cdot, V \cdot V$ & $r \varepsilon$ & $\cdot, V R r$ & $r \varepsilon$ & $\cdot, \vee_{1}$. & $1 \leq$ & $\cdot, \vee Y O$ & $\varepsilon$ \\
\hline$\cdot, V \backslash r$ & $\leqslant 0$ & •, VRr & ro & $\cdot, \vee \vee \leq$ & ro & $\cdot, \vee Y \leq \varepsilon$ & 10 & , , VRr & 0 \\
\hline$\cdot, v \leq 1$ & $\leq 7$ & $\cdot, V Y I$ & ry & $\cdot, V Y I$ & ry & $\cdot, \vee \wedge \wedge$ & 17 & $\cdot, \vee \backslash \backslash$ & 7 \\
\hline$\cdot, v \cdot r$ & $\leqslant V$ & $\cdot, v \cdot r$ & $r v$ & •, VTr & $r V$ & $\cdot, V \backslash r$ & iv & $\cdot, V Y r$ & $v$ \\
\hline \multirow[t]{3}{*}{$\cdot, V Y r$} & $\leqslant \Lambda$ & ., १ १४ & $r \Lambda$ & $\cdot, v \cdot \Lambda$ & $r \Lambda$ & •, VTr & 11 & $\cdot, \mathrm{V} \leq \leq$ & $\wedge$ \\
\hline & & $\begin{array}{r}\cdot, \mathrm{V} \\
\cdot 1\end{array}$ & $r^{r}$ & $\begin{array}{l}\cdot, \mathrm{V} \\
\cdot 9\end{array}$ & $\begin{array}{r}r \\
Y\end{array}$ & $\begin{array}{c}\cdot, V \\
\text { Ir }\end{array}$ & 1 & $\begin{array}{r}\cdot, \mathrm{V} \\
r 0\end{array}$ & 9 \\
\hline & & $\cdot, V \cdot \varepsilon$ & $\varepsilon$ & $\cdot, \vee \backslash 1$ & $r$. & $\cdot, v \cdot r$ & $r$. & •, VRr & 1. \\
\hline
\end{tabular}

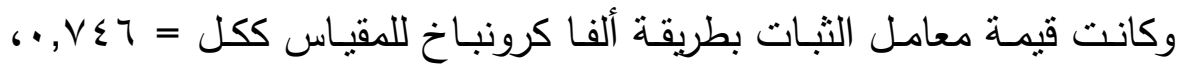

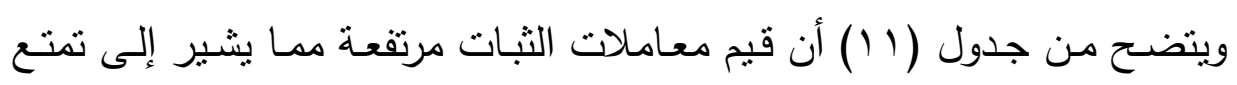
المقياس بدرجة مقبولة من الثبات. 
ץ - طريقة إعادة تطبيق المقياس: قامت الباحثة بإعادة تطبيق المقياس على الطالبات بعد مرور أسبوعين على التطبيق الأول وقامت بحساب معامل الارتباط

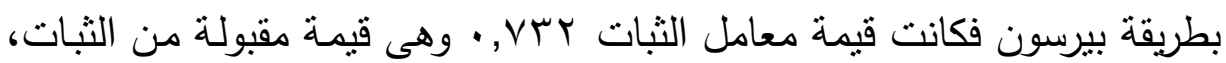
مما يشير إلى ثبات المقياس.

ثالثًا الاتساق الاخلى للمقياس: تُات المغئس حساب معاملات الارتباط بين درجة كل

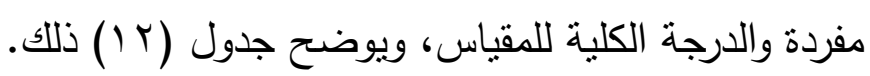
جدول (r Y ) قيم معاملات الارتباط بين درجة كل مفردة والدرجة الكلية لمقياس الاضطرابات السيكوسوماتية

\begin{tabular}{|c|c|c|c|c|c|c|c|}
\hline معامل الارتباط الدرجة & المفردة & 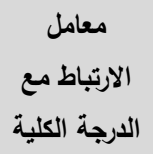 & المفردة & $\begin{array}{c}\text { الارتباط الدعلة الكلية } \\
\text { الداطة }\end{array}$ & المفردة & $\begin{array}{c}\text { الارتباط معامل } \\
\text { الدرجة الكلية }\end{array}$ & المفردة \\
\hline$\cdot, V Y \leq$ & $r v$ & •, VRY & ro & $\cdot, \vee \backslash \leq$ & ir & $\cdot, v \cdot \Lambda$ & 1 \\
\hline$\cdot, v \leq q$ & rᄉ & $\cdot, \vee \vee 14$ & Y & $\cdot, \curlyvee \wedge \wedge$ & $1 \varepsilon$ & $\cdot, \mathrm{V}$. & $r$ \\
\hline זヘז, & rq & . , TVY & $r V$ & $\cdot, v \cdot \wedge$ & 10 & $\cdot, \mathrm{VYY}$ & $r$ \\
\hline$\cdot, v \circ \leq$ & $\varepsilon$ & וצו, & rA & $\cdot, V{ }_{1}$ & 17 &., 799 & $\varepsilon$ \\
\hline •, VRr & $\leqslant 1$ &.,$\vee 19$ & rq & $\cdot, V Y r$ & iv & $\cdot, V Y V$ & 0 \\
\hline$\cdot, v \cdot l$ & $\varepsilon r$ & $\cdot, v \leq r$ & $r$. & $\cdot, \vee 01$ & 11 & $\cdot, v \cdot l$ & 7 \\
\hline$\cdot, v \leq 1$ & $\leqslant r$ & $\cdot, \vee \vee q$ & $r$ & $\cdot, V Y Y$ & 19 & $\cdot, v \cdot r$ & v \\
\hline , vor & $\leq \varepsilon$ & $\cdot, v \cdot l$ & $r r$ & $\cdot, \times 19$ & $r$. & $\cdot, \times 11$ & $\wedge$ \\
\hline$\cdot, v \circ r$ & $\leqslant 0$ & , VYo & $r r$ & $\cdot, v \cdot 1$ & $r$ & צ & 9 \\
\hline$\cdot \mathrm{Vr}$. & $\leqslant 7$ & ,, YY & ع & $\cdot, v \leq q$ & rr & $\cdot, \mathrm{VM}$ & 1. \\
\hline$\cdot, \vee \vee \wedge$ & $\leqslant V$ & $\cdot, \vee \vee 1$ & ro & $\cdot, \vee r \varepsilon$ & r & $\cdot, V Y I$ & 11 \\
\hline •, & $\leqslant \wedge$ & $\cdot, \vee \vee \neg$ & q & $\cdot, V Y r$ & $r \leq$ & $\cdot, V \leq r$ & ir \\
\hline
\end{tabular}

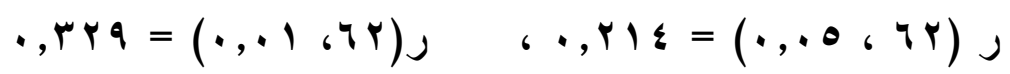

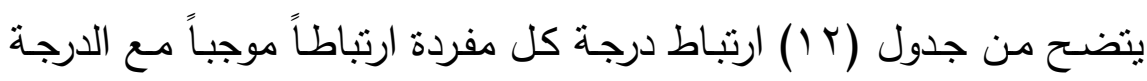

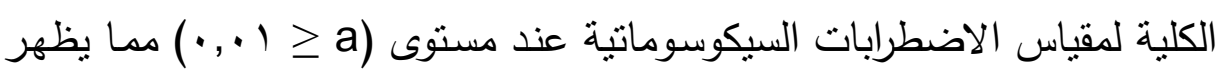

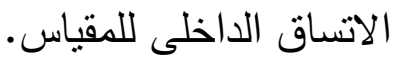


برنامج إرشادي انتقائي تكاملي لخفض حدة الاليكسيثيميا د.جيهان عثمان محمود

$$
\text { r- البرنامج الإرشادي: إعداد الباحثة إنة }
$$

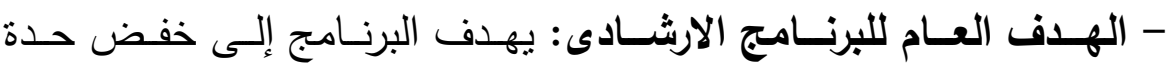

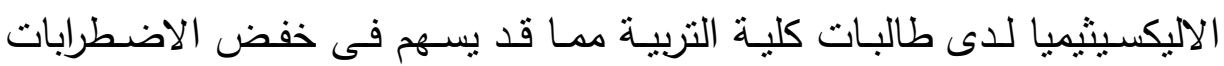

السيكوسوماتية لديهن.

\section{- الأهداف الإجرائية للبرنامجج:}

- أن تتعرف الطالبات على مفهوم الاليكسيثيميا.

-أن تكتسب الطالبات مهارة الوعى بالذات.

-أن تكتسب الطالبات مهارة استكثاف مشاعرهن.

- أن تكتسب الطالبات مهارة كثف الذات.

- أن تحدد الطالبات مشاعرهن وتعبر عنها.

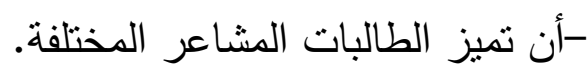
- أن تدرك الطالبات العلاقة بين التفكير والمشاعر والسلوك. -أن تعبر الطالبات بحرية عن مشاعرهن. - أن تعبر الطالبات عن مشاعرهن الايجابية والسلبية. - أن تمارس الطالبات فنية عكس المشاعر.

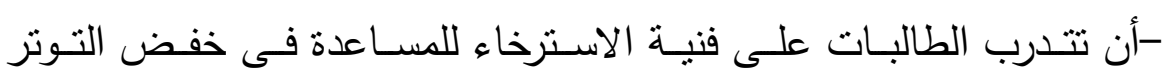
ولاستبصار المشاعر. - أن تكتشف الطالبات مشاعر الآخرين. - أن تعبر الطالبات عن مشاعرهن للآخرين. - أن تكتسب الطالبات مهارة التخيل. - أن تعبر الطالبات عن المشاعر نحو الآخرين.

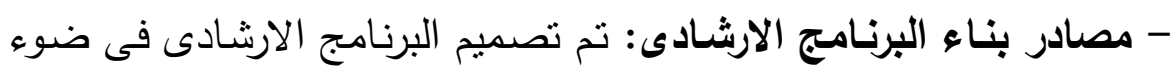
الإطار النظرى للاراسة ومن خلال الاطلاع على المراجع والدراسات التي تتاولت

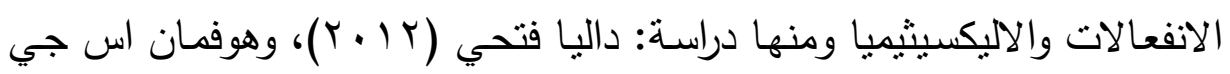




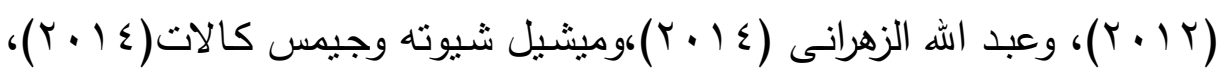

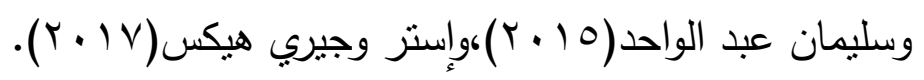

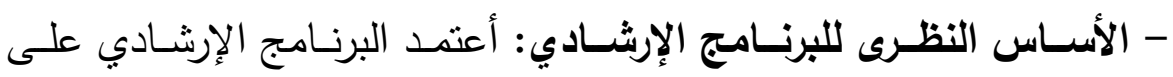

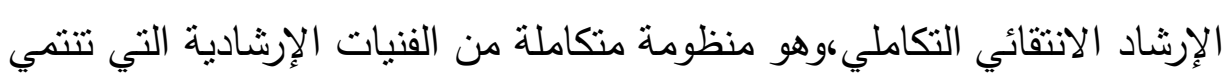

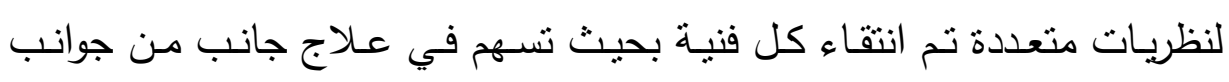

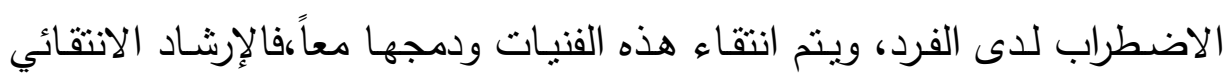

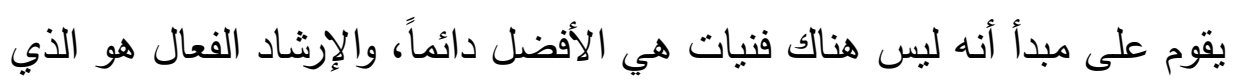

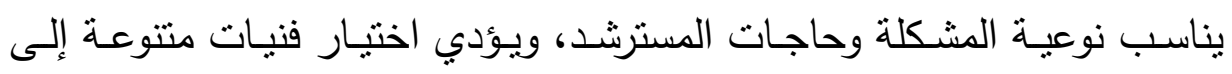

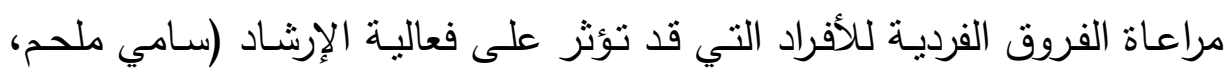
.(^ז: Y...

- أسـلوب الإرشــاد:هو الإرشـاد الجمعي لمناسبته لأهداف البحث وطبيعـة

- فنيات البرنامج الإششادي:استخدمت الباحثة العديد من الفنيات وهي: -المحاضرة والمناقشّة الجماعية: يلعب عنصر التعلم وإعادة التعلم دوراً رئيسياً في الإرشاد حيث تهدف المحاضرات والمناقنـات إلى زيادة

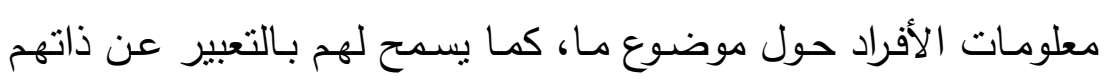

$$
\text { وأفكارهم ومشاعرهم. }
$$

-التعزيـز: أكثر الفنيات الإرشـادية استخداماً وتتلخص طريقته فى وفى تقديم مكافآت للأفراد بهدف تقوية سلوك المسترشد المرغوب وزيادة معدل تكرار حدوث السلوك مستقبلاً.

-استخدام الأنشطة: تعتبر الأنشطة التى يقوم بها الفرد سواء عقلية أو بدنية وسيلة مهمة لمساعدة الأفراد على التعرف على قدراتهم وأفكارهم

$$
\text { ومشاعرهم. }
$$


برنامج إرشادي انتقائي تكاملي لخفض حدة الاليكسيشيميا د.جيهان عثمان محمود

-التنفيس الانفعالي: وهي طريقة نسمح بتفريغ الانفعالات واكتشافها

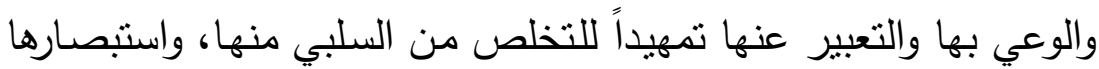

وتمبيزها، وبطلق البعض علي هذه الطريقة التطهير الانفعالي.

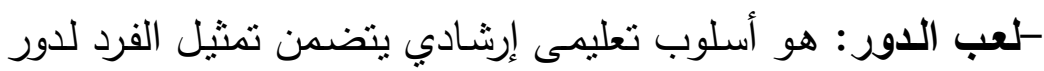

معين ويهدف إلى فهم أفضل لمشكلات الفرد واكتسـاب أنماط سلوكية

إيجابية، وهو من الأساليب الإرشادية التى يعاد فيها تتظيم وبناء المجال

النفسى والاجتماعى، ويتم فيها التنفيس عن الانفعالات.

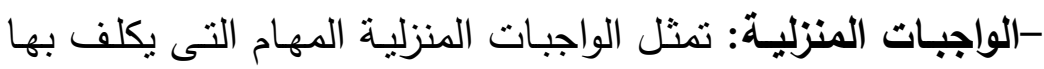

المسترشد خارج نطاق جلسة الإرشاد وهى تعمل على نقل الأثر الايجابي

الذى تعلمه لمواقف أخرى.

-الالسـترخاء: هو تهدئـة وتوقيف للانقباضـات والتقلصـات العضلية

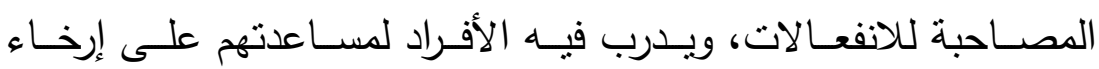

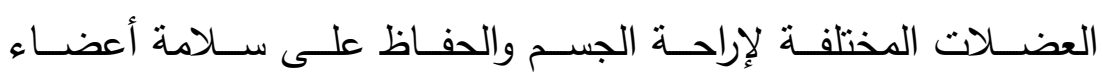

الجسـم،وزيادة تركيـز انتبـاههم و وعـيهم بانفعـالاتهم، ويشـمل اسـترخاء

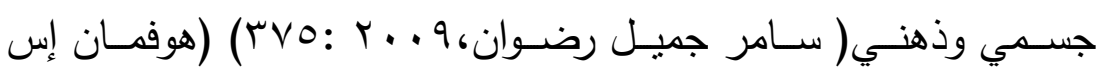

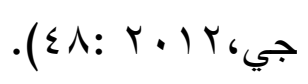

- تقويم البرنامج الإششادى:

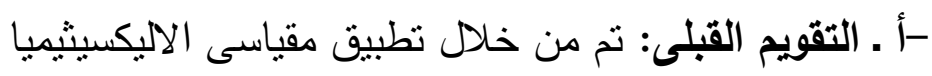

والاضطرابات السيكوسوماتية على طالبات المجموعتين التجريبية

والضابطة قبل تتفيذ البرنامج.

-ب ـ التقويم التكوينى (المرحلى): تم من خلال الأسئلة والواجبات

المنزلية فى كل جلسة. 
- ج • التقويم النهائى: تم من خلال تطبيق مقياسى الاليكسيثيميا والاضطرابات السيكوسوماتية على طالبات المجموعتين التجريبية والضابطة بعد الانتهاء من تطبيق البرنامج مباشرة.

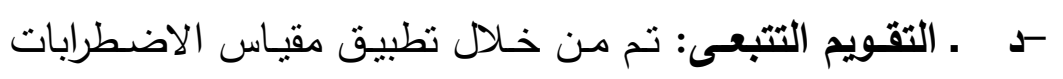

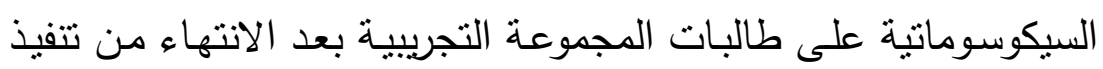
البرنـامج الإرشـادي بشـهر بهدف التحقق من استمرارية فعاليـة البرنـامج الإرشادي.

- تحكيم البرنامج الإرشـادي: تم من قبل السادة أعضاء هيئة التدريس فى

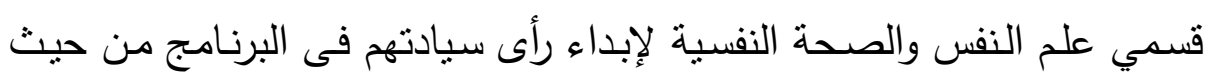

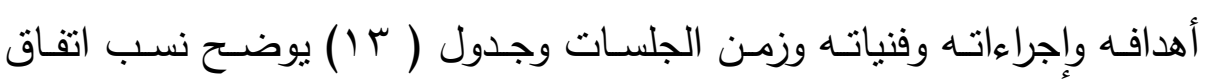
السادة المحكمين على البرنامج الإرشادي.

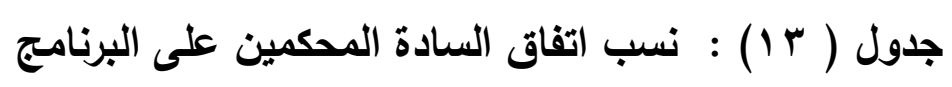

\begin{tabular}{|c|c|c|c|c|}
\hline نسبة الاتفاق & الاختلاف عدات & عداتد مرات & العناصر & م \\
\hline$\% \wedge$. & 1 & $\varepsilon$ & أهداف الجلسات & 1 \\
\hline$\% \wedge$. & r & $\varepsilon$ & محتوى الجلسات & r \\
\hline$\% 1 \ldots$ & - & 0 & الجلسات الفنـــات المســتخدمة فــى & $r$ \\
\hline$\% 1 \ldots$ & - & 0 & زمن تنفيذ الجلسات وعددها & $\varepsilon$ \\
\hline
\end{tabular}

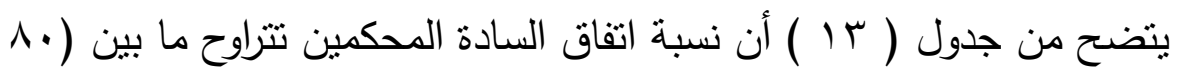

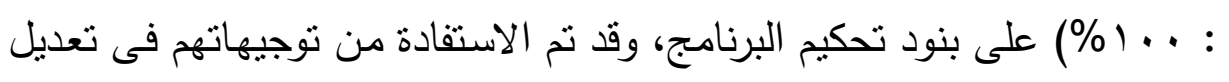
بعض الأهداف والربط بين محتوى البرنامج والأهداف وزيادة عدد الأنشطة.

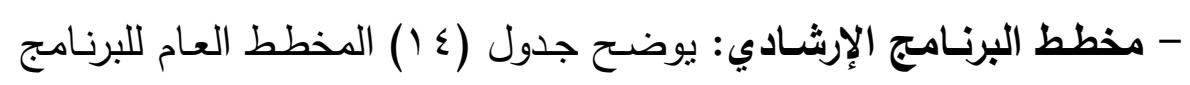
الإرشادي من حيث عنوان الجلسة وأهدافها ومحتواها والفنيات المستخدمة والزمن.

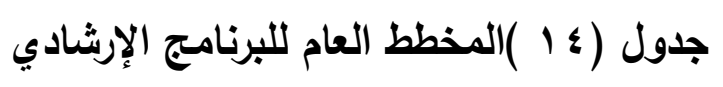


برنامج إرشادي انتقائي تكاملي لخفض حدة الاليكسيثيميا د.جيهان عثمان محمود

\begin{tabular}{|c|c|c|c|c|}
\hline الزمن & الفنيات & أهداف الجلسة & الجلسة & الرقم \\
\hline $\begin{array}{l}0 \\
\text { دقيقة } \\
Y \cdot-\end{array}$ & المحاضرة،والمناقشة & 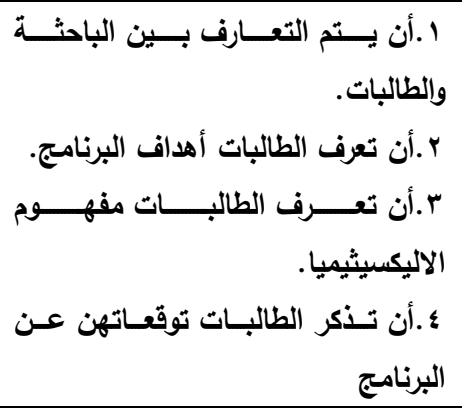 & بالبرنامج التعريف & $r$ \\
\hline $\begin{array}{l}\text { دقيقة } 0 \\
1 \cdot-\end{array}$ & المناقثة والواجب & بالذان بأن تكتسب الطالبـات مهـارة الـوعى & بالذات & $r$ \\
\hline 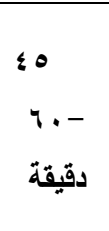 & $\begin{array}{l}\text { تعزيز والتنفيس الانفعار،والمناقثة،وال } \\
\text { التفيس }\end{array}$ & 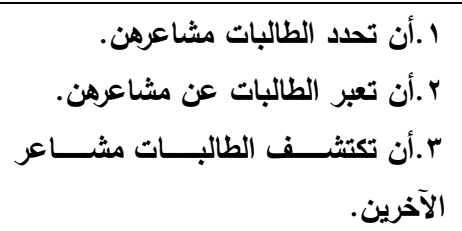 & المشتكشاف & $\stackrel{0}{0}$ \\
\hline $\begin{array}{l}\leq 0 \\
1 \cdot-- \\
\text { دقيقة }\end{array}$ & والأنثطة والواجبة والمناقشة & 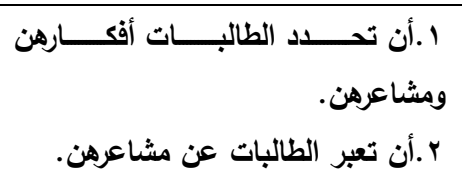 & كثف الذات & 7 \\
\hline $\begin{array}{l}\text { دقيقة } 0 \\
1 \cdot-\end{array}$ & الدور المناقثة ولعب & 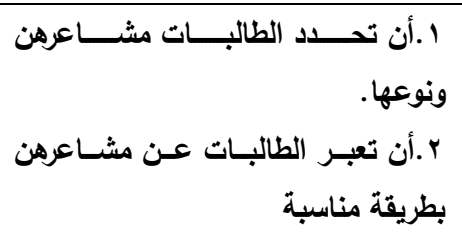 & المشاعبير عن & v \\
\hline $\begin{array}{c}\text { ؛ } 0 \\
- \\
\text { 7دقيقة. }\end{array}$ & والتنفيس الانفعالئ، والتعزيز & 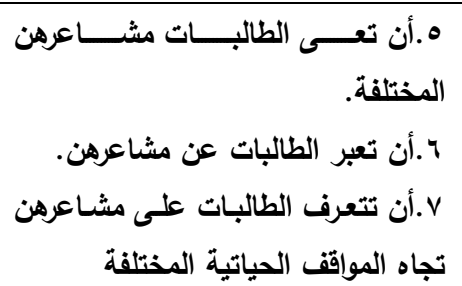 & المثنوعة مثاعرى & 9 \\
\hline 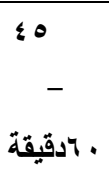 & المناقشة والتعزيز & 1. أن أن تدرك الطالبات مشاعرهن. & المشاعر صندوق & 1 \\
\hline $\begin{array}{l}\leq 0 \\
7 .-\end{array}$ & المناقسة والتعزيز & مشاعرهن. 1 .أن تتعـــرف الطالبـــات علـــى & قياس شدة & 1 \\
\hline
\end{tabular}

DOI : $10.12816 / 0052303$ 


\begin{tabular}{|c|c|c|c|c|}
\hline 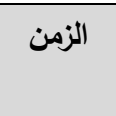 & الفنيات & أهداف الجلسة & الجلسة & 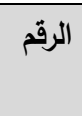 \\
\hline دقيقة & & وبتجيل المشـاعر. & & \\
\hline 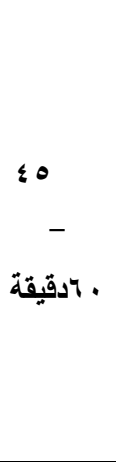 & المحاضرة والمناقشة & 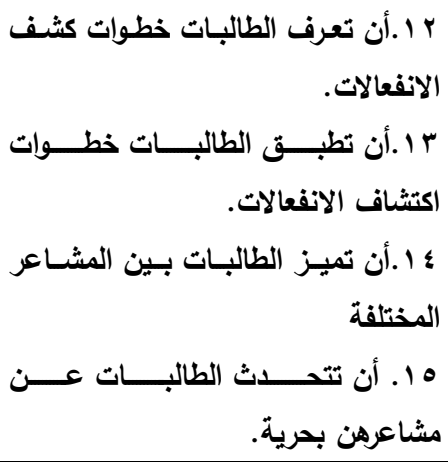 & الانفعالات اكتشاف & $\begin{array}{l}1 \\
-r \\
14\end{array}$ \\
\hline 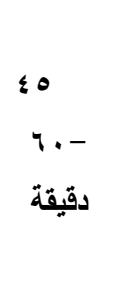 & والأنشطة والواجب والمناقشة & 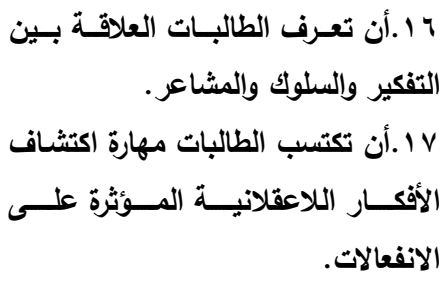 & والسلوك & $\begin{array}{l}1 \\
-\varepsilon \\
10\end{array}$ \\
\hline 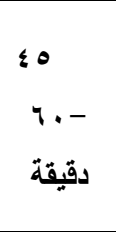 & المناقثة والأنشطة & 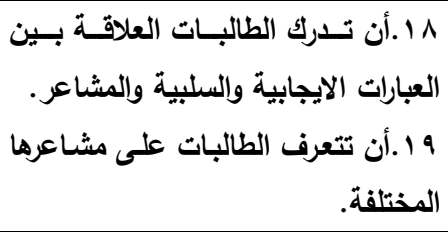 & ومشاعرنا & 1 \\
\hline $\begin{array}{c}\text { ؛ } 0 \\
- \\
\text { Tدقيقة. }\end{array}$ & ولأنشطة والمناقشة، & 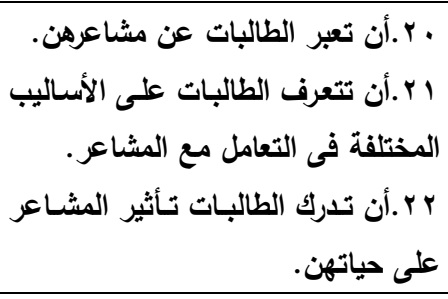 & التعبير عن حرية & v \\
\hline 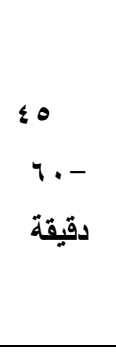 & والتعيزيز والواجب والمناقشة & 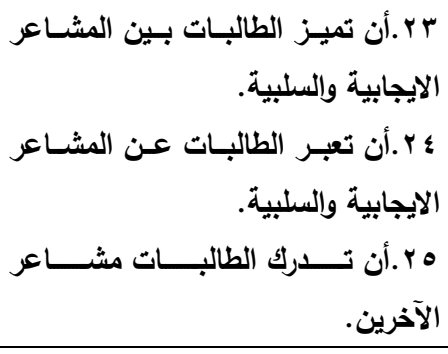 & الالتعبير عن المباعر & $\begin{array}{l}1 \\
-1 \\
19\end{array}$ \\
\hline \&. & المحاضرة والمناقشة & عـ ب.أن تتعـرف الطالبـات علـى معــى & المرايا & $r$ \\
\hline
\end{tabular}


برنامج إرشادي انتقائي تكاملي لخفض حدة الاليكسيثيميا د.جيهان عثمان محمود

\begin{tabular}{|c|c|c|c|c|}
\hline الزمن & الفنيات & أهداف الجلسة & الجلسة & الرقم ل \\
\hline دقيقة & & 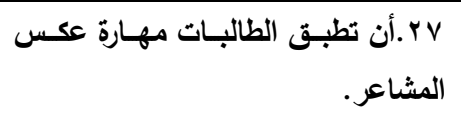 & & ri \\
\hline 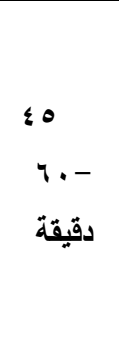 & الأنشطة والمناقشة & 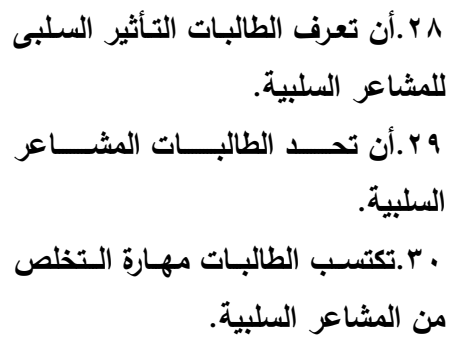 & 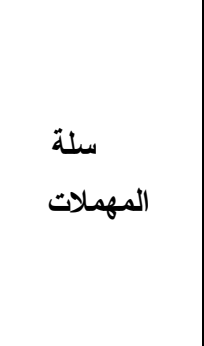 & $\begin{array}{l}r \\
-r \\
r\end{array}$ \\
\hline $\begin{array}{l}\text { دقيقة } \\
1 \cdot- \\
\cdot-\end{array}$ & والتعزيز والواجب المنزلى والمناقشة & 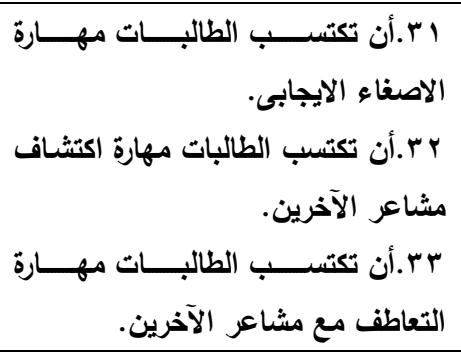 & مشاعر الآخرين & r \\
\hline $\begin{array}{c}\leq 0 \\
- \\
\text {. } 0 .\end{array}$ & والتعزيز والواجب المنزلى الأنشاقشة & 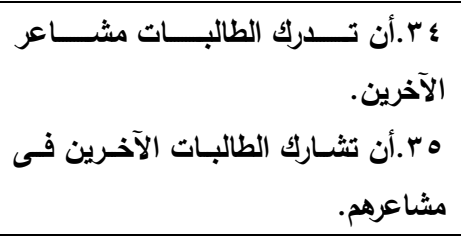 & مشاعر الآخرين & r \\
\hline $\begin{array}{l}\text { دقيقة } 0 \\
\qquad \cdot-\end{array}$ & المناقشة والتعزيز & צrr أ.أن تكتسب الطالبات مهارة التخيل. & التخيل مهارات & $\begin{array}{c}r \\
r \\
r\end{array}$ \\
\hline 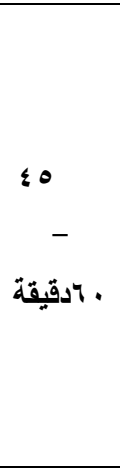 & الأنشطة والمناقثة & 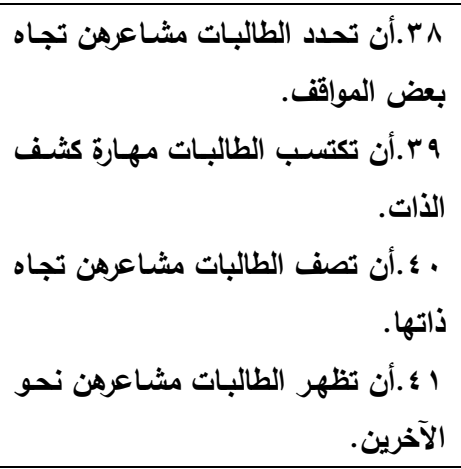 & الإفصاح & $\begin{array}{r}r \\
-1 \\
r q\end{array}$ \\
\hline 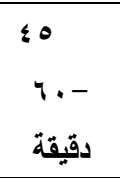 & المحاضرة والمناقشة & 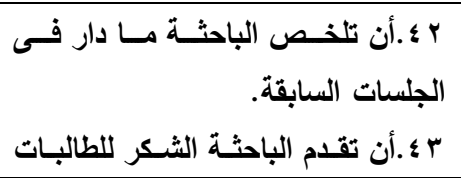 & تامية & $r$ \\
\hline
\end{tabular}

DOI : $10.12816 / 0052303$ 


\begin{tabular}{|c|c|c|c|c|}
\hline 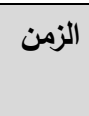 & الفنيات & أهداف الجلسة & الجلسة عنوان & الرقم \\
\hline & & المشاركات بالبرنامج. & & \\
\hline
\end{tabular}

- نتائج البحث ومناقشتها وتفسيرها:

ينص الفرض الأول على أنه " توجد فروق دالة إحصائياً بين متوسطي رثنا:

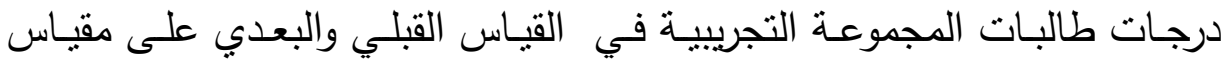
الاليكسيثيميا في اتجاه القياس القبلي" ولاختبار صحة هذا الفرض قامت الباحثة

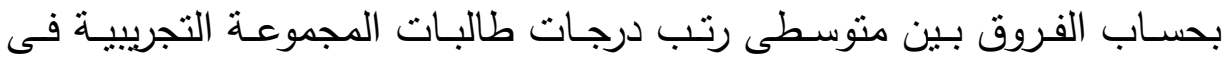
القياسين القبلى والبعدى على مقياس الاليكسيثيميا باستخدام معادلة ويلكوكسون Wilcoxon جدول ( ه 1) : نتائج اختبار "ويلكوكسون وقيمة (Z) وحجم التأثير للفروق بين رتب درجات طالبات المجموعة التجريبية فى القياسين القبلى والبعدى ولى ولئي

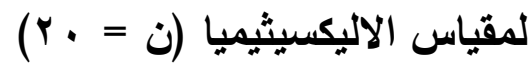

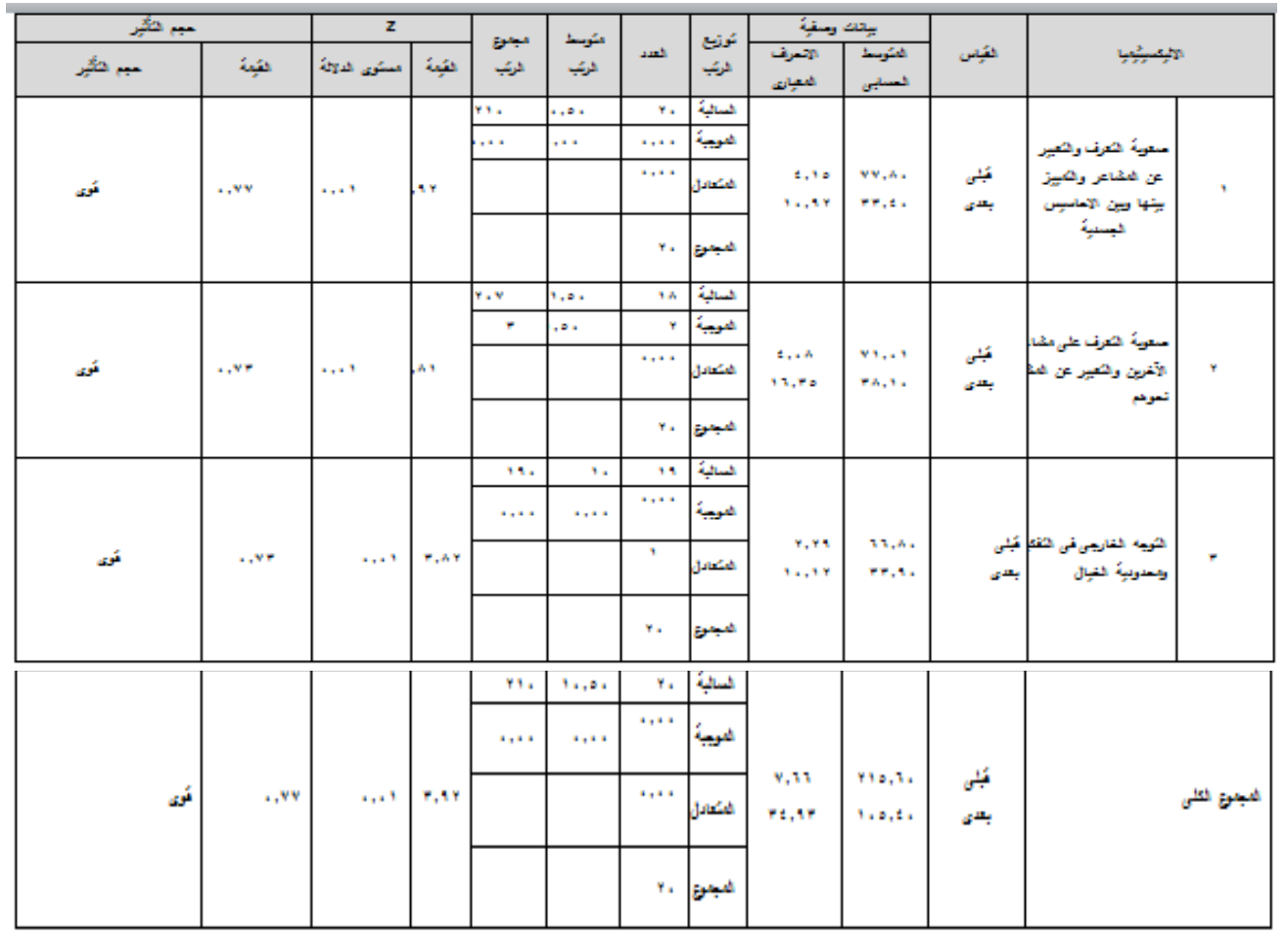


برنامج إرشادي انتقائي تكاملي لخفض حدة الاليكسيثيميا د.جيهان عثمان محمود

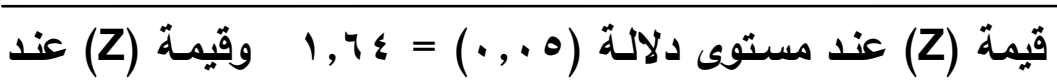

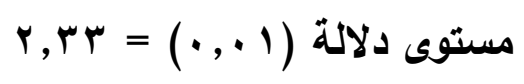

يتضح من جدول ( 10 ) أن قيم (Z) المحسوبة أكبر من قيم (Z) الجدولية

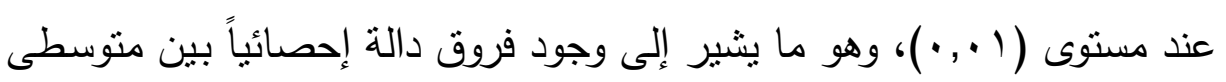
رتب درجات المجموعة التجربيية بين القياسين القبلى والبعدى لأبعاد الاليكسيثيميا ومجموعها الكلى وذلك في اتجاه القياس القبلى بعد تطبيق البرنامج، ويوضـح شكل ( ) الأعمدة البيانية لمتوسطى درجات المجموعـة التجريبية فى القياسين

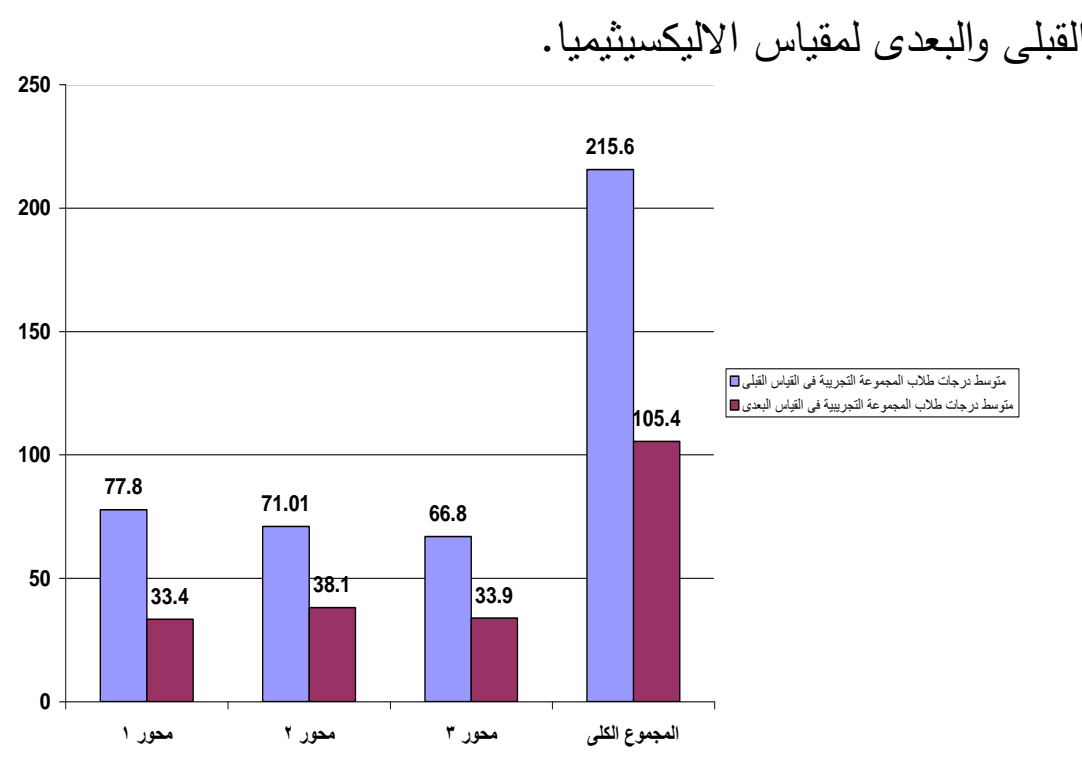

شكل (1) الأعمدة البيانية لمتوسطى درجات المجموعة التجريبية فى المئي

\section{القياسين القبلى والبعدى لمقياس الاليكسيثيميا}

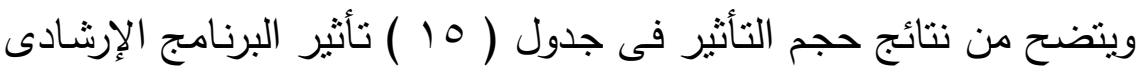

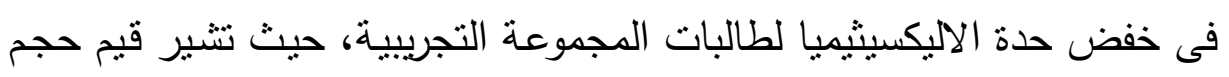
التأثير إلى نأثير قوى للبرنامج الإرشادى وفقاً لمحكات مربع إيتا، وتتففق نتيجة

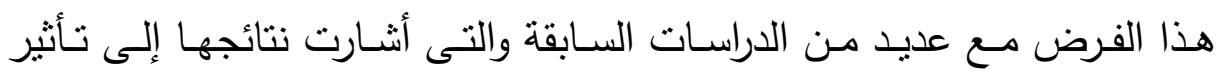

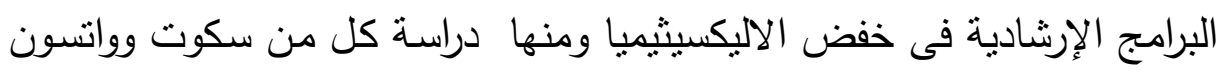


Scott \& Watson (r.. r)

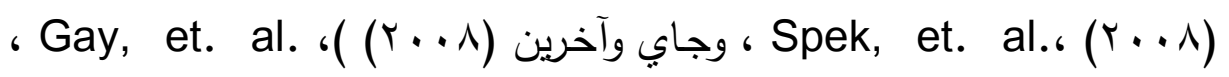

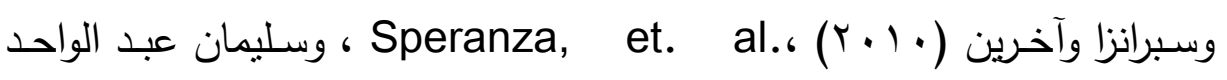

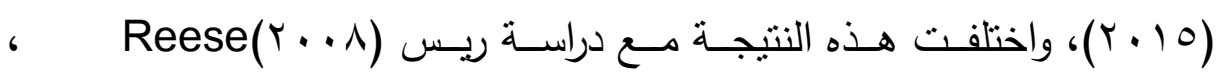

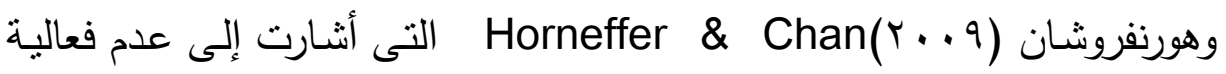

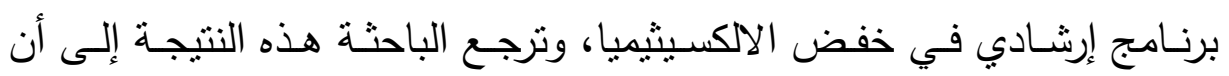

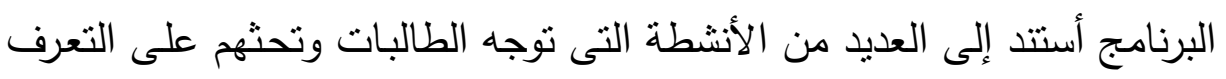

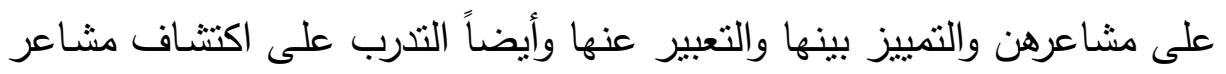
الآخرين والتعبير عن المشاعر نحوهم وعدم إهمال الوعي بالمشاعر فى الأحداث

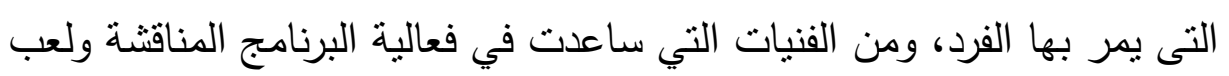

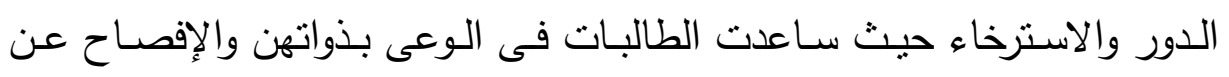

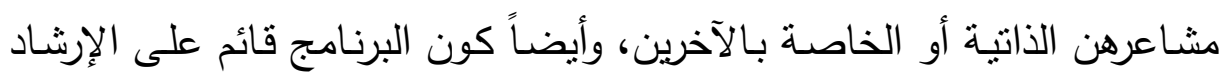

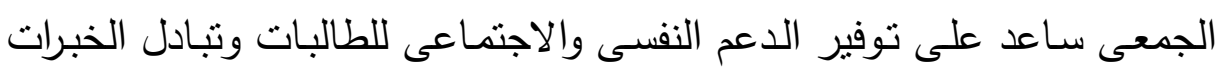

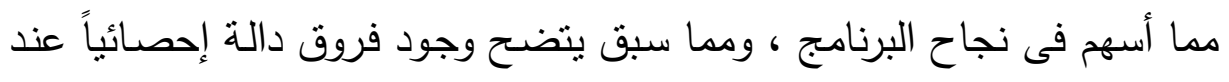

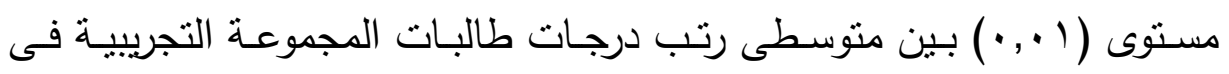

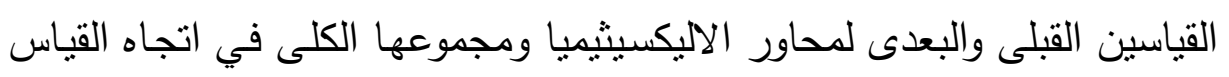
القبلى، ومن ثم فقد تم قبول الفرض الأول.

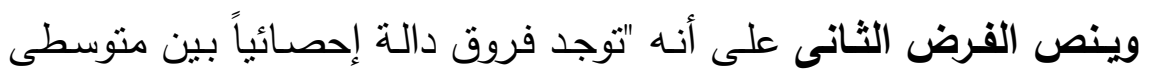

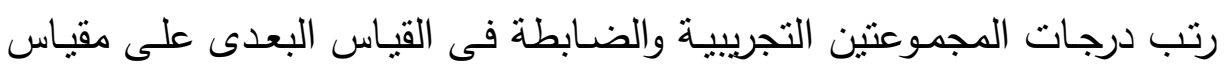

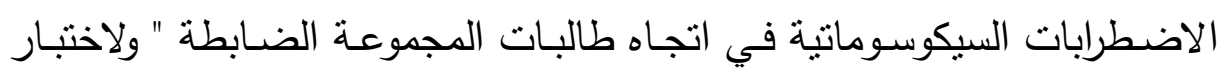

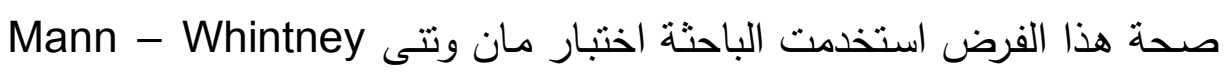

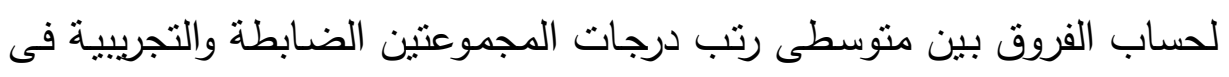

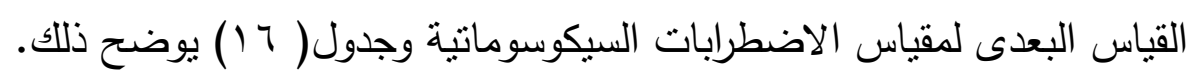


برنامج إرشادي انتقائي تكاملي لخفض حدة الاليكسيثيميا د.جيهان عثمان محمود

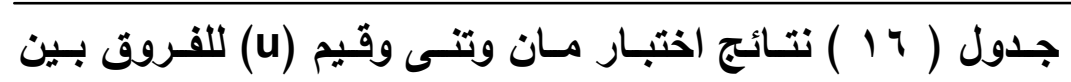

متوسطى رتب درجات كل من المجموعتين الضـابطة وإلتجريبيـة فى ولى

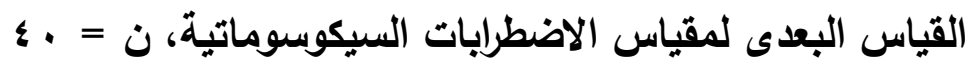

\begin{tabular}{|c|c|c|c|c|c|c|c|c|c|c|}
\hline \multicolumn{2}{|c|}{ مريع إيتا } & \multicolumn{2}{|c|}{ U } & \multirow{2}{*}{ الرتبوع } & \multirow{2}{*}{ الرتب } & \multirow[b]{2}{*}{ العلد } & \multirow{2}{*}{ المعيارى } & \multirow{2}{*}{ الحسابى } & \multirow[b]{2}{*}{ المجموعة } & \multirow{2}{*}{ السيكوسوماتية } \\
\hline التأثير & القيمة & الدلالة & القيمة & & & & & & & \\
\hline قوى & 0, & $\cdot, \cdot 1$ & $11, .1$ & $\begin{array}{l}r, \ldots \\
a q, . .\end{array}$ & $\begin{array}{r}11,00 \\
r 9,90\end{array}$ & $r$ & $\begin{array}{l}r \leqslant, q \Gamma \\
r \leqslant, \wedge \wedge\end{array}$ & $\begin{array}{l}1,0,0,0 \\
r, \varepsilon, 0 .\end{array}$ & تجريبية & المجموعات \\
\hline
\end{tabular}

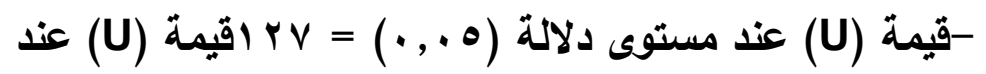

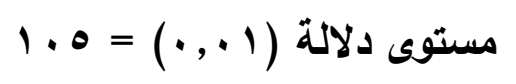

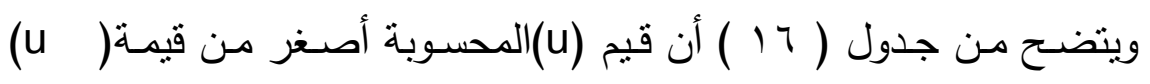

الجدولية عند مستوى (1 ., •) وهو ما يشير إلى وجود فروق دالة إحصائياًين

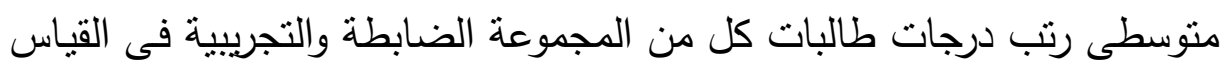

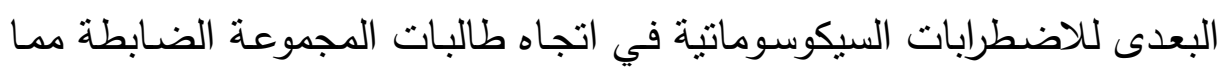

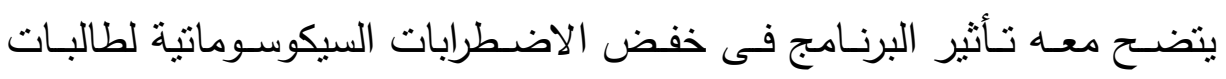

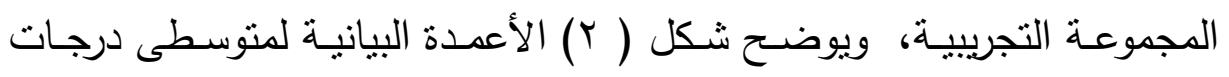
طالبات المجموعتين التجريبية والضابطة فى القياس البعدى لمقياس الاضطرابات السيكوسوماتية. 


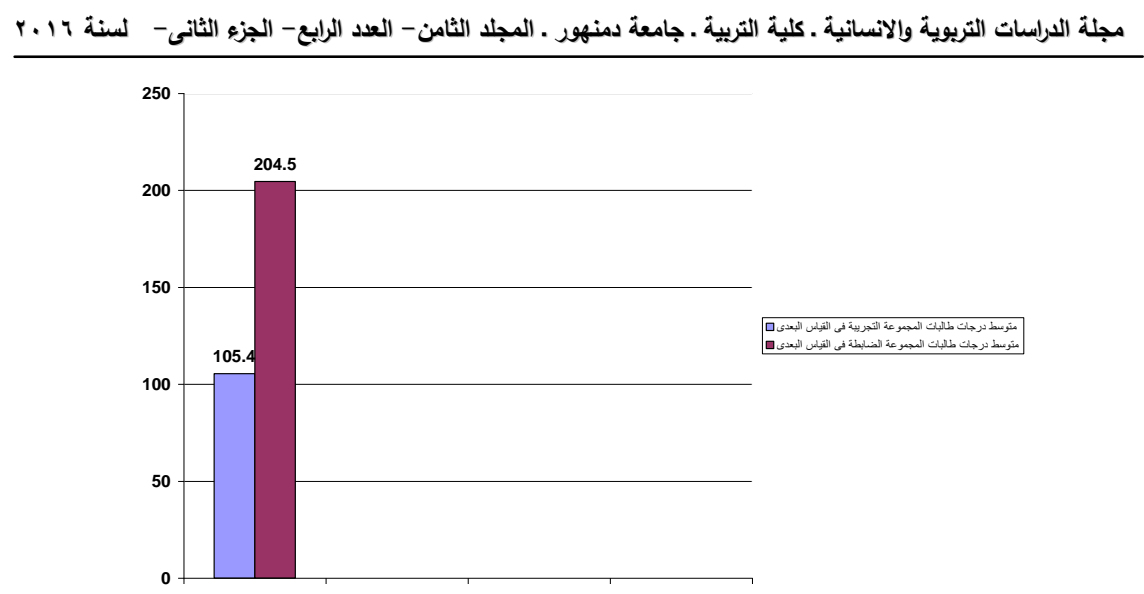

شكل(Y) الأعمدة البيانية لمتوسطى درجات المجموعتين التجريبية والضايطة

\section{فى القياس البعدى لمقياس الاضطرابات السيكوسوماتية}

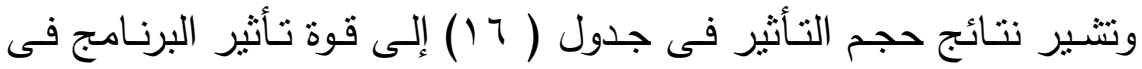

خفض الاضطرابات السيكوسوماتية، وفقاً لمحكات مربع إيتا، وتتفق هذه النتيجة

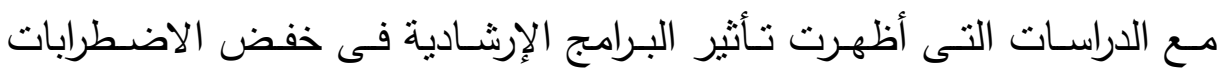

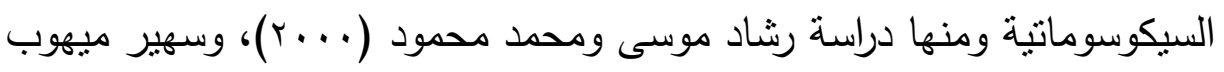

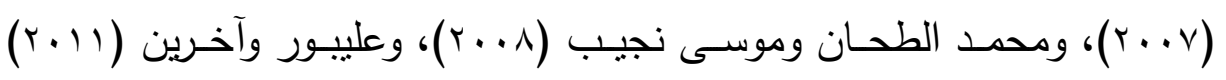
Alipour, et al.،

وترجع الباحثة هذه النتيجة إلى موضـوعات الجلسـات الإرشـادية والفنيات

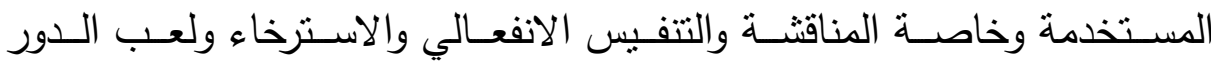

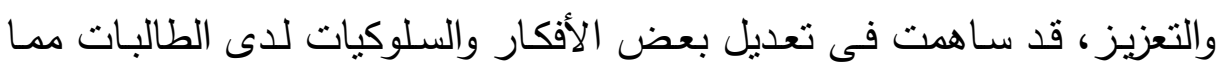

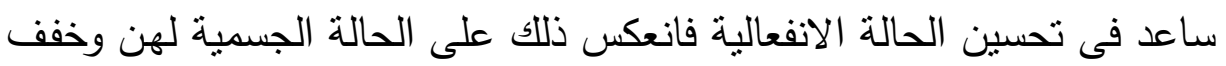

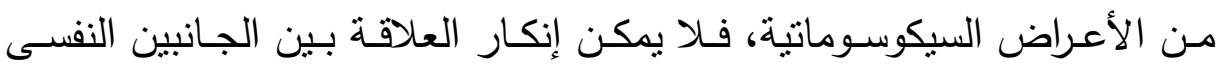
والجسمى للفرد فقد تبين ذللك من خلال نتائج العديد من الدراسات التى أشثارت

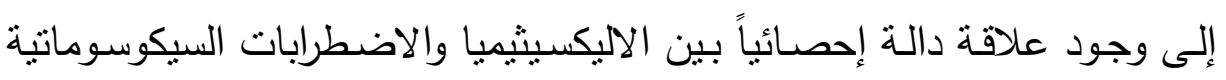

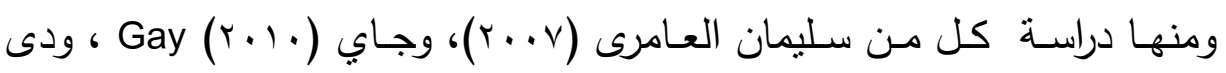

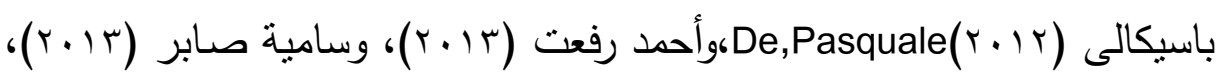


برنامج إرشادي انتقائي تكاملي لخفض حدة الاليكسيثيميا د.جيهان عثمان محمود

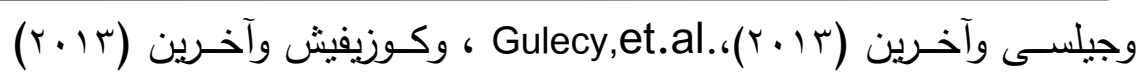

Kusevic,et.al.,

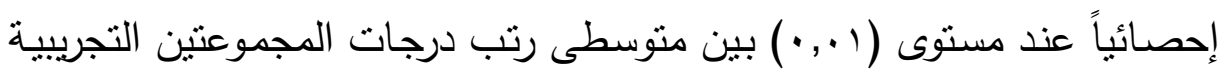
والضابطة فى القياس البعدى على مقياس الاضطرابات السيكوسوماتية في اتجاه طالبات المجموعة الضابطة، ومن ثم فقد تم قبول الفرض الثانى.

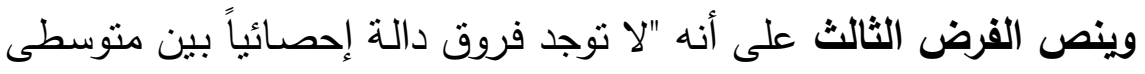

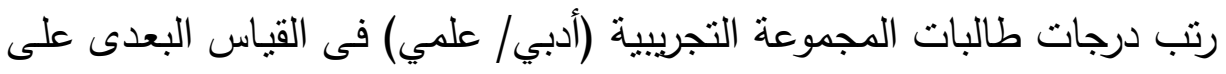

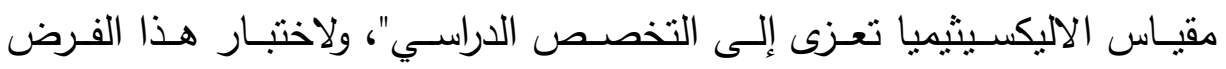
استخدمت الباحثة اختبار مان وينتى لحساب الفروق بين منوسطى رتب درجات

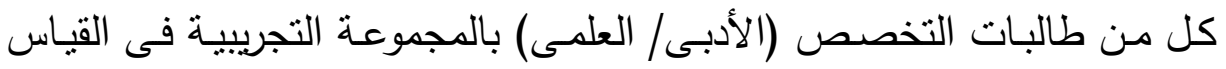
البعدى على مقياس الاليكسيثيميا والنتائج يوضحها جدول ( IV ).

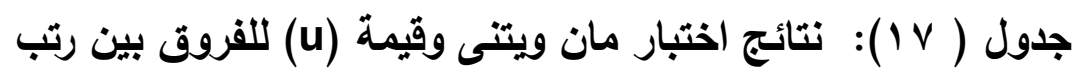

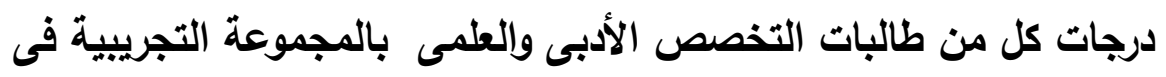

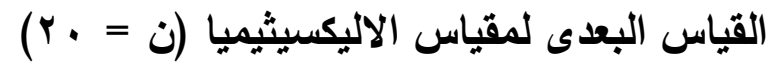

\begin{tabular}{|c|c|c|c|c|c|c|c|c|c|}
\hline \multicolumn{2}{|c|}{ U } & \multirow{2}{*}{ مجموع } & \multirow{2}{*}{ الرتب } & \multirow[b]{2}{*}{ العدد العد } & \multirow{2}{*}{ الانحراف } & \multirow{2}{*}{ الحسابى المتوسط } & \multirow[b]{2}{*}{ التخصص } & \multirow{2}{*}{\multicolumn{2}{|c|}{ أبعاد مقياس الاليكسيثيميا }} \\
\hline مستوى الدلالة & القيمة & & & & & & & & \\
\hline غالة & $\leq 1$ & $\begin{array}{l}97 \\
11 \leq\end{array}$ & $\begin{array}{l}9,7 . \\
11,4 .\end{array}$ & 1. & $\begin{array}{l}1 \cdot, 90 \\
9,95\end{array}$ & $\begin{array}{l}\text { rr, } \\
r q, 0 .\end{array}$ & علمى أدبى & صعوية التعرف والتعبير عن & 1 \\
\hline غير & . & $\begin{array}{l}\wedge \Lambda, 0 . \\
|r|, 0 .\end{array}$ & $\begin{array}{l}\Lambda, \wedge 0 \\
1 r, 10\end{array}$ & 1. & $\begin{array}{l}9, Y Y \\
\text { IY,Y. }\end{array}$ & $\begin{array}{l}r, 0 . \\
r v, .1\end{array}$ & علمى - أدبى & صعوية التعرف والتعبير عن & r \\
\hline غير & $\leqslant 9,0$. & $\begin{array}{l}1.0,0 . \\
1.2,0 .\end{array}$ & $\begin{array}{l}1,000 \\
1 ., 100\end{array}$ & 1. & $\begin{array}{l}\Lambda, \leqslant Y \\
\vee, \vee V\end{array}$ & $\begin{array}{l}r r, r . \\
r, 1 .\end{array}$ & 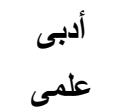 & التوجه الخارجى فى التفكير & $r$ \\
\hline غير & $\leqslant r$ & $\begin{array}{l}9 V \\
114\end{array}$ & $\begin{array}{l}q, v \cdot \\
11, r .\end{array}$ & 1. & $\begin{array}{l}r V, r r \\
r V, O r\end{array}$ & $\begin{array}{l}9 \vee, 1 . \\
1 . \varepsilon, 7 .\end{array}$ & 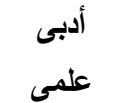 & المجموع الكلى & \\
\hline
\end{tabular}

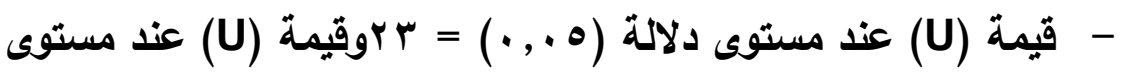

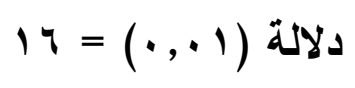

DOI : $10.12816 / 0052303$ 


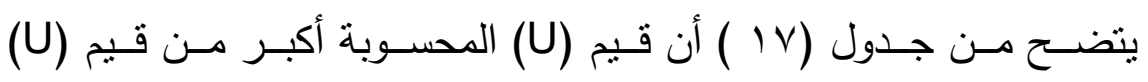

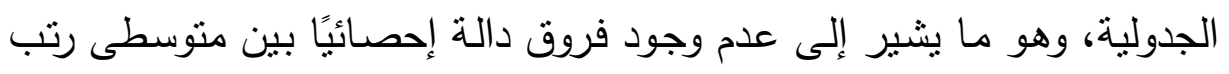

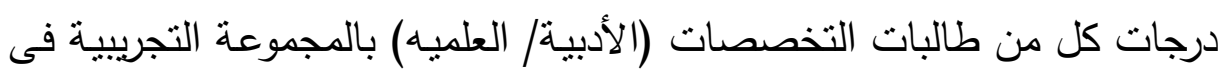
القياس البعدى على مقياس الاليكسيثميا.

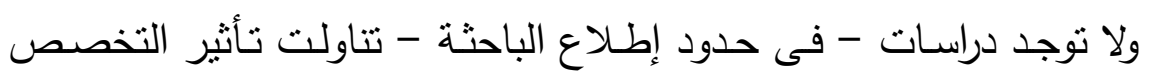
الدراسى على خفض الاليكسيثميا فلم تتمكن الباحثة من مقارنة نتائج هذا الفرض فئل

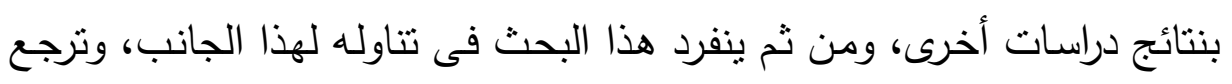

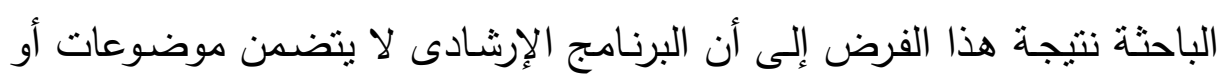

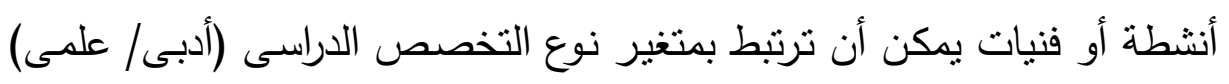

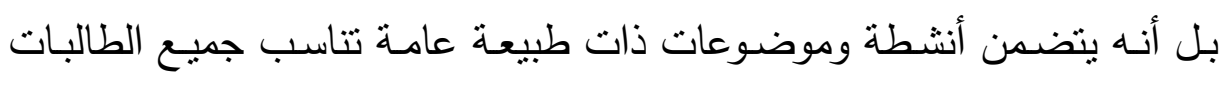

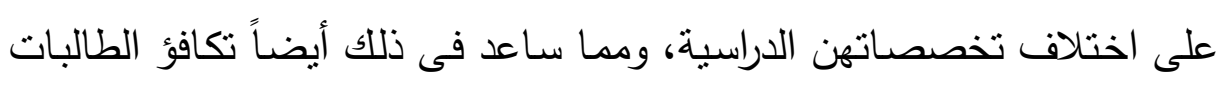

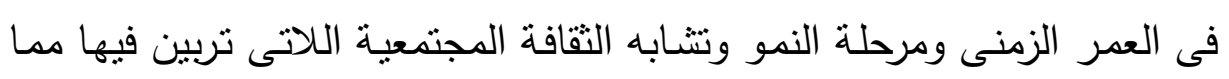
جعل اختلاف التخصص الدراسى عامـل غير مؤثر على الاليكسيثيميا للدى

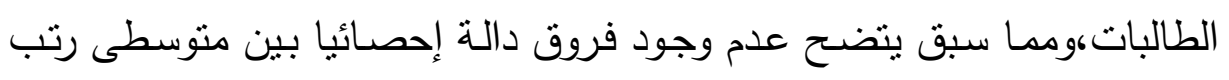

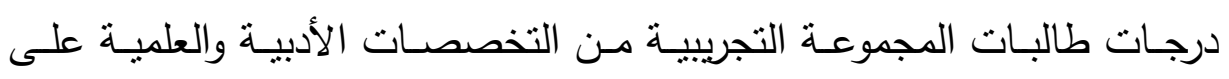
محاور الاليكسيثيميا ومجموعها الكلى، ومن ثم فقد تم قبول الفرض الثالث.

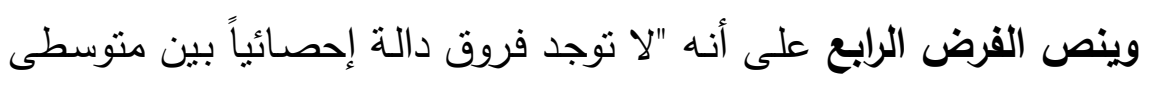

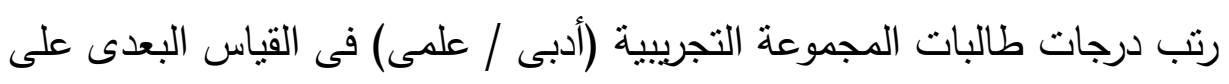

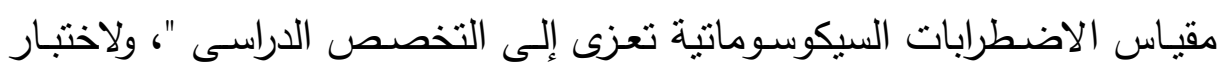

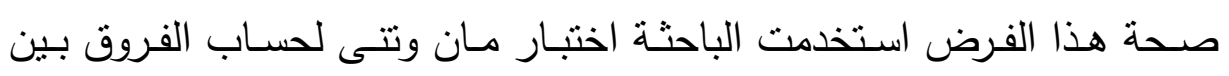
منوسطى رتب درجات كل من طالبات التخصصين الأدبى والعلمى فى القياس

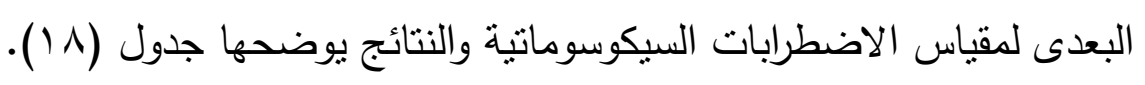


برنامج إرشادي انتقائي تكاملي لخفض حدة الاليكسيثيميا د.جيهان عثمان محمود

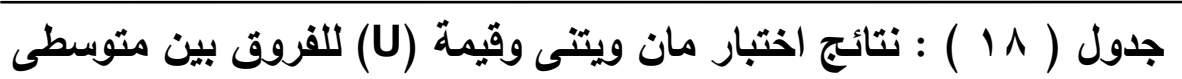

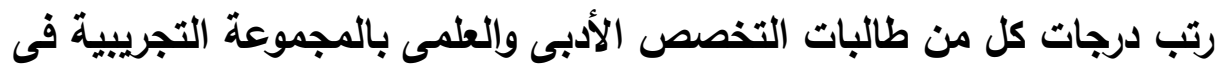

القياس البعدى لمقياس الاضطرابات السيكوسوماتية (ن = ب )

\begin{tabular}{|c|c|c|c|c|c|c|c|c|c|c|}
\hline \multicolumn{2}{|c|}{ مريع إيتا } & \multicolumn{2}{|c|}{$\mathbf{U}$} & \multirow{2}{*}{ مجموع } & \multirow{2}{*}{ متوسط } & \multirow[b]{2}{*}{ العدد } & \multirow{2}{*}{ الانحراف } & \multirow{2}{*}{ الحسابى المتط } & \multirow[b]{2}{*}{ التخصص } & \multirow{2}{*}{ الاضطرابات } \\
\hline التأثير & القيمة & الدلالة & القيمة & & & & & & & \\
\hline متوسط & $\cdot, \leqslant \wedge$ & $\cdot, \cdot 1$ & 9 & $\begin{array}{l}1 \leqslant 7 \\
1 \leq\end{array}$ & $\begin{array}{l}1 \leq, 7 . \\
7, \leqslant .\end{array}$ & $\begin{array}{l}1 . \\
1 .\end{array}$ & $\begin{array}{l}\text { ४,Ar } \\
19, \wedge 9\end{array}$ & $\begin{array}{l}\text { Ir, . . } \\
\nabla r, \Lambda .\end{array}$ & علمي & المجموعات \\
\hline
\end{tabular}

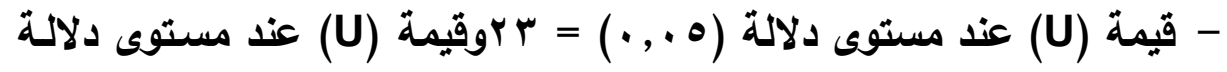

$$
17=(\cdot, \cdot 1)
$$

وبتضـح من جدول ( ^ l) أن قيم (U) المحسوبة أقل من قيم (U) الجدولية

عند مستوى ( 1 , • ) بين منوسطى رتب درجات كل من طالبات التخصصين

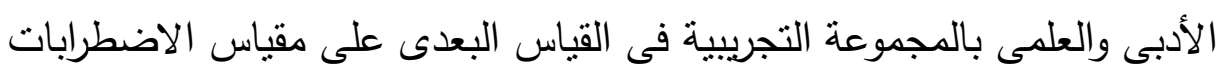

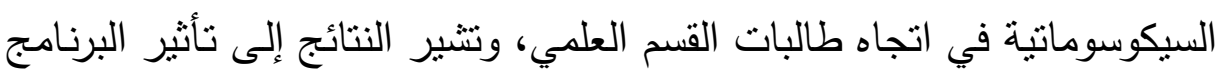

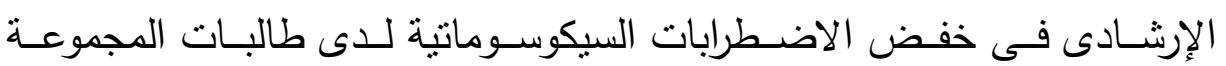
التجريبية من القسم الأدبى أكبر مقارنة بطالبات القسم العلمى.

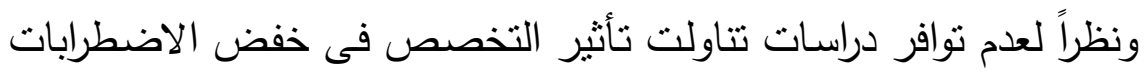
السيكوسوماتية، فلم تتمكن الباحثة من مقارنـة نتيجة هذا الفرض بنتائج دراسات

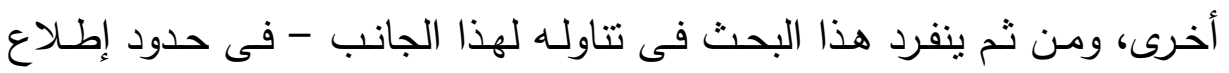

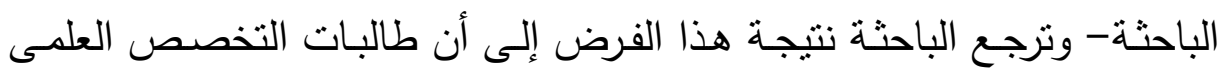

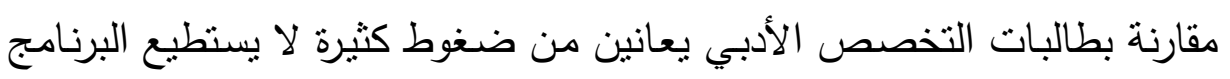

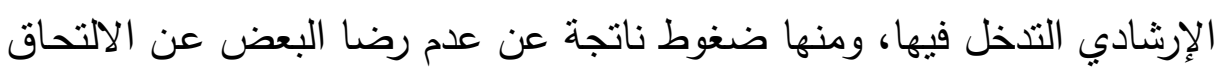

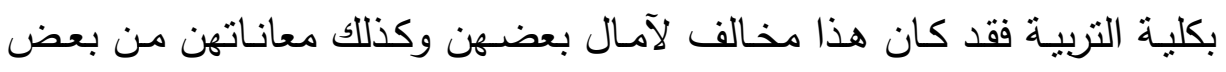

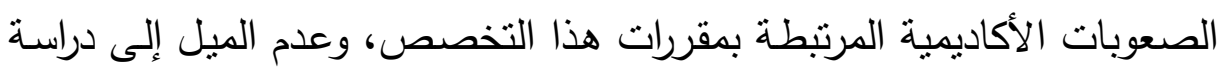

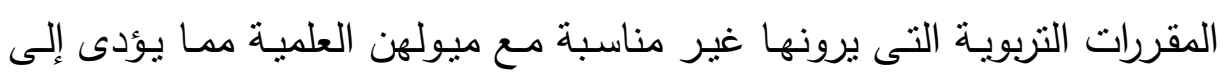

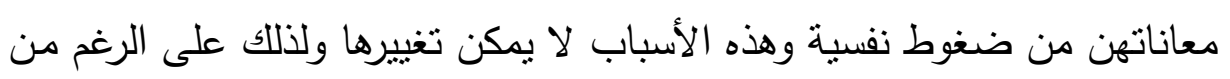
DOI : $10.12816 / 0052303$ 
انخفاض الاضطرابات السيكوسوماتية لايهن إلا أنهن كنا أقل نأثراً من زميلاتهن

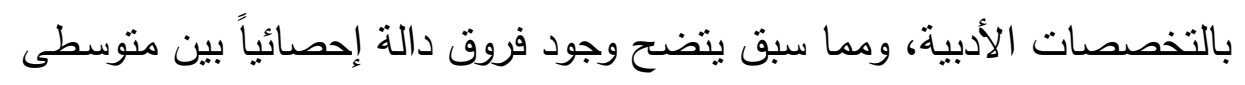

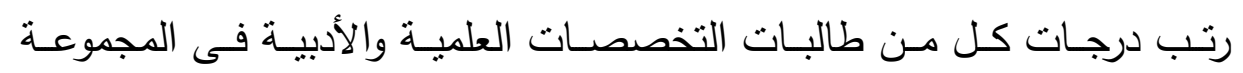
التجريبية فى القياس البعدى على مقياس الاضطرابات السيكوسوماتية في اتجاه

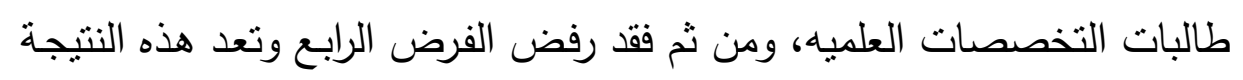

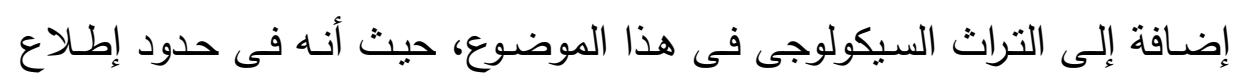

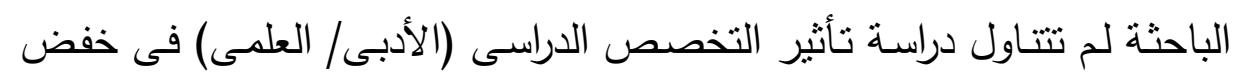
الاضطرابات السيكوسوماتية لدى طالبات كلية التربية.

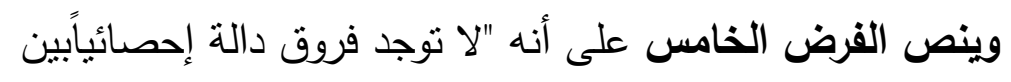

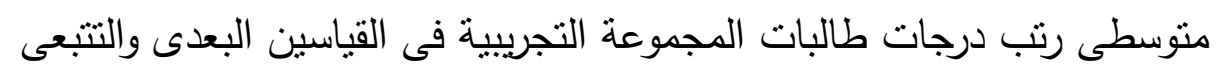
على مقياس الاضطرابات السيكوسوماتية"، ولاختبار صحة هذا الفرض قامت لهت الباحثة بحساب الفروق بين متوسطى رتب درجات طالبات المجموعة التجربيية

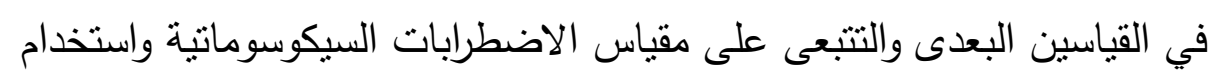
معادلة ويلكوكسون Wilcoxon، والنتائج يوضحها جدول (9 (1 ) ).

جدول (9 9 ) : نتائج اختبار ويلكوكسون وقيمة (Z) وحجم التأثير للفروق

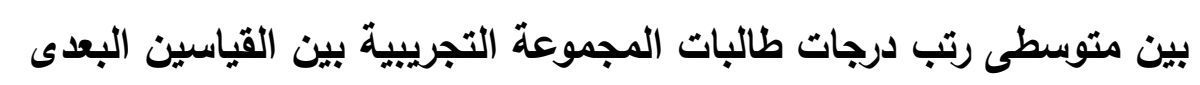
والتتبعى على مقياس الاضطرابات السيكوسوماتية (ن = . ب)

\begin{tabular}{|c|c|c|c|c|c|c|c|c|c|}
\hline \multicolumn{2}{|c|}{ z } & \multirow[b]{2}{*}{ مجموع } & \multirow[b]{2}{*}{ متوسط } & \multirow[b]{2}{*}{ 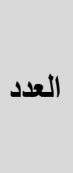 } & \multirow[b]{2}{*}{ توزيع } & \multirow[b]{2}{*}{ المعيارى } & \multirow[b]{2}{*}{ الحسابى } & \multirow[b]{2}{*}{ القياس } & \multirow[b]{2}{*}{ الاضطرابات السيكوسوماتية } \\
\hline مستلوى & القيمة & & & & & & & & \\
\hline غالة & l, rr & 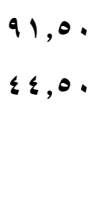 & $\begin{array}{l}\Lambda, r r \\
\Lambda, q .\end{array}$ & $\begin{array}{l}11 \\
0 \\
\varepsilon \\
r .\end{array}$ & المالمجبة المجادة & $\begin{array}{l}r \&, q \Gamma \\
r q, q)\end{array}$ & $\begin{array}{l}1,0, \& . \\
\ldots, \lambda \text {. }\end{array}$ & تتبعي & نوع القياس \\
\hline
\end{tabular}


برنامج إرشادي انتقائي تكاملي لخفض حدة الاليكسيشيميا د.جيهان عثمان محمود

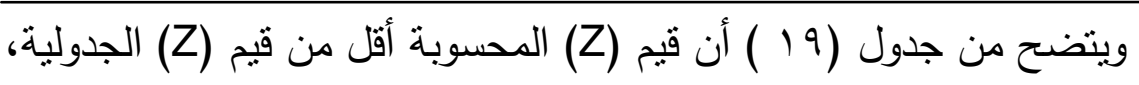

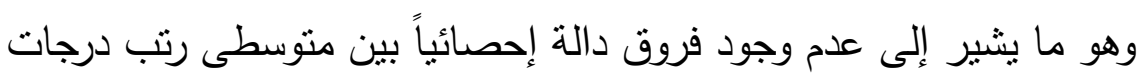

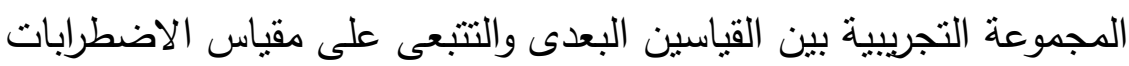

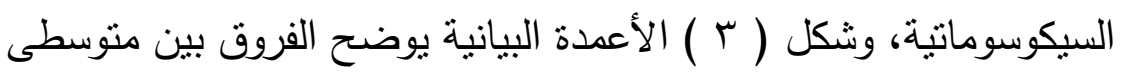

درجات المجموعة التجريبية فى القياس البعدى والتتبعى على مقياس الاضطرابات السيكوسومانية.

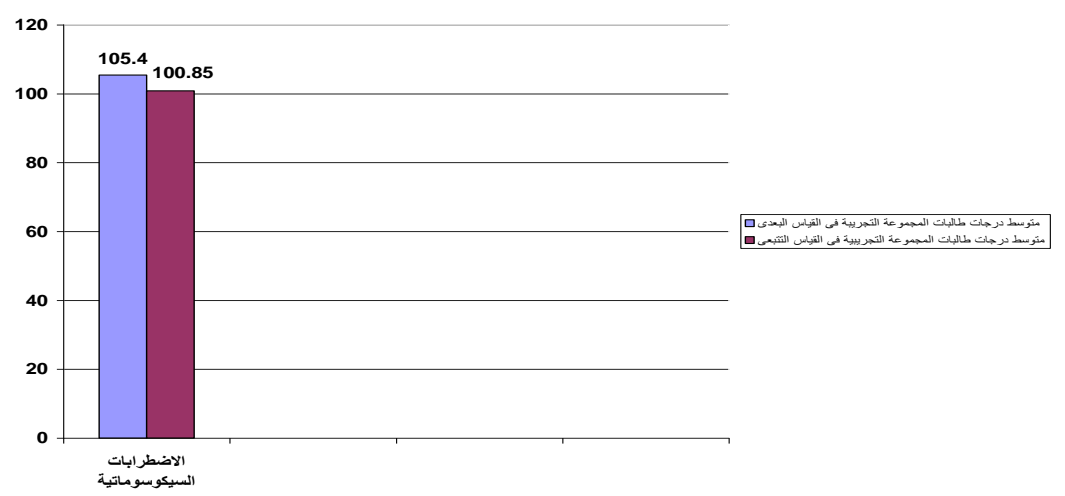

\section{وشكل (ץ) : الأعمدة البيانية لمتوسطى درجات المجموعة التجريبية فى}

\section{القياس البعدى وإلتتبعى للاضطرابات السيكوسوماتية}

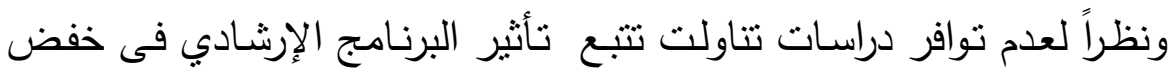

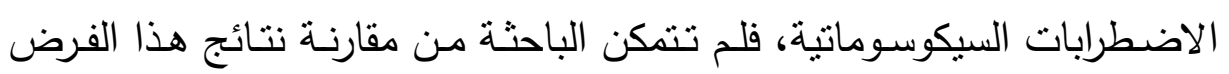

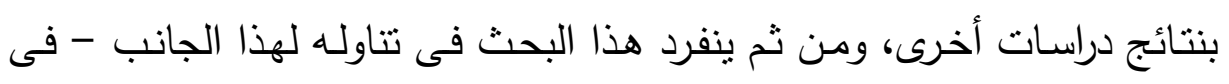

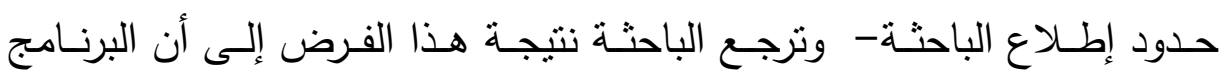

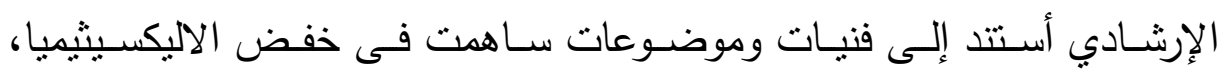

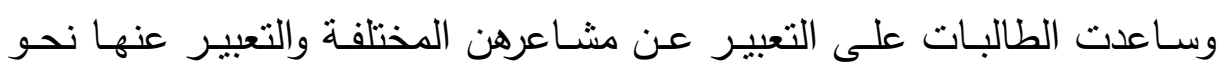
الآخرين مما ساهم فى تخفيف التوتز الناتج عن الاليكسيثيميا وهذا التوتر الكامن

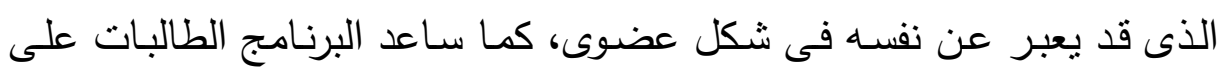

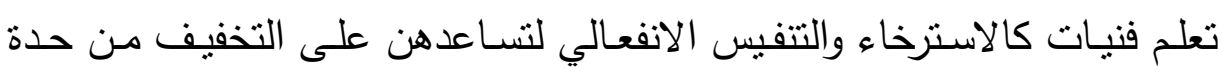

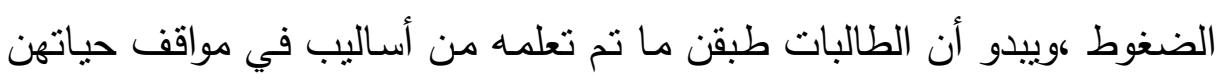


بعد انتهاء البرنامج ، وهذا يفسر استمرارية تأثثر البرنامج الإششادي، ومما سبق

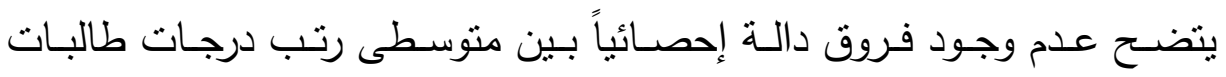

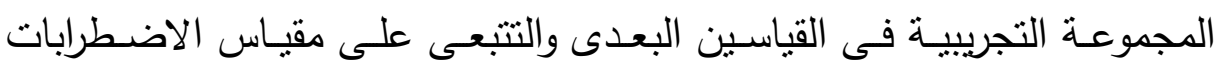

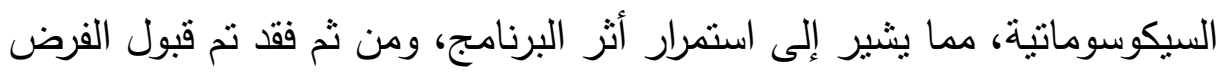
الخامس. 
برنامج إرشادي انتقائي تكاملي لخفض حدة الاليكسيثيميا د.جيهان عثمان محمود 


\section{المراجع:}

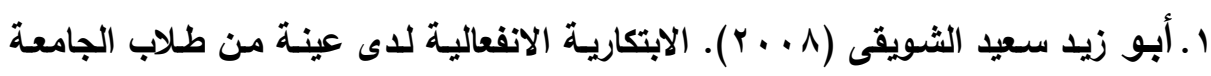

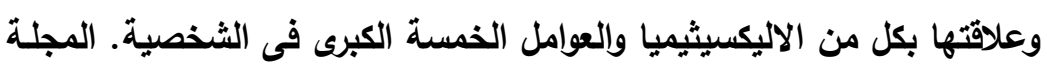

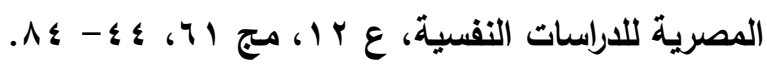

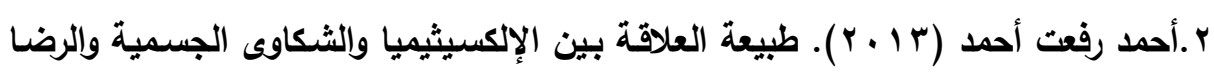

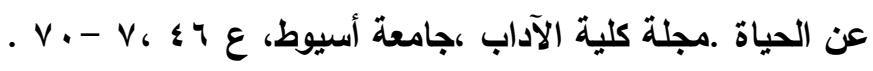

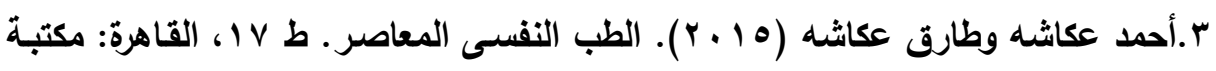
الأنجلو المصرية.

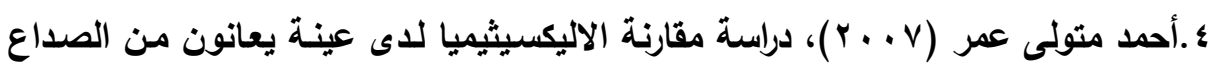

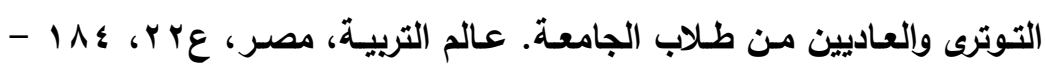
r r

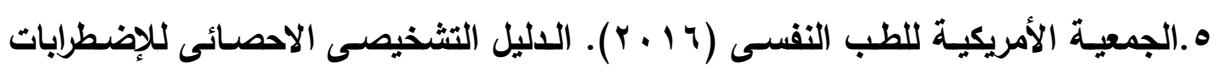

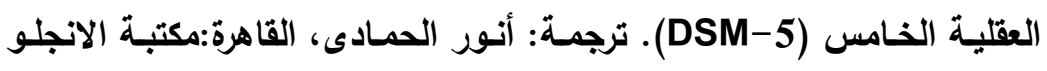

$$
\text { المصرية. }
$$

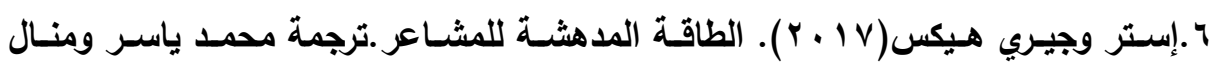
الخطيب، بيروت: دار الخيال.

V.إيمان اليماني قطب (7 1 ـ ץ). فعالية برنامج تدريبى قائم على مهارات التفكير الايجابى فى خفض بعض الاضطرابات السيكوسوماتية لدى عينة من طلاب كلية التربية جامعة الإسكندرية. رسالة دكتوراه ، كلية التربية ،جامعة الإسكندرية.

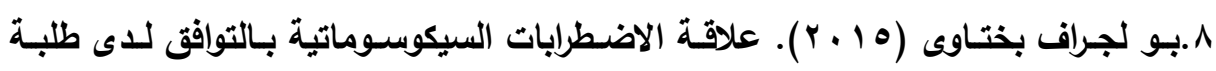
الجامعة .مجلة العلوم الانسانية الاجتماعية، جامعة قاصدى مرباح، الجزائر،

$$
. \wedge \uparrow-\vee 0,1 \wedge \varepsilon
$$

9 .حامد عبد السلام زهران (ه . . ץ). الصحة النفسية والعلاج النفسى. ط؛، القاهرة: عالم الكتب.

• 1 .حسن مصطقى عبد المعطى (r . . r). الأمراض السيكوسوماتية. القاهرة: مكتبة زهراء الشرق. 
برنامج إرشادي انتقائي تكاملي لخفض حدة الاليكسيثيميا د.جيهان عثمان محمود

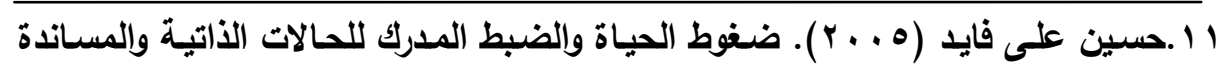

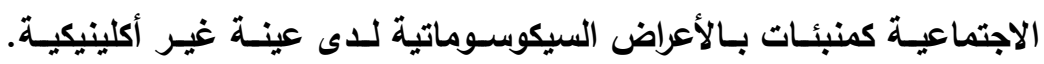

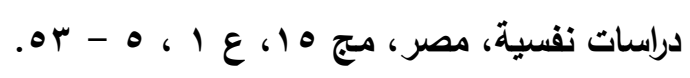

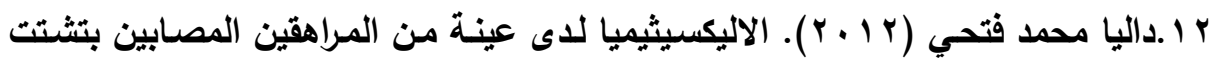

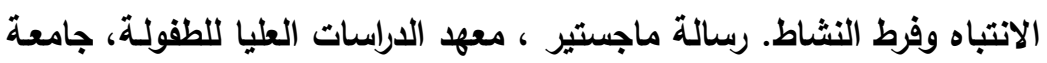

$$
\text { عين شمس. }
$$

r 1 .رشاد موسى ومحمد محمود ( . . ץ). العلاج الاينى للأمراض السيكوسوماتية، القاهرة: الفاروق الحديثة للطباعة وإلنشر.

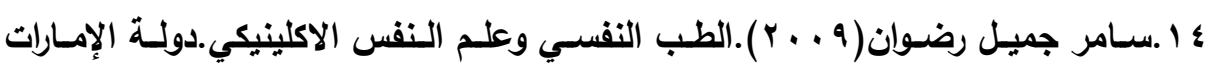

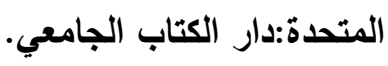

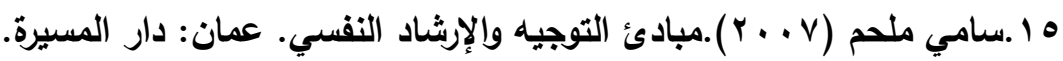

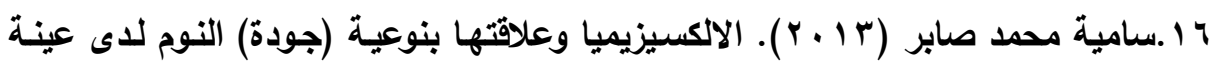

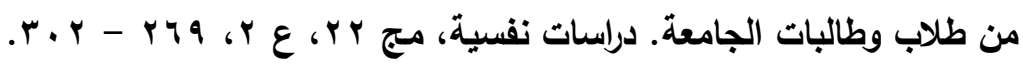

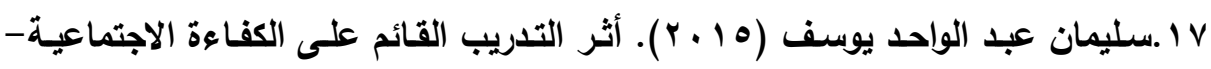

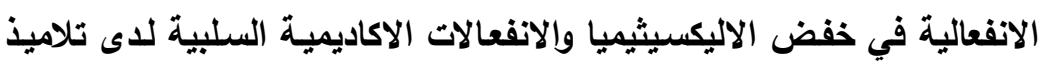

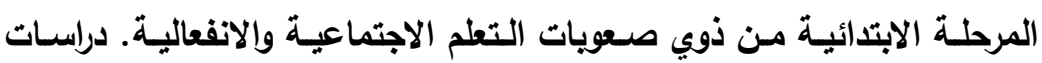

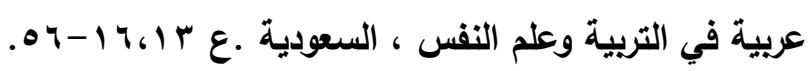

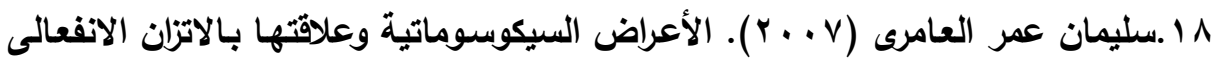

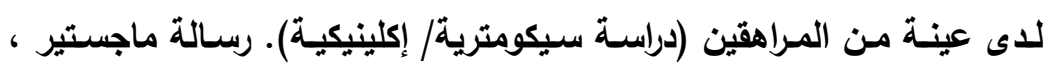
كلية التربية، جامعة الملك خالد، السعودية.

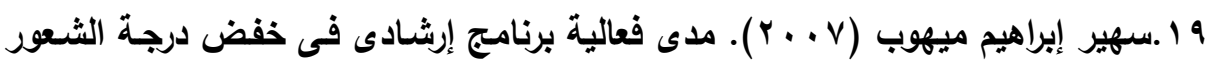

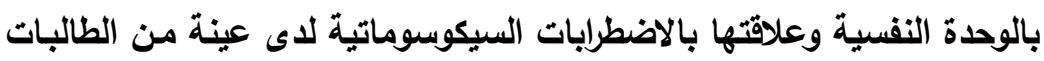

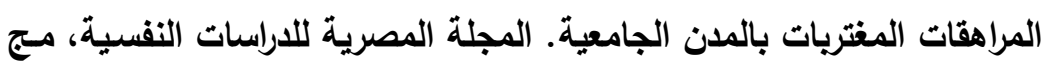

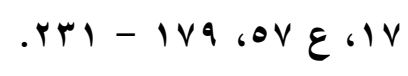

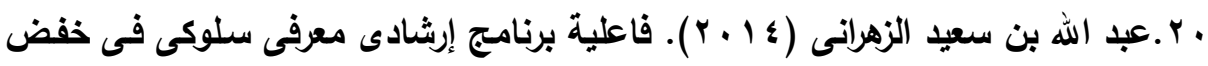

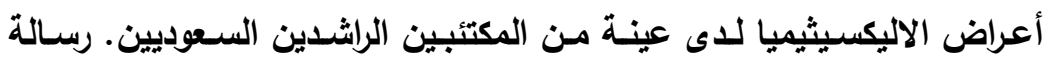
دكتوراه ، الجامعة الأردنية، كلية الدراسات العليا.

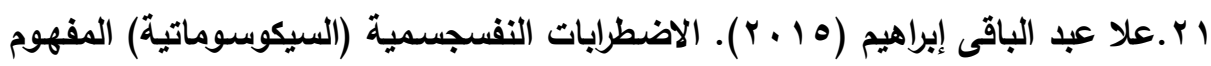

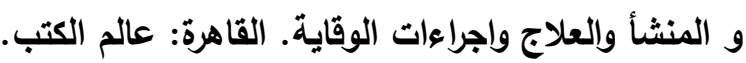

DOI : $10.12816 / 0052303$ 


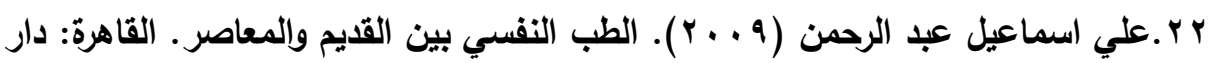
اليقين.

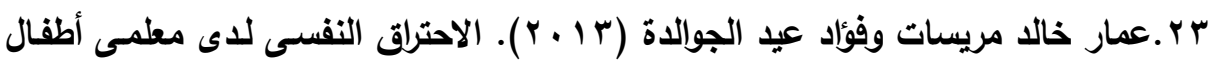

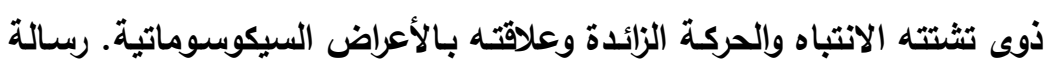
ماجستير ، كلية العلوم التريوية والنفسية، جامعة عمان العربية، الأردن.

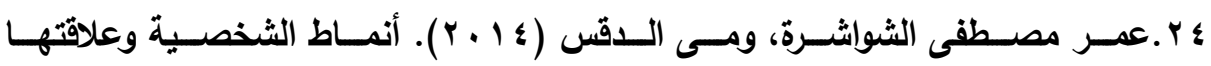

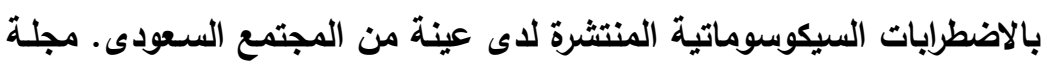

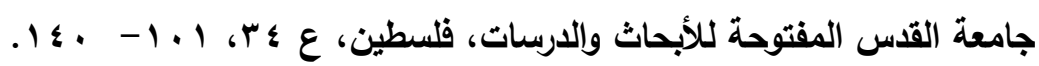

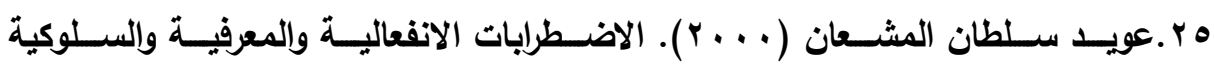

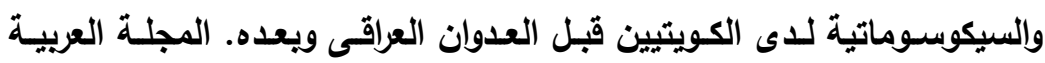

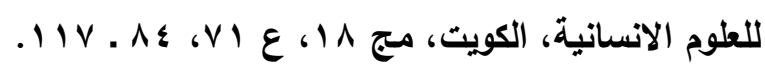

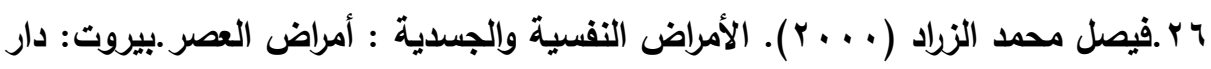
النقاش للنشر والتوزيع.

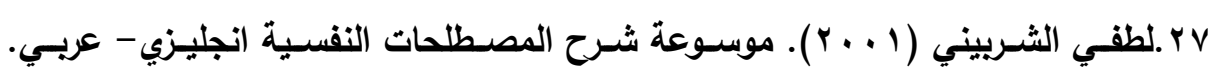
بيروت: دار النهضة العربية.

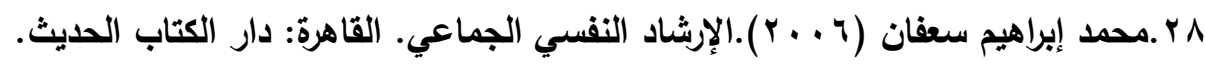

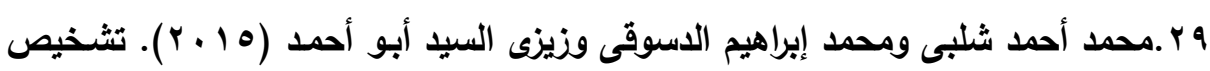

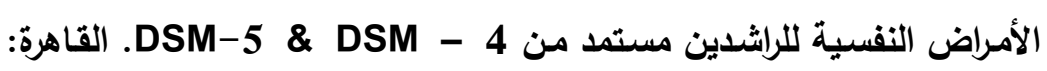
مكتبة الأنجلو المصرية.

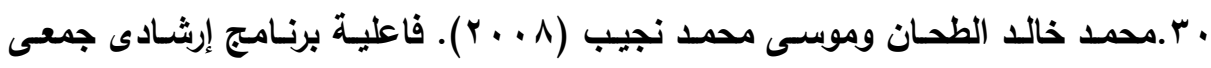
يستند إلى النظريـة الإنسـانية فى كل من مستوى الاضطرابات السيكوسوماتية

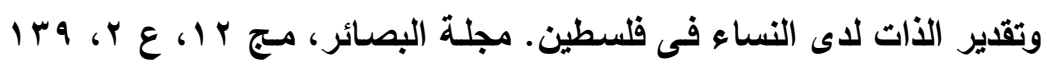

$$
\text { rrq- }
$$

اب.محمد شعبان محمد، ومحمد عبد العال الثيخ ومحمد محمود هليل (ع ا ـ ب). البناء

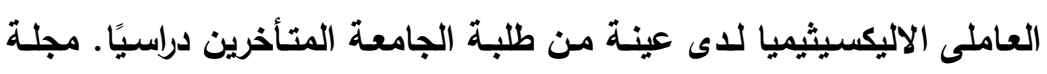

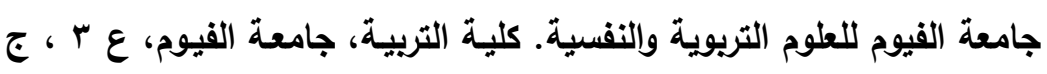
. M I I IVO T 
برنامج إرشادي انتقائي تكاملي لخفض حدة الاليكسيثيميا د.جيهان عثمان محمود

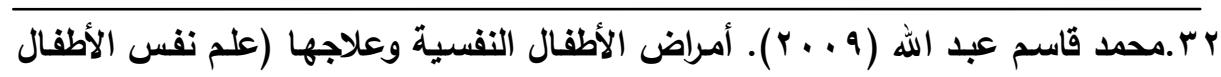
المرضى)، دمثق: دار المكتبى للطباعة والنشر والتتوزيع.

بr.محمود السيد أبو النيل ( ( . . ץ). مقياس كورنل للاضطرابات السيكوسوماتية.القاهرة: المؤسسة الابراهيمية لطباعة الأوفس.

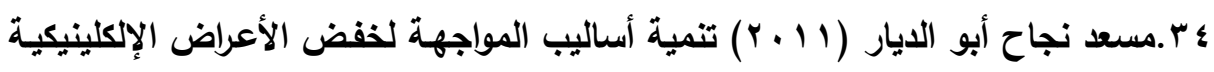

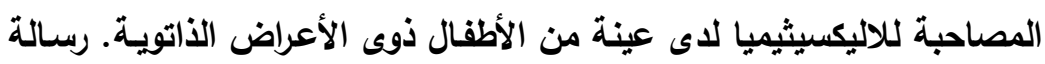
دكتوراه ، كلية البنات للآداب والعلوم والتربية، جامعة عين شمس.

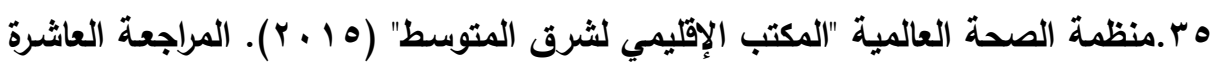

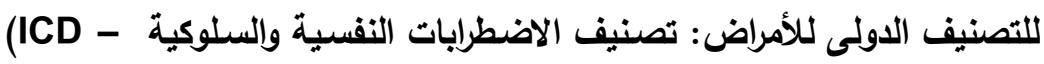
(10) ترجمة: وحدة الطب النفسى بجامعة عين شمس، القاهرة، جامعة عين شمس: المكتب الإقليمى لثرق المتوسط.

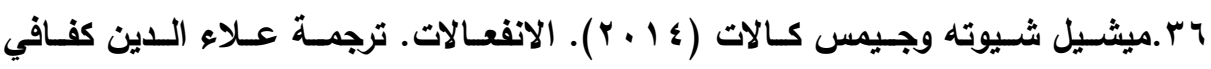
ومريسات النيال وسهير سالم، الأردن: دار الفكر. V.rv

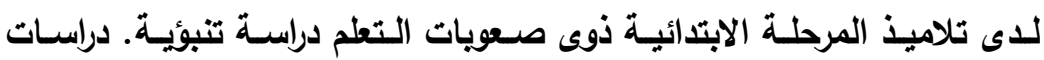

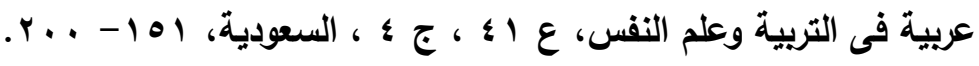

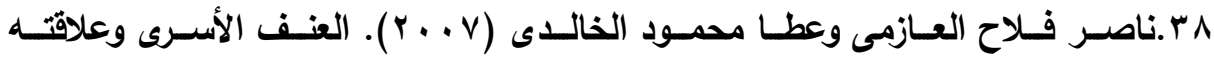

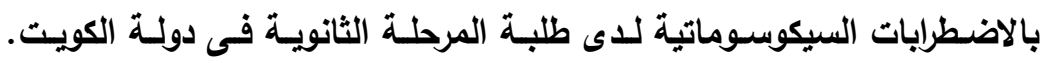
رسالة ماجستير ، كلية الدراسات التربوية، جامعة عمان العربية، الأردن.

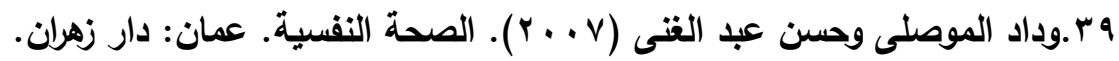

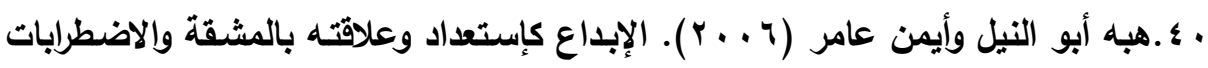

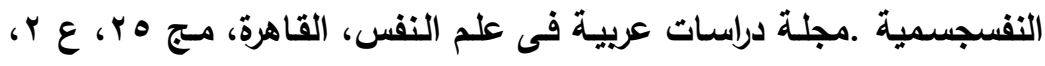
.rIV - rqu

اء ـ هثام عبد الرحمن الخولى (ه . . ץ). دراسة العلاقة بين العجز/ النقص فى القدرة على التعبير عن الشعور (الاليكسيثيميا) والمخادعة، ا (الميكافيلية). المؤتمر الثانى عشر، مركز الارشاد النفسى، جامعة عين شمس.

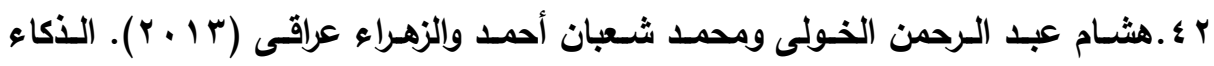
الانفعـالى وعلاقته بالاليكسيثيميا لــى عينـة مـن طـلاب وطالبـات الجامعـة. 


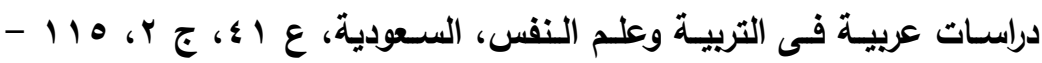
$.1 \mathrm{VY}$

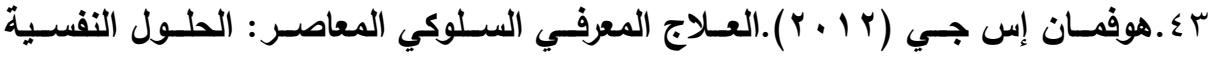

لمشكلات الصحة العقلية. ترجمة مراد على عيسى ،القاهرة:دار الفجر

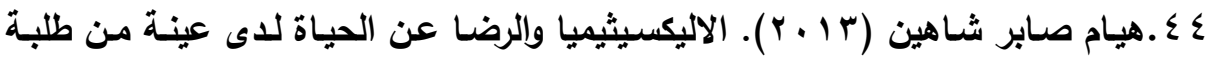

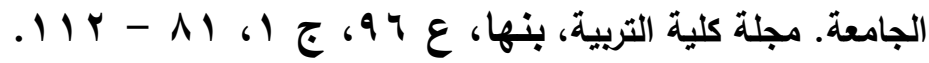

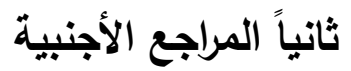

45. Aino, K., OUti, P., Koivisto, A., Raimo, K. \& Matti, J. (2007). Alexithymia and life satisfaction in primary health care patients. Psychosomatics, 48, 6, 523-529.

46.Alipour, N., Y. Zdanfar, A. (2011). The effectiveness of emotional disclosure intervention on declining stress and inhibition among Psychosomatic patient, Journal of jahrom University of medical sciences, 9,2, 116-131. 47.Balaban,H.,Semiz,M,.Ahmet,S.(2012).Migraine prevalence, alexithymia and post-traumatic stress disorder among medical students in turkey.J.headachepain,13,459-467.

48.Bernard, j. (2014). the relationship between alexithymia, coping, and health .The University of New Mexico, ProQuest

Dissertations Publishing, 3641181. 49.Besharat, M.\& Shahidi, S.(2011). What is the relationship between Alexithymia and ego defense styles? A correlational study with Iranian students Asian, psychiatry, 4, 145-149.

50.Birt,O. Roysamb, E. (2004). Mental health life stress and social support among young Norwegian adolescents with immigrant and host national back ground. Scandinavian Journal of Psychology 45 : 2, 131.

51.Bratis, E. (2010). Sleep disturbance symptoms and their associations with Alexithymia, depression and anxiety. Annals of general psychiatry, 9, 1, 163.

52.Briody, M. (2005). Emotional intelligence personality, Gender and cultural factors, PHD., Farleigh Dickinson university.

53.Capuzzi, D.(2000).Counseling and psycholtherapy anintegrative perspective. New York: John Wiley \& sons.

54.Celikel, F. (2007). Alexithymia and anxiety sensitivity in Turkish depressive, anxiety and somatic form disorder out patients. International journal of psychiatry in clinical practice. 11, 2 , 140-145. 
برنامج إرشادي انتقائي تكاملي لخفض حدة الاليكسيثيميا ـ.جيهان عثمان محمود

55.Chung,M.,Rudd,H.,\&Wall,N.(2012). Posttraumatic stress disorder following asthma attack (post-asthma attack PTSD) and psychiatric co-morbidity: The impact of alexithymia and coping. Psychiatry Research, 197, 246-252.

56.Considince, C. (2011). Alexithymia assessed through auditory affective perception and interpersonal problems as mediators of the relationship between trauma and depression. Master, Canada: University of Windsor.

57.De Gennaro, L., Martina, M., Curcio, G.\& Ferrara, M. (2004). The relationship between alexithymia, depression and sleep complaints. Psychiatry research, 128, 3, 253-258.

58.De, Pasquale,T.(2012). Allergy and psychologicl evaluation of patient with multiple drug intoierrance syndrome.Internal and emergency medicine, 7,1-13.

59.Domenico, D., Alessandro, D., Francesco, G., Gianni, S., Alessandra, V.,Chiara, M. (2009). Alexithymia and its relationships with dissociative experiences and internet addiction in an clinical, sample.Cyber psychology, behavior,12,(1),67-69.

60.Duprey, C. (2010). The relationships between mindfulness, eating disorders, Alexithymia, emotion regulation, and self consciousness meditational model. Psy Mary wood university.

61.Estabrook, J.(2008). Assessment of adolescent Alexithymia: Examining the ability of the TAS-20TO measure Alexithymia in samples of community and clinical adolescents. Unpublished doctoral dissertation, Trent university, Canada.

62.Evern, E. (2003). Alexithymia among alcohol dependent patient and its relationship with depression, anxiety and personality disorders, journal of Bagimlik - Dergisi, 4, 2, 47-52.

63.Freund, S.(2012). An examination of the cognitive, affective, and physiological aspects of alexithymia. University of Windsor (Canada), ProQuest Dissertations Publishing, MR84433.

64.Gay,M.(2010). Predictors of depression in multiple sclerosis patients.Acta neurologica scandinavica,121,(3),257.

65.Gay, M., Hanin, D. \& Luminet, O. (2008). Effectiveness of an hypnotic imagery intervention on reducing Alexithymia hypnosis, 25, 1-13. 
66.Gennaro, L. \& Martina, M. (2004). The relationship between Alexithymia depression and sleep paints, Journal of psychiatry research, 128, 3, 258-353.

67.Güleç MY, Altintaş M, Inanç L, Bezgin CH, Koca EK, Güleç H. (2013). Effects of childhood trauma on somatization in major depressive disorder: The role of alexithymia. J Affect Disord. 20;146(1):137-41.

68.Hale, K. (2012). Validity of the Toronto Alexithymia scale (TAS-20) in an impatient population unpublished doctoral dissertation, college of Education, The Florida state university.

69.Hans, J. \& Grabe, C. (2004). Alexithymia and personality in relation to dimensions of psychopathy. American Journal psychiatry, 161, 7, 1299-1301.

70.Hatin, B. (2011). Alexithymia right hemisphere dysfunction or in interhemispheric transfer deficit?. Master, University of Regina, Canada.

71.Hiltunen, L. (2008). The psychological and physical effects of expressive writing in individuals with bring eating disorder. Proquest dissertation and theses, 13, 8, 622.

72.Horneffer, K. \& Chan, K. (2009). Alexithymia and relaxation considerations in optimizing the emotional effectiveness of journaling about stressful experiences. Cognition and emotion, 23, 3, 611-622.

73.Joann, A. (2004). Self - Esteem Perception of relationship and commotional distress. Across cultural study Personal relationships, 11, 2, 231.

74.Junilla, K., Branda, N., Bermond, N., Bermond, B. \& Hijman, R. (2003). Cognitive and emotional characteristic of Alexithymia a review of neurobiological studies. Psychosomatic research, 54, 533-541.

75.Kagee, A. \& Freeman, M. (2008). Mental health and physical health (including Hiv/Aids). San Diego. CA: Academic press.

76.Kelko, S., Kiwamu, T. \& Akitoyo, H. (2010). Alexithymia and its relationship with eating behavior self esteem and body esteem in college women. Kobe university, Japan, 56, 231238.

77.Krystal, H. (1988). Alexithymia. In Integration and self healing affect, trauma\& Alexithymia, 242-285.

78.Kusevic, Z., Civljak, M., Rukavina, T. V.,Babic, G., Loncar,. M., Cusa, B. V., \& Gregurek, R. 
برنامج إرثادي انتقائي تكاملي لخفض حدة الاليكسيثيميا د.جيهان عثمان محمود

(2013). The connection. between alexithymia and somatic morbidity in a popula-. tion of combat veterans with chronic

PTSD.21,(1),7-11.

79.Landa, A.(2009). Beyond the unexplainable pain: Relational dynamics and alexithymia in somatization. Long Island University, The Brooklyn Center, ProQuest Dissertations

Publishing, 3364804.

80.Larsen, K. \& Van, S. (2006). Gender differences in the association between Alexithymia and emotional eating in obese individual's. Journal of psychosomatic research, 60,3 ,

237-243.

81.Lee, V. (2010). The impact of Alexithymia, emotional intelligence material values, and culture on relationship satisfaction.

82.Lee, Y., Seung, J., Hee, L., Koh, s. \& Kim, s. (2009). Direct and indirect effects of the temperament and character on Alexithymia: a pathway analysis with mood and anxiety. Comprehensive psychiatry, 1-20.

83.Li Juan, D. (2009). The relationship between the effective component of Alexithymia and facial recognition and expression of emotion. Master university of Singapore.

84.Lovallo, W. (2000). Abnormal Psychology pattern Issues interventions, New York, Jhon wisely \& Sons.

85.Lumely , M. (2004). Alexithymia emotional disclosure and health. Personality, 72, 6, 1272.

86.Luminet, O., Bagby, R. \& Taylor, G. (2001). An evaluation of the absolute and relativset ability of Alexithymia in patients with major depression. Psychotherapy and psychosomatics, 70, 254-260.

87.Luminet, O., Rokbanic,L. (2007)., David, O., \& Vincent, J. (2007). An evaluation of the absolute and relative stability of Alexithymia in women with breast cancer, psychosomatic research, 62, 641-648.

88.McMillan, K. (2003). Alexithymia in relation to the use of Qualifiers, and the quality of emotional tone. Personality and individual differences, 24, 767-772.

89.Mc Namara, S. (2000). Stress in young people. London: Routledge. 90.Petrova, E.\&Aleksandar.(2008). The relationship between alexithymia and functional somatization in college students 
in the United States. Auburn University, ProQuest

Dissertations Publishing, 3333144.

91.Muller, R. (2000). When a patient has no story to tell: Alexithymia psychiatric times. Clinical psychology, 7, 252-

263.

92.Muller, J. \& Alpers, W. (2006). Two facets of being bothered by bodily sensations: Anxiety sensifity and Alexithymia in psychosomatic patients. Comprehensive psychiatry, 47, 6, 489-595.

93.Nicolo, G., Semerari, A., Lysaker, p., Dimaggo, C, Conti, L., Angerio, S., Procacci, M., popolo, R.\& Carcione, A. (2011). Alexithymia in personality disorders: correlations with symptoms and interpersonal functioning, psychiatry research, 19, 37-42.

94.Nielsen, T., Levrier, K., Mont Plaisir, J. (2011). Dreaming correlates of Alexithymia among sleep disordered patients. American phonological Association, 21, 1, 16-31.

95.Pirlot, G. \& Corses, M. (2012). Understanding Alexithymia within a psychoanalytical framework. International Journal of psycho anal, 93, 1403-1425.

96.Reddy, S. (2009). Alexithymia and collectivisms in survivors of domestic violence: An exploratory study, PHD., The Chicago school of professional psychology.

97.Reese, J. (2008). Predicting improvement in cognitive behavioral therapy for somatization disorder: the role of Alexithymia PHD. New jersey university, U.S.A.

98.Rose, D. (2002). Theory and treatment of Alexithymia: An affect theory prespective. Unpublished doctor dissertation

99.Rudel, M., Scheele, H., Britine, M.\& Assion, I. (2010). Alexithymia, emotlon and social anxiety in adult with ADHD,. 15, 403-409.

100.Sarah, J., Dennis, E. (2009). The relationship between Alexithymia and alcohol - related risk perceptions: the moderating effect of general trauma in a college population. Addictive Behaviors, 14, 32, 420 - 422.

101.Saxena, P., Dubey, A. \& Pandy, R. (2011). Role of emotion regulation difficulties in predicting mental health \& well being. Journal of protective psychology \& mental health, 18, 2, $147-154$.

102.Schmitz, M. (2000). Alexithymia, selfcare \& satisfaction with life in college students. Unpublished doctoral dissertation. 
برنامج إرشادي انتقائي تكاملي لخفض حدة الاليكسيثيميا د.جيهان عثمان محمود

The faculty of the graduate school, University of Missouri Columbia.

103.Scott, E \& Watson, P. (2003). Alexithymia, Irrational beliefs and the rational emotive explanation of emotional disturbance Rational - Emotive \& Cognitive - Behavior therapy, 21, 1, 57-72.

104.Sigurlina, D. (2006). Psychological processes and life style by age: Predictors for Psychosomatic Complaints. Counseling and clinical Psychology Journal, 3,3, 245-260.

105.Smith, S. (2006). The relationship between Alexithymia and lower socioeconomic status African American, PHD, Faculty of older school of professional psychology. Michigan state unive.

106.Spleka, V., Myklicek, I., Cuijpers, P. \& pop, V. (2008). Alexithymia and cognitive behavioral therapy out comes for subthreshold depression. Act psychiatry scand, 18, 164-168

107.Speranza, M., Gwenole, L., Olivier, G. \& Maurice, C. (2010). Are treatment option to Alexithymia in eating disorders results from a three 1 year naturalistic longitudinal study. Science direct, 177, 2920 - 2927.

108.Stingel, M., Bausch, S., Bertram, W., Sabine, K.,Falk, L. (2008). Effects of inpatient psychotherapy on the stability of Alexithymia characteristics. Journal of psychosomatic research, 65, 173-180.

109.Sutherland, V. (2011). The relationship among Alexithymia, attachment styles, and racial identity of African American women in a residential substance abuse treatment facility. Texas university - commerce.

110.Suzuki, T. (2005): Hypnotic imagery - therapy for a Hives patient with Alexithymia characteristics contemporary hypnosis, 22, 2, 94-98.

111.Taylor, G. (2000). In review recent developments in Alexithymia theory and research, the Canadian journal of psychiatry, 45, 1, 134-142.

112.Taylor, G. \& Bagby, R. (2000). An overview of the Alexithymia construct, in Reuven Bar - on and James, D., \& Parker (Eds). The handbook of emotional intelligent: theory, development, assessment and application at home, school and work place, San Francisco: Jossey, 41-67.

113.Taylor, G., Parker, J. \& Bagby, R. (2003). Relationships between Alexithymia and related constructs. In Disorders of 
affect regulation: Alexithymia in medical and psychiatric illness. Cambridge university press, 103-112.

114. Thomas, P. (2010). Alexithymia and emotion awareness time for a shift in the measurement of the concept? Science direct behaviors, 1, $205-210$.

115.Tominaga, T., Choi, H., Nagoshi, y., Wada, y.\& Fukui, K. (2014). Relationship between Alexithymia and coping strategies in patients with soma to form disorder. Neuropsychiatric disease and treatment, 10, 38-62.

116.Tony, M., Parker, J. \& Taylor, G. (2008). Sleep problems and sleep hygiene in young adults with Alexithymia, personality and individual differences. 45, 4, 318 - 322 .

117.Turesky, D. (2011). A descriptive analysis of Alexithymia among patients with chronic back pain. PHD., University of Iowa.

118.Vanheule, S., Desmet, M., Rosseel, Y., Verhaeghe, P.\& Meganck, R. (2007). Relationship patterns in Alexithymia: A study using the core conflictual relationship them method psychopathology, 40, 14-21.

119.Volkan, T.V Kuscu, M.(2003). Alexithymia depression and anxiety levels in mastalgia patients. Yeni symposium. Psychopathology, 41, 4, 178-181.

120.Warner, B. (2007). The relationship between Alexithymia, wellness and substance dependence, PHD., university of new Orleans.

121.Zaidi, I., Mohsin, M. \& Saeed, W. (2013). Relationship between Alexithymia and locus of control among graduation students: A case study from Faisalabad. Environment ecology \& Family, 33, 90-99. 
برنامج إرثادي انتقائي تكاملي لخفض حدة الاليكسيشيميا د.جيهان عثمان محمود 